Cochrane Database of Systematic Reviews

\title{
Different strategies for diagnosing gestational diabetes to improve maternal and infant health (Review)
}

Farrar D, Duley L, Dowswell T, Lawlor DA

Farrar D, Duley L, Dowswell T, Lawlor DA.

Different strategies for diagnosing gestational diabetes to improve maternal and infant health.

Cochrane Database of Systematic Reviews 2017, Issue 8. Art. No.: CD007122.

DOI: 10.1002/14651858.CD007122.pub4.

www.cochranelibrary.com 
TABLE OF CONTENTS

ABSTRACT 1

PLAIN LANGUAGE SUMMARY

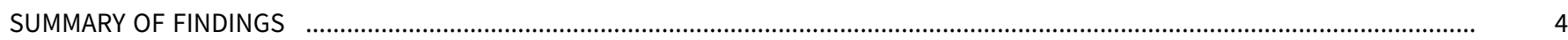

BACKGROUND

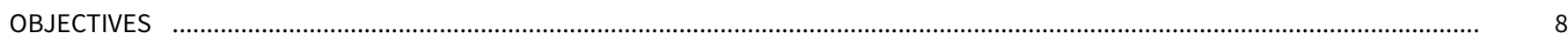

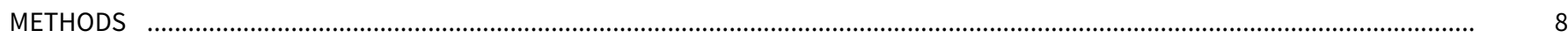

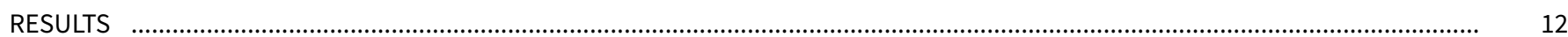

Figure 1.

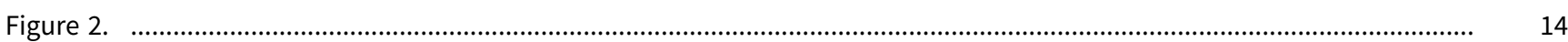

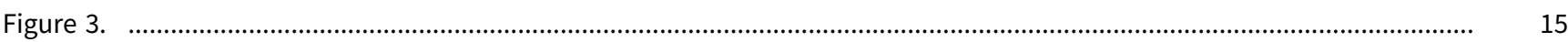

DISCUSSION

AUTHORS' CONCLUSIONS

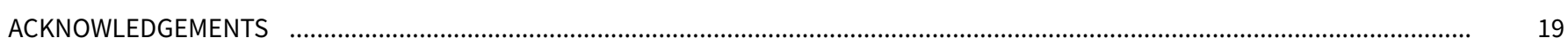

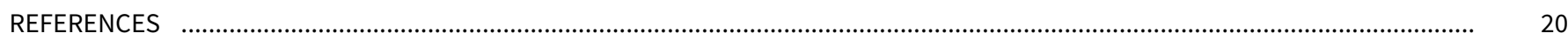

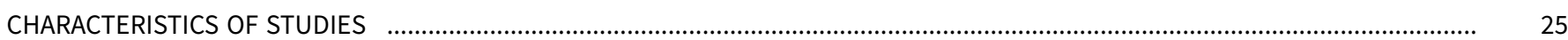

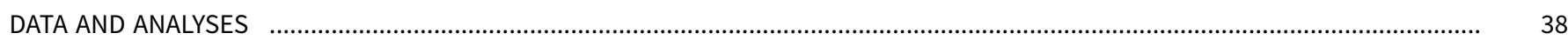

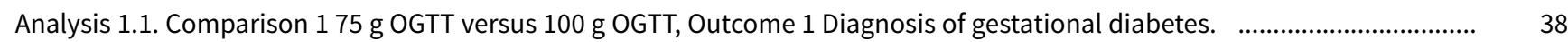

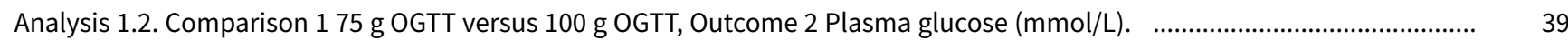

Analysis 2.1. Comparison 250 g glucose polymer drink versus 50 g glucose monomer drink, Outcome 1 Maternal side effects. ... 40

Analysis 2.2. Comparison 250 g glucose polymer drink versus 50 g glucose monomer drink, Outcome 2 Plasma glucose (mmol/ 41

L).

Analysis 2.3. Comparison $250 \mathrm{~g}$ glucose polymer drink versus $50 \mathrm{~g}$ glucose monomer drink, Outcome 3 Gestational age at birth (weeks).

Analysis 3.1. Comparison 3 Candy bar versus $50 \mathrm{~g}$ glucose monomer drink, Outcome 1 Maternal side effects. ........................

Analysis 3.2. Comparison 3 Candy bar versus $50 \mathrm{~g}$ glucose monomer drink, Outcome 2 1-hour serum glucose level (mmol/L). ..

Analysis 4.1. Comparison $450 \mathrm{~g}$ glucose in food versus $50 \mathrm{~g}$ glucose drink, Outcome 1 Maternal side effects. .........................

Analysis 4.2. Comparison $450 \mathrm{~g}$ glucose in food versus $50 \mathrm{~g}$ glucose drink, Outcome 2 Need for repeat testing by same or alternative method.

Analysis 5.1. Comparison 575 g OGTT (WHO criteria) versus 75 g OGTT (ADA criteria), Outcome 1 Caesarean section. .............

Analysis 5.2. Comparison $575 \mathrm{~g}$ OGTT (WHO criteria) versus $75 \mathrm{~g}$ OGTT (ADA criteria), Outcome 2 Instrumental delivery. .........

Analysis 5.3. Comparison 575 g OGTT (WHO criteria) versus 75 g OGTT (ADA criteria), Outcome 3 Diagnosis of gestational diabetes.

Analysis 5.4. Comparison 575 g OGTT (WHO criteria) versus 75 g OGTT (ADA criteria), Outcome 4 Macrosomia. .......................

Analysis 5.5. Comparison 575 g OGTT (WHO criteria) versus 75 g OGTT (ADA criteria), Outcome 5 Stillbirth. ............................

Analysis 6.1. Comparison 6 Two-step (50 g OGCT and $100 \mathrm{~g}$ OGTT) versus one-step (75 g OGTT) approach, Outcome 1 Diagnosis of gestational diabetes.

ADDITIONAL TABLES

APPENDICES

WHAT'S NEW

HISTORY

CONTRIBUTIONS OF AUTHORS

DECLARATIONS OF INTEREST

SOURCES OF SUPPORT

DIFFERENCES BETWEEN PROTOCOL AND REVIEW

INDEX TERMS 
[Intervention Review]

\section{Different strategies for diagnosing gestational diabetes to improve maternal and infant health}

Diane Farrar ${ }^{1}$, Lelia Duley², Therese Dowswell ${ }^{3}$, Debbie A Lawlor ${ }^{4}$

1Maternal and Child Health, Bradford Institute for Health Research, Bradford, UK. 2Nottingham Clinical Trials Unit, Nottingham Health Science Partners, Nottingham, UK. ${ }^{3}$ Cochrane Pregnancy and Childbirth Group, Department of Women's and Children's Health, The University of Liverpool, Liverpool, UK. ${ }^{4}$ MRC Centre for Causal Analyses in Translational Epidemiology, School of Social and Community Medicine, University of Bristol, Bristol, UK

Contact: Diane Farrar, Maternal and Child Health, Bradford Institute for Health Research, Bradford Royal Infirmary, Duckworth Lane, Bradford, BD9 6RJ, UK. diane.farrar@bthft.nhs.uk.

Editorial group: Cochrane Pregnancy and Childbirth Group.

Publication status and date: New search for studies and content updated (no change to conclusions), published in Issue 8, 2017.

Citation: Farrar D, Duley L, Dowswell T, Lawlor DA. Different strategies for diagnosing gestational diabetes to improve maternal and infant health. Cochrane Database of Systematic Reviews 2017, Issue 8. Art. No.: CD007122. DOI: 10.1002/14651858.CD007122.pub4.

Copyright $@ 2017$ The Cochrane Collaboration. Published by John Wiley \& Sons, Ltd.

\section{A B S T R A C T}

\section{Background}

Gestational diabetes mellitus (GDM) is carbohydrate intolerance resulting in hyperglycaemia with onset or first recognition during pregnancy. If untreated, perinatal morbidity and mortality may be increased. Accurate diagnosis allows appropriate treatment. Use of different tests and different criteria will influence which women are diagnosed with GDM. This is an update of a review published in 2011 and 2015.

\section{Objectives}

To evaluate and compare different testing strategies for diagnosis of gestational diabetes mellitus to improve maternal and infant health while assessing their impact on healthcare service costs.

\section{Search methods}

We searched Cochrane Pregnancy and Childbirth's Trials Register, ClinicalTrials.gov, WHO International Clinical Trials Registry Platform (ICTRP) (9 January 2017) and reference lists of retrieved studies.

\section{Selection criteria}

We included randomised trials if they evaluated tests carried out to diagnose GDM. We excluded studies that used a quasi-random model, cluster-randomised or cross-over trials.

\section{Data collection and analysis}

Two review authors independently assessed trials for inclusion and risk of bias, extracted data and checked them for accuracy. The quality of the evidence was assessed using the GRADE approach.

\section{Main results}

We included a total of seven small trials, with 1420 women. One trial including 726 women was identified by this update and examined the two step versus one step approach. These trials were assessed as having varying risk of bias, with few outcomes reported. We prespecified six outcomes to be assessed for quality using the GRADE approach for one comparison: $75 \mathrm{~g}$ oral glucose tolerance test (OGTT) versus 100 g OGTT; data for only one outcome (diagnosis of gestational diabetes) were available for assessment. One trial compared three different methods of delivering glucose: a candy bar ( 39 women), a $50 \mathrm{~g}$ glucose polymer drink (40 women) and a 50 g glucose monomer drink (43 
women). We have included the results reported by this trial as separate comparisons. No trial reported on measures of costs of health services.

We examined six main comparisons.

$75 \mathrm{~g}$ OGTT versus $100 \mathrm{~g}$ OGTT (1 trial, 248 women): women who received $75 \mathrm{~g}$ OGTT had a higher relative risk of being diagnosed with GDM (risk ratio (RR) 2.55, 95\% confidence interval ( $\mathrm{Cl}$ ) 0.96 to 6.75; very-low quality evidence). No data were reported for the following additional outcomes prespecified for GRADE assessment: caesarean section, macrosomia > $4.5 \mathrm{~kg}$ or however defined in the trial, long-term type 2 diabetes maternal, long-term type 2 diabetes infant and economic costs.

Candy bar versus $\mathbf{5 0} \mathbf{g}$ glucose monomer drink ( 1 trial, 60 women): more women receiving the candy bar, rather than glucose monomer, preferred the taste of the candy bar ( $\mathrm{RR} 0.60,95 \% \mathrm{Cl} 0.42$ to 0.86$)$ and 1-hour glucose was less with the candy bar. There were no differences in the other outcomes reported (maternal side effects). No infant outcomes were reported or any review primary outcomes.

50 g glucose polymer drink versus 50 g glucose monomer drink ( 3 trials, 239 women): mean difference (MD) in gestation at birth was - 0.80 weeks ( 1 trial, 100 women; $95 \% \mathrm{Cl}-1.69$ to 0.09 ). Total side effects were less common with the glucose polymer drink ( 1 trial, 63 women; RR $0.21,95 \% \mathrm{Cl} 0.07$ to 0.59 ), and no clear difference in taste acceptability was reported (1 trial, 63 women; RR $0.99,95 \% \mathrm{Cl} 0.76$ to 1.29 ). Fewer women reported nausea following the $50 \mathrm{~g}$ glucose polymer drink compared with the $50 \mathrm{~g}$ glucose monomer drink ( 1 trial, 66 women; RR $0.29,95 \% \mathrm{Cl} 0.11$ to 0.78 ). No other measures of maternal morbidity or outcomes for the infant were reported.

$50 \mathrm{~g}$ glucose food versus $\mathbf{5 0} \mathbf{g}$ glucose drink (1 trial, 30 women): women receiving glucose in their food, rather than as a drink, reported fewer side effects (RR $0.08,95 \% \mathrm{Cl} 0.01$ to 0.56 ). No clear difference was noted in the number of women requiring further testing (RR 0.14 , $95 \% \mathrm{Cl} 0.01$ to 2.55). No other measures of maternal morbidity or outcome were reported for the infant or review primary outcomes.

$75 \mathrm{~g}$ OGTT World Health Organization (WHO) criteria versus $75 \mathrm{~g}$ OGTT American Diabetes Association (ADA) criteria (1 trial, 116 women): no clear differences in included outcomes were observed between women who received the $75 \mathrm{~g}$ OGTT and were diagnosed using criteria based on WHO (1999) recommendations and women who received the $75 \mathrm{~g}$ OGTT and were diagnosed using criteria recommended by the ADA (1979). Outcomes measured included diagnosis of gestational diabetes (RR 1.47, 95\% Cl 0.66 to 3.25), caesarean section (RR 1.07, $95 \% \mathrm{Cl} 0.85$ to 1.35 ), macrosomia defined as $>90$ th percentile by ultrasound or birthweight equal to or exceeding $4000 \mathrm{~g}$ (RR $0.73,95 \% \mathrm{Cl}$ 0.19 to 2.79 ), stillbirth (RR $0.49,95 \% \mathrm{Cl} 0.02$ to 11.68 ) and instrumental birth (RR $0.21,95 \% \mathrm{Cl} 0.01$ to 3.94 ). No other secondary outcomes were reported.

Two-step approach (50 $\mathrm{g}$ oral glucose challenge test followed by selective $100 \mathrm{~g}$ OGTT Carpenter and Coustan criteria) versus onestep approach (universal $75 \mathrm{~g}$ OGTT ADA criteria) (1 trial, 726 women): women allocated the two-step approach had a lower risk of being diagnosed with GDM at 11 to 14 weeks' gestation compared to women allocated the one-step approach (RR $0.51,95 \% \mathrm{Cl} 0.28$ to 0.95 ). No other primary or secondary outcomes were reported.

\section{Authors' conclusions}

There is insufficient evidence to suggest which strategy is best for diagnosing GDM. Large randomised trials are required to establish the best strategy for correctly identifying women with GDM.

\section{PLAIN LANGUAGE SUMMARY}

\section{Different strategies for diagnosing gestational diabetes mellitus (GDM) to improve maternal and infant health}

\section{What is the issue?}

We aimed to evaluate and compare different ways of diagnosing gestational diabetes mellitus (GDM). We searched for all relevant studies in January 2017.

\section{Why is this important?}

Between seven and 24 pregnant women in every 100 develop GDM. GDM is when there is an inability to process carbohydrates properly, which leads to high blood sugar (hyperglycaemia). GDM can result in increased risks of problems around the time of birth for the mother and her baby. Treatment can reduce these risks, and therefore diagnosing the condition accurately means that treatment can be given to improve the health of mothers and their babies.

Different testing strategies aim to diagnose GDM. We wanted to compare the different strategies, to see how they affected the health of women and their infants, and to assess the cost of the strategies to the healthcare service.

\section{What evidence did we find?}

We found seven trials. A total of 1420 women were included, in settings in Turkey, Mexico, Nigeria, New Zealand, Canada and the USA. Across the trials, different testing approaches and criteria were evaluated as were different diagnostic tests including different oral glucose tolerance test loads; a glucose drink; a candy bar and food high in glucose. Women were given these items to eat/drink, and this was then 
followed by a blood test to measure blood sugar levels and questionnaires. In some tests, women were required to fast from the night before.

The main outcomes we looked for were frequency of diagnosis, incidence of caesarean section, assisted birth and vaginal birth, and incidence of macrosomia in babies (larger than normal weight at birth). Other outcomes spanned a range, including any side effects of the tests, the mothers' preferences, and the health of the babies.

There were a number of weaknesses among the studies: the methodology was not clear and there were important gaps in the data. The studies in this review do not provide enough evidence to guide clinical practice and health policy regarding identifying women with GDM.

\section{What does this mean?}

We are uncertain about which strategies to diagnose GDM are better, as we have assessed the quality of evidence as very low. Large randomised trials are needed to establish the best way for identifying women with GDM. 


\section{SUMMARY OF FINDINGS}

\section{Summary of findings for the main comparison. $75 \mathrm{~g}$ OGTT versus $100 \mathrm{~g}$ OGTT for diagnosing GDM to improve maternal and infant health}

$75 \mathrm{~g}$ oral glucose tolerance test (OGTT) versus $100 \mathrm{~g}$ OGTT for diagnosing gestational diabetes mellitus (GDM) to improve maternal and infant health

Patient or population: pregnant women at low or high risk of gestational diabetes

Settings: 1 study, Nigeria

Intervention: 75 g OGTT

Comparison: $100 \mathrm{~g}$ OGTT

\begin{tabular}{|c|c|c|c|c|c|c|}
\hline \multirow[t]{3}{*}{ Outcomes } & \multicolumn{2}{|c|}{$\begin{array}{l}\text { Illustrative comparative risks }{ }^{\star} \\
(95 \% \mathrm{CI})\end{array}$} & \multirow[t]{3}{*}{$\begin{array}{l}\text { Relative effect } \\
(95 \% \mathrm{CI})\end{array}$} & \multirow{3}{*}{$\begin{array}{l}\text { Number of par- } \\
\text { ticipants } \\
\text { (studies) }\end{array}$} & \multirow{3}{*}{$\begin{array}{l}\text { Quality of the } \\
\text { evidence } \\
\text { (GRADE) }\end{array}$} & \multirow[t]{3}{*}{ Comments } \\
\hline & Assumed risk & $\begin{array}{l}\text { Corresponding } \\
\text { risk }\end{array}$ & & & & \\
\hline & $100 \mathrm{~g} \mathrm{OGTT}$ & $75 \mathrm{~g}$ OGTT & & & & \\
\hline \multirow{2}{*}{$\begin{array}{l}\text { Diagnosis of gesta- } \\
\text { tional diabetes }\end{array}$} & \multicolumn{2}{|c|}{ Study population } & \multirow{2}{*}{$\begin{array}{l}\text { RR } 2.55 \\
(0.96 \text { to } 6.75)\end{array}$} & \multirow{2}{*}{$\begin{array}{l}248 \\
\text { (1 study) }\end{array}$} & \multirow{2}{*}{$\begin{array}{l}\oplus \ominus \ominus \ominus \\
\text { Very low } a, b\end{array}$} & \multirow{2}{*}{$\begin{array}{l}\text { Women who received the } 75 \mathrm{~g} \text { OGTT test were } 2.55 \\
\text { times more likely to test positive for gestational di- } \\
\text { abetes. }\end{array}$} \\
\hline & 45 per 1000 & $\begin{array}{l}\mathbf{1 1 6} \text { per } 1000 \\
(44 \text { to } 307)\end{array}$ & & & & \\
\hline Caesarean section & See comment & See comment & Not estimable & $\begin{array}{l}0 \\
(0)\end{array}$ & See comment & $\begin{array}{l}\text { None of the included studies reported this out- } \\
\text { come. }\end{array}$ \\
\hline $\begin{array}{l}\text { Macrosomia }>4.5 \mathrm{~kg} \\
\text { or as defined in trial }\end{array}$ & See comment & See comment & Not estimable & $\begin{array}{l}0 \\
(0)\end{array}$ & See comment & $\begin{array}{l}\text { None of the included studies reported this out- } \\
\text { come. }\end{array}$ \\
\hline $\begin{array}{l}\text { Long-term type } 2 \\
\text { diabetes infant }\end{array}$ & See comment & See comment & Not estimable & $\begin{array}{l}0 \\
(0)\end{array}$ & See comment & $\begin{array}{l}\text { None of the included studies reported this out- } \\
\text { come. }\end{array}$ \\
\hline Economic costs & See comment & See comment & Not estimable & $\begin{array}{l}0 \\
(0)\end{array}$ & See comment & $\begin{array}{l}\text { None of the included studies reported this out- } \\
\text { come. }\end{array}$ \\
\hline
\end{tabular}

${ }^{*}$ The basis for the assumed risk (e.g. median control group risk across studies) is the risk. The corresponding risk (and its $95 \%$ confidence interval) is based on the assumed risk in the comparison group and the relative effect of the intervention (and its $95 \% \mathrm{Cl}$ ).

Cl: Confidence interval; RR: Risk ratio. 
GRADE Working Group grades of evidence.

High quality: Further research is very unlikely to change our confidence in the estimate of effect.

Moderate quality: Further research is likely to have an important impact on our confidence in the estimate of effect and may change the estimate.

Low quality: Further research is very likely to have an important impact on our confidence in the estimate of effect and is likely to change the estimate.

Very low quality: We are very uncertain about the estimate.

aOne study with design limitations $(-1)$

bWide confidence intervals crossing the line of no effect, few events and small sample size. 


\section{B A C K G R O U N D}

\section{Description of the condition}

Diabetes mellitus is a metabolic disorder that results from a defect in insulin secretion by pancreatic $\beta$-cells, insulin action or both. Insulin is a hormone that is secreted by specialised cells in the pancreas (pancreatic $\beta$-cells) in response to increases in blood glucose (blood sugar) levels. The effect of insulin is to lower blood glucose. Insulin enables most body cells to absorb glucose from the blood for use as fuel, for conversion to other needed molecules or for storage. Insulin is the principal instigator for conversion of glucose (the basic sugar used for fuel) to glycogen for internal storage in liver and muscle cells. A consequence of a defect that results in reduced insulin secretion or reduced ability of insulin to promote uptake of glucose from the blood (i.e. resistance to insulin action) is hyperglycaemia (high levels of glucose in the blood). If this becomes chronic (long term), disturbances in the metabolism of carbohydrate, fat and protein may occur: once levels of blood glucose are chronically above a specific level, diabetes is diagnosed. If diabetes is not treated, prolonged hyperglycaemia leads to damage and to poor function of various organs, especially eyes, kidneys, nerves, heart and blood vessels.

\section{Classification of diabetes mellitus}

The two most common types of diabetes are known as type 1 and type 2 diabetes mellitus (Expert 2000).

\section{Type 1 diabetes mellitus}

People with type 1 diabetes mellitus have absolute, or nearly absolute, insulin deficiency. This type of diabetes develops quickly with hyperglycaemia, rapid acidification of the blood (ketoacidosis) and death, unless treated with insulin. Type 1 diabetes usually presents with acute onset of symptoms, including increased urination and thirst, but it can also present first with collapse or coma. The disease may occur at any age, but onset in childhood or adolescence is most common. Type 1 diabetes usually results when the immune system attacks cells in the pancreas that produce insulin (autoimmune destruction of pancreatic $\beta$-cells). Type 1 diabetes requires life-long treatment with insulin.

\section{Type 2 diabetes mellitus}

People with type 2 diabetes mellitus may have resistance to insulin action or relative insulin deficiency or, more commonly, both. In many individuals with type 2 diabetes, problems begin with resistance to insulin action, meaning that higher levels of insulin are required to complete usual actions, including removal of glucose from the blood. The greater requirement for pancreatic $\beta$-cells to secrete insulin results in impairment of their action and ultimately in insulin deficiency and diabetes. The pancreas generally retains some ability to produce insulin, but it is insufficient to meet the body's needs. Autoimmune destruction of pancreatic $\beta$-cells does not occur, and ketoacidosis is rare. Insulin therapy may not be required. Type 2 diabetes mellitus usually develops slowly and is commonly asymptomatic, with up to $50 \%$ of adults with type 2 diabetes remaining undiagnosed (Thomas 2005; Williams 2003). The risk of type 2 diabetes increases with age, obesity and lack of physical activity. It can occur at any age but is relatively rare before the age of 30 years, however in concert with increasing obesity and reducing levels of physical activity, type 2 diabetes is becoming more common in young adults and is now seen in children.

\section{Other types of diabetes}

Less common types of diabetes mellitus include diabetes due to rare genetic disorders, congenital problems in the pancreas and trauma to the pancreas, as well as diabetes that occurs as a side effect of some drugs (e.g. steroids). Gestational diabetes is described in the section below.

\section{Normal pregnancy and insulin resistance}

Normal pregnancy is associated with insulin resistance similar to that found in type 2 diabetes. Physiological resistance to insulin action during pregnancy becomes apparent in the second trimester, and insulin sensitivity declines progressively to term. These changes facilitate transport of glucose across the placenta to ensure normal fetal growth and development. Transfer of glucose across the placenta stimulates fetal insulin secretion, and insulin acts as an essential growth hormone. However, if resistance to maternal insulin action becomes too pronounced, fetal hyperinsulinaemia, accelerated growth and possible organ damage may occur. In normal pregnancy after delivery, maternal pregnancy-associated insulin resistance returns rapidly to normal, and glucose tolerance usually returns to normal within six weeks of delivery.

\section{Gestational diabetes mellitus}

Gestational diabetes mellitus (GDM) is defined as "carbohydrate intolerance resulting in hyperglycaemia of variable severity with onset or first recognition during pregnancy" (Expert 2000; WHO 1999). GDM is defined in this way for women with undiagnosed pre-existing diabetes and for those in whom the first onset of hyperglycaemia is identified during pregnancy. To identify early in pregnancy women with previously undiagnosed diabetes, the International Association of Diabetes and Pregnancy Study Groups (IADPSG) (Metzger 2010) recommends assessment of highrisk populations using glycated haemoglobin, fasting or random plasma glucose at first pregnancy booking. Other groups including the American Diabetes Association (ADA) (ADA 2017) and the UK National Institute for Health and Care Excellence (NICE 2015) also recommend early testing of high-risk groups to identify women with pre-existing diabetes.

In the past GDM has been categorised by severity of glucose impairment, with less severe cases referred to as impaired glucose tolerance, and more severe cases as GDM. Hyperglycaemia is now viewed as a continuum, with levels along the complete distribution of glycaemia in pregnant women associated with adverse effects (HAPO Study Cooperative Research Group 2008). Because of this, the term 'impaired glucose tolerance' is no longer used, and all abnormalities of glucose intolerance in pregnancy are now referred to as 'GDM'. GDM necessarily includes women who first develop diabetes during pregnancy, as well as those with previously undiagnosed type 1 or 2 diabetes mellitus (frank or pre-existing diabetes) recognised for the first time in pregnancy, because it is impossible at the time of first recognition to distinguish clearly between these different diagnoses. GDM complicates between 1\% and 24\% of pregnancies (Farrar 2015a; Farrar 2016; NIH 2013) and varies with the population characteristics and the diagnostic glucose thresholds used. It is the most common metabolic disorder of pregnancy and is associated with increased maternal and perinatal morbidity (Bitó 2005; Crowther 2005; Kim 2002; Landon 2009; Schytte 2004). Reducing modifiable risk factors for developing GDM by eating a healthy balanced diet, achieving 
and maintaining a healthy normal weight and exercising before and throughout pregnancy may reduce the risk of development of GDM or its severity, but the evidence is limited (Ceysens 2006; Tieu 2017). Maternal hyperglycaemia leads to transfer of excessive glucose to the fetus, resulting in fetal hyperinsulinaemia. Fetal hyperinsulinaemia causes increased risk of fetal adiposity, macrosomia (increased birthweight) and perinatal complications (Jovanovic 2001; Kjos 1999). Specifically, GDM is associated with overgrowth of insulin-sensitive tissue such as adipose tissue, especially around the chest, shoulders and abdomen, which increases the risk of shoulder dystocia, perinatal death and birth trauma and makes the need for caesarean section more likely (Jovanovic 2001; Kjos 1999). Risk of hypoxaemia is increased in utero, and this can lead to increased risk of intra-uterine death, fetal polycythaemia (too many red blood cells), hyperbilirubinaemia (jaundice) and renal vein thrombosis (blood clot in the kidney vein). Evidence also suggests increased risk of neonatal metabolic complications, including hypoglycaemia, in babies of mothers experiencing GDM (Jovanovic 2001; Kjos 1999; Kostalova 2001; Pribylová 1996; Silverman 1995). Observational data suggest that babies of women with GDM are at increased risk of obesity (Dabelea 2000; Gillman 2003; Pettitt 1983) and hypertension (Akisü 1999) later in life. However, data from trials of treatment of women with mild to moderate GDM suggest similar adiposity in infants, regardless of their mother's group allocation (Gillman 2010; Landon 2015), data are few and length of follow up limited.

\section{Description of the intervention}

A range of recommendations and guidelines for identification of women with GDM have been published by the World Health Organization (WHO) (WHO 1999; WHO 2013), the International Association of Diabetes and Pregnancy Study Groups (IADPSG) (Metzger 2010), the American Diabetes Association (ADA 2017), the National Institute for Health and Clinical Excellence (NICE 2015), the Australasian Diabetes in Pregnancy Society (ADIPS 1998), the Royal Australian and New Zealand College of Obstetricians and Gynaecologists (RANZCOG 2014) and the Scottish Intercollegiate Guideline Network (Jovanovic 2004).

The criteria for diagnosis of GDM have been debated for some time. A linear association has been noted between maternal glucose levels and adverse perinatal outcomes across the whole distribution of glucose levels in pregnancy (HAPO Study Cooperative Research Group 2008). Thus, there is no clear threshold above which women are at high risk and below which they are at low risk. Criteria for diagnosis of GDM have been developed in attempts to identify thresholds that best predict adverse maternal and neonatal outcomes; however, lack of sufficient evidence of increased effectiveness in improving outcomes of one criterion over another has led to the use of different criteria, which are arbitrary and often are based on expert opinion. The IADPSG (Metzger 2010) has recommended revised thresholds (Table 1) in the light of Hyperglycaemia and Adverse Pregnancy Outcome (HAPO) study results, which suggest adverse effects on fetal outcomes with glucose levels previously considered within the normal range (HAPO Study Cooperative Research Group 2008). The WHO (WHO 2013) and the ADA (ADA 2017) have recently endorsed the IADPSG criteria; however, the ADA has also endorsed the 'twostep' approach favoured by the American National Institutes of Health (NIH 2013).
Tests most commonly used for diagnosis of GDM are the two-hour $75 \mathrm{~g}$ oral glucose tolerance test (OGTT) recommended by IADPSG and WHO (Metzger 2010; WHO 1999; WHO 2013) and the three-hour $100 \mathrm{~g}$ OGTT recommended by the National Institutes of Health $(\mathrm{NIH}$ 2013). Limitations of these tests are that they require women to fast from the night before (although in some studies non-fasting OGTT has been performed), to drink a glucose solution and to wait for two or three hours before undergoing the final blood test. Whether the drink itself has side effects is unclear, as is whether this might be a factor contributing to non-attendance for the test. Alternative tests that have been proposed for the diagnosis of GDM include glycated haemoglobin, fasting blood glucose and random blood glucose, or glycosuria (sugar in the urine); however, it has been suggested that these tests are not as reliable as the OGTT for correctly identifying women with hyperglycaemia (Scott 2002). Globally the number of women diagnosed with GDM is rising; factors associated with this rise include increasing rates of obesity and reduced levels of exercise (Catalano 2011; NICE 2015; Simmons 2011); however lowering thresholds for diagnosis will increase prevalence. Now more than ever, efficient and effective strategies for identifying those with GDM are needed.

\section{How the intervention might work}

\section{Oral glucose tolerance test and diagnostic criteria}

Until 2013 the World Health Organization recommended that diagnosis of GDM should be based on the same criteria used for non-pregnant adults (WHO 1999). The WHO recommended that with the $75 \mathrm{~g}$ OGTT, GDM (including impaired glucose tolerance) was diagnosed if the fasting plasma glucose level was greater than $7.0 \mathrm{mmol} / \mathrm{L}$, or if the two-hour level was greater than 7.8 $\mathrm{mmol} / \mathrm{L}$. The UK National Institute for Health and Care Excellence (NICE) recommendations (NICE 2015) are based on these criteria; however, although still recommending the $75 \mathrm{~g}$ OGTT, NICE recommend that GDM should be diagnosed when either fasting plasma glucose level is equal to or greater than $5.6 \mathrm{mmol} / \mathrm{L}$, or when the two-hour postload level is equal to or greater than $7.8 \mathrm{mmol} / \mathrm{L}$.

The National Diabetes Data Group (NDDG) recommendations for GDM diagnosis were first published by the American Diabetes Association in 1997 (NDDG 1997); these criteria are based on initial screening with an oral glucose challenge test (OGCT). This test did not require women to fast; they were given a $50 \mathrm{~g}$ glucose drink and had blood glucose checked after one hour. If the one-hour value was equal to or greater than $7.8 \mathrm{mmol} / \mathrm{L}$, a three-hour $100 \mathrm{~g}$ OGTT followed. Subsequently, the NDDG revised its recommendations, suggesting a one-step approach for high-risk women, using a 100 $\mathrm{g}$ three-hour OGTT (Expert 2000). For low-risk women, the NDDG continued to recommend a two-step approach with an initial 50 g glucose challenge test, followed by a $100 \mathrm{~g}$ three-hour OGTT for women who screen positive with the one-hour OGCT threshold of $7.8 \mathrm{mmol} / \mathrm{L}$. Blood glucose levels for diagnosis of GDM on the threehour test are equal to or greater than $5.3 \mathrm{mmol} / \mathrm{L}$ for fasting blood sugar, equal to or greater than $10.0 \mathrm{mmol} / \mathrm{L}$ at one hour, equal to or greater than $8.6 \mathrm{mmol} / \mathrm{L}$ at two hours and equal to or greater than $7.8 \mathrm{mmol} / \mathrm{L}$ at three hours (Expert 2000).

As discussed, the IADPSG has published guidance recommending the $75 \mathrm{~g}$ OGTT with lowered thresholds (compared with WHO 1999 criteria) in the light of HAPO study findings (Metzger 2010). Lowering the diagnostic threshold will result in the diagnosis of GDM in more women who have less severe hyperglycaemia. 
Evidence indicates that treatment of women with mild to moderate GDM reduces the risk of adverse perinatal outcomes; however the beneficial effects of treatment based on diagnosis determined using one criterion may not be the same as those of treatment based on diagnosis of GDM using different criteria.

Current recommendations on the criteria for diagnosis are presented in Table 1, Table 2, Table 3 and NICE 2015. It is clear that the choice of test and diagnostic criteria varies both within and between countries (Kanguru 2014).

\section{Other tests for gestational diabetes}

The main disadvantages of the OGTT are that it is costly and unpleasant for women. Simpler, cheaper and more acceptable tests for initial screening and even diagnosis would be advantageous, provided they were accurate in identifying women with GDM or its complications or both. Random plasma glucose testing has been popular in the past, as it is convenient to perform. However, it fails to identify a large proportion of women who have GDM (low sensitivity) (McElduff 1994). Fasting plasma glucose has greater sensitivity and specificity than random glucose tests, but it relies on women fasting overnight, and it does not perform as well as the OGTT in identifying those with GDM (Perucchini 1999) because worsening insulin resistance in women with GDM may be compensated for by increased insulin production, which means that fasting glucose can be normal, with the early abnormality becoming apparent only after meals.

Glycated haemoglobin, which reflects glucose levels over the past four weeks, does not require an overnight fast and needs only a single blood sample; it is increasingly recommended as a potentially valuable tool for diagnosing diabetes in nonpregnant people (Fonseca 2009). Use of glycated haemoglobin to diagnose GDM has not been well studied. In countries where fasting or random glucose or glucose challenge tests are not used to universally screen for GDM, the presence of glycosuria has been used as a screening method. Assessment of glycosuria is relatively cheap, non-invasive and acceptable to pregnant women (Hanna 2008). However, guidance from NICE 2008 and ADA 2017 no longer recommend its use as a screening method, instead suggesting that risk assessment (e.g. based on ethnicity, family history, obesity) should be used as the primary screening method in the absence of a universal blood test for glycaemia. Evidence indicates that glycosuria has low sensitivity for identifying hyperglycaemia/GDM determined by glucose tolerance testing (Scott 2002). However, its sensitivity has not been directly compared with that of risk factors used as the preliminary screening tool in the UK, and limited evidence suggests an association between glycosuria and macrosomia and risk of obesity for future children (Scott 2002).

\section{When to test for gestational diabetes}

Views on the most appropriate time to test women for GDM are varied. Timing is important because consideration of the burden on pregnant women and on healthcare service resources means that ideally the test should be performed only once during pregnancy. At the same time, earlier diagnosis and treatment in any woman with GDM may prevent adverse perinatal outcomes. Administering the test during the first trimester results in identification of women with previously undiagnosed type 1 or type 2 diabetes, as well as those with early-onset newly occurring diabetes. Women at particularly high risk, such as those who had GDM in a previous pregnancy, are often offered an OGTT in the first trimester. However, as most physiological pregnancy-related changes in insulin sensitivity (sometimes referred to as a glucose challenge test of pregnancy) begin during the second trimester, testing in the first trimester may miss a large proportion of women who will develop GDM. For this reason it has been suggested that high-risk women who have a normal test in the first trimester will usually require a second test later in pregnancy.

To avoid the need for repeated testing, most women are offered a single test in the late second trimester. This timing serves as a balance between testing too early (thus missing some women who do not develop gestational diabetes until after the test) and testing too late (leaving little time to intervene to reduce plasma glucose and improve outcomes).

\section{Universal versus selective testing}

The question of whether to offer universal or selective screening remains controversial and is the topic of another Cochrane Review (Screening for gestational diabetes mellitus to improve maternal and infant health) (Tieu 2014). In the past, screening has been targeted at those with increased risk of developing the condition, for example, women who have had GDM in a previous pregnancy, those with a family history, women of Asian or Carribean ethnicity and those who are obese; however some women without risk factors may develop GDM and may remain untreated. If all women are offered an OGTT, more women with hyperglycaemia will be identified and more women may benefit from treatment (Farrar 2014). There are however no robust trial data to suggest which approach (universal or selective) is best for improving maternal and infant outcomes, even though treatment trials (Crowther 2005; Landon 2009) and reviews (Brown 2017; Farrar 2016) have demonstrated an improvement in several important perinatal outcomes when hyperglycaemia is reduced (a Cochrane Protocol also details a review that will provide an overview of Cochrane Reviews of interventions (Martis 2016)).

\section{Why it is important to do this review}

Accurate identification of women with GDM is important, so that treatment can be provided to reduce the risk of adverse outcomes associated with hyperglycaemia. The aim of this Cochrane Review was to compare alternative diagnostic tests for identification of GDM and to assess their association with maternal and infant outcomes and use of healthcare service resources.

\section{OB JECTIVES}

To evaluate and compare different testing strategies for diagnosis of gestational diabetes mellitus to improve maternal and infant health while assessing their impact on healthcare service costs.

\section{METHODS}

\section{Criteria for considering studies for this review}

\section{Types of studies}

We included randomised trials that evaluated diagnostic tests carried out to diagnose gestational diabetes mellitus (GDM). We excluded studies that clearly were not randomised trials, as well as studies that used a quasi-random design, such as alternate days or date of birth, for allocation to the intervention group. Cluster or cross-over designed trials were not eligible for inclusion. Abstracts 
were eligible for inclusion if sufficient information was available for assessment and data extraction.

\section{Types of participants}

We included studies if they recruited pregnant women at risk of GDM. We included women if they were at low risk or high risk (such as women who were obese, those with a first-degree relative with diabetes, high-risk ethnic groups, high-fasting or random plasma glucose and previous gestational diabetes) of developing GDM. We included women with single or multiple gestations.

We excluded women with diabetes diagnosed before the incident pregnancy.

\section{Types of interventions}

We intended to include all diagnostic tests for GDM, such as glycated haemoglobin, random and fasting blood sugar and oral glucose tolerance tests. We included comparisons of any testing with no testing, as well as comparisons of one form of testing versus another.

We would have included comparisons of testing at different gestational ages if they had been available.

\section{Types of outcome measures}

We included the following outcomes in the review. We would have used primary outcomes for subgroup and sensitivity analyses if appropriate.

${ }^{\star} A$ number of the primary and secondary maternal and infant outcome measures were based on the core outcomes for Cochrane gestational diabetes reviews reached by consensus among authors of reviews for treatment of GDM. A number of these had been included in previous versions of this review, but some were added for this update (see Differences between protocol and review).

\section{Primary outcomes}

\section{Maternal}

1. Mode of birth: normal, caesarean section, instrumental delivery.*

2. Diagnosis of gestational diabetes: as assessed by need for treatment such as diet or insulin.

\section{Neonatal}

1. Macrosomia: birthweight greater than $4.5 \mathrm{~kg}$, or however defined in the trial.*

\section{Secondary outcomes}

\section{Maternal}

1. Induction of labour.*

2. Side effects of testing, such as vomiting and bruising.

3. Compliance with testing, including attendance.

4. Need for repeat testing by the same or an alternative method.

5. Plasma glucose (non-prespecified outcome).

6. Perineal trauma.*

7. Placental abruption. ${ }^{\star}$

8. Weight gain during pregnancy. ${ }^{\star}$

9. Breastfeeding (e.g. at discharge, six weeks postpartum).*
10. Measures of costs for healthcare services, such as number of antenatal visits, admissions to hospital. ${ }^{\star}$

11. Measures of costs for women, such as time off work, need for additional child care.

12.Longer-term outcomes: postnatal depression, weight retention, GDM in a subsequent pregnancy, cardiovascular health (defined by trials, including blood pressure and hypertension), development of type 2 diabetes. ${ }^{*}$

13.Women's views, including their preferences and measures of satisfaction.*

14.Quality of life measures.*

Neonatal

1. Death: including perinatal death (stillbirth, death in the first week of life), neonatal death (death in the first 28 days of life) and infant death (death in the first year of life).*

2. Birth trauma, including shoulder dystocia, nerve palsy and fracture.

3. Preterm birth: birth before 37 completed weeks' gestation, birth before 34 weeks.

4. Large-for-gestational age: greater than 90th centile, or however defined in the trial.

5. Measures of neonatal morbidity, such as hypoglycaemia, hypocalcaemia, polycythaemia, respiratory distress syndrome, jaundice, admission to special care.

6. Apgar score (less than seven at five minutes).*

7. Gestational age at birth: mean.

8. Birthweight and z-score.

9. Ponderal index.*

10. Measures of adiposity. ${ }^{\star}$

11.Shoulder dystocia.*

12.Bone fracture.*

13. Nerve palsy.

14. Relavent biomarkers, e.g. cord C-peptide, cord insulin. *

15.Longer-term outcomes: measures of growth and adiposity and neurodevelopment during childhood and educational achievement, diabetes, blood pressure. ${ }^{\star}$

16. Measures of costs for healthcare services, such as number of days on the neonatal unit, length of stay..

\section{Search methods for identification of studies}

The following Methods section of this review is based on a standard template used by Cochrane Pregnancy and Childbirth.

\section{Electronic searches}

We searched Cochrane Pregnancy and Childbirth's Trials Register by contacting their Information Specialist (6 January 2017).

The Register is a database containing over 22,000 reports of controlled trials in the field of pregnancy and childbirth. For full search methods used to populate Pregnancy and Childbirth's Trials Register including the detailed search strategies for CENTRAL, MEDLINE, Embase and CINAHL; the list of handsearched journals and conference proceedings, and the list of journals reviewed via the current awareness service, please follow this link to the editorial information about the Cochrane Pregnancy and Childbirth in the 
Cochrane Library and select the 'Specialized Register' section from the options on the left side of the screen.

Briefly, Cochrane Pregnancy and Childbirth's Trials Register is maintained by their Information Specialist and contains trials identified from:

1. monthly searches of the Cochrane Central Register of Controlled Trials (CENTRAL);

2. weekly searches of MEDLINE (Ovid);

3. weekly searches of Embase (Ovid);

4. monthly searches of CINAHL (EBSCO);

5. handsearches of 30 journals and the proceedings of major conferences; and

6. weekly current awareness alerts for a further 44 journals plus monthly BioMed Central email alerts.

Search results are screened by two people and the full text of all relevant trial reports identified through the searching activities described above is reviewed. Based on the intervention described each trial report is assigned a number that corresponds to a specific Pregnancy and Childbirth review topic (or topics), and is then added to the Register. The Information Specialist searches the Register for each review using this topic number rather than keywords. This results in a more specific search set which has been fully accounted for in the relevant review sections (Included studies; Excluded studies; Studies awaiting classification; Ongoing studies).

In addition, we searched ClinicalTrials.gov and the WHO International Clinical Trials Registry Platform (ICTRP) for unpublished, planned and ongoing trial reports (6 January 2017) using the terms given in Appendix 1.

\section{Searching other resources}

We searched the reference lists of retrieved studies.

We did not apply any language or date restrictions.

\section{Data collection and analysis}

For methods used in the previous version of this review, see Farrar 2015.

For this update, the following methods were used for assessing the 12 reports that were identified as a result of the updated search.

\section{Selection of studies}

Two review authors independently assessed for inclusion all potential studies identified as a result of the search. We resolved disagreements through discussion, or, if required, we consulted a third review author.

\section{Data extraction and management}

We designed a form for use in extracting data. For eligible studies, two review authors extracted data using the agreed upon form. We resolved discrepancies through discussion, or, if required, we consulted a third review author. We entered data into Review Manager software (RevMan 2014) and checked them for accuracy.
When information regarding any of the above was unclear, we planned to contact authors of the original reports to request further details.

\section{Assessment of risk of bias in included studies}

Two review authors independently assessed risk of bias for each study using the criteria outlined in the Cochrane Handbook for Systematic Reviews of Interventions (Higgins 2011). Disagreements were resolved by discussion or by consultation with a third assessor.

\section{(1) Random sequence generation (checking for possible selection bias)}

We described for each included study the method used to generate the allocation sequence in sufficient detail to allow an assessment of whether it should produce comparable groups.

We assessed the method as:

- low risk of bias (any truly random process, e.g. random number table; computer random number generator);

- high risk of bias (any non-random process, e.g. odd or even date of birth; hospital or clinic record number); or

- unclear risk of bias.

\section{(2) Allocation concealment (checking for possible selection bias)}

We described for each included study the method used to conceal allocation to interventions before the time of assignment and assessed whether intervention allocation could have been foreseen in advance of or during recruitment, or changed after assignment.

We assessed these methods as:

- low risk of bias (e.g. telephone or central randomisation; consecutively numbered sealed opaque envelopes);

- high risk of bias (open random allocation; unsealed or nonopaque envelopes; alternation; date of birth); or

- unclear risk of bias.

\section{(3.1) Blinding of participants and personnel (checking for possible performance bias)}

We described for each included study the methods used, if any, to blind study participants and personnel from knowledge of which intervention a participant received. We considered that studies were at low risk of bias if they were blinded, or if we judged that lack of blinding was unlikely to affect results. We assessed blinding separately for different outcomes or different classes of outcomes.

We assessed the methods as:

- low, high or unclear risk of bias for participants; or

- low, high or unclear risk of bias for personnel.

\section{(3.2) Blinding of outcome assessment (checking for possible detection bias)}

We described for each included study the methods used, if any, to blind outcome assessors from knowledge of which intervention a participant received. We assessed blinding separately for different outcomes or different classes of outcomes.

We assessed methods used to blind outcome assessment as: 
- low, high or unclear risk of bias.

(4) Incomplete outcome data (checking for possible attrition bias due to the quantity, nature and handling of incomplete outcome data)

We described for each included study, and for each outcome or class of outcomes, the completeness of data, including attrition and exclusions from the analysis. We stated whether attrition and exclusions were reported and the numbers included in the analysis at each stage (compared with the total number of randomly assigned participants), reasons for attrition or exclusion when reported and whether missing data were balanced across groups or were related to outcomes. When sufficient information was reported, or could be supplied by the trial authors, we planned to re-include missing data in the analyses that we undertook.

We assessed methods as:

- low risk of bias (e.g. no missing outcome data; missing outcome data balanced across groups);

- high risk of bias (e.g. numbers or reasons for missing data imbalanced across groups; 'as treated' analysis done with substantial departure of intervention received from that assigned at randomisation); or

- unclear risk of bias.

\section{(5) Selective reporting (checking for reporting bias)}

We described for each included study how we investigated the possibility of selective outcome reporting bias and what we found.

We assessed the methods as:

- low risk of bias (when it was clear that all of the study's prespecified outcomes and all expected outcomes of interest to the review had been reported);

- high risk of bias (when not all of the study's prespecified outcomes had been reported; one or more reported primary outcomes were not prespecified; outcomes of interest were reported incompletely and so could not be used; study failed to include results of a key outcome that would have been expected to have been reported); or

- unclear risk of bias.

(6) Other bias (checking for bias due to problems not covered by (1) to (5) above)

We described for each included study important concerns that we had about other possible sources of bias.

\section{(7) Overall risk of bias}

We made explicit judgements about whether studies were at high risk of bias, according to the criteria given in the Cochrane Handbook for Systematic Reviews of Interventions (Higgins 2011). With reference to (1) to (6) above, we planned to assess the likely magnitude and direction of bias, and whether we considered it likely to impact study findings. In future updates, we will explore the impact of the level of bias by undertaking sensitivity analyses (see Sensitivity analysis).

\section{Assessment of the quality of the evidence using the GRADE approach}

For this update the quality of the evidence was assessed using the GRADE approach as outlined in the GRADE handbook in order to assess the quality of the body of evidence relating to the following outcomes for the main comparisons.

We assessed the quality of the body of evidence as related to the following outcomes for the comparison of $75 \mathrm{~g}$ oral glucose tolerance testing (OGTT) versus $100 \mathrm{~g}$ GTT.

1. Diagnosis of gestational diabetes.*

2. Caesarean section. ${ }^{\star}$

3. Macrosomia $>4.5 \mathrm{~kg}$, or however defined in the trial.

4. Long-term type 2 diabetes maternal.*

5. Long-term type 2 diabetes infant. ${ }^{\star}$

6. Economic costs.

Some of the outcomes above* relate to outcomes from GRADE core outcomes for Cochrane gestational diabetes reviews reached by consensus among authors of reviews for treatment of GDM.

We used GRADEpro Guideline Development Tool to import data from Review Manager 5.3 (RevMan 2014) to create a 'Summary of findings' table. A summary of the intervention effect and a measure of quality for each of the above outcomes was produced using the GRADE approach. The GRADE approach uses five considerations (study limitations, consistency of effect, imprecision, indirectness and publication bias) to assess the quality of the body of evidence for each outcome. The evidence can be downgraded from 'high quality' by one level for serious (or by two levels for very serious) limitations, depending on assessments for risk of bias, indirectness of evidence, serious inconsistency, imprecision of effect estimates or potential publication bias.

\section{Measures of treatment effect}

\section{Dichotomous data}

For dichotomous data, we presented results as summary risk ratios (RRs) with 95\% confidence intervals (Cls).

\section{Continuous data}

We used mean differences (MDs) when outcomes were measured in the same way between trials. We planned to use the standardised mean differences (SMDs) to combine trials that measured the same outcome but used different methods. SMDs were not used in this update.

\section{Unit of analysis issues}

\section{Cluster-randomised trials}

Cluster-randomised trials were not eligible for inclusion.

\section{Cross-over trials}

Cross-over trials were not eligible for inclusion.

\section{Multi-armed trials}

When a multi-armed trial was included, we recorded and included in the review all outcome data as two-arm comparisons. We included the data for different arms in independent two-arm 
comparisons in separate meta-analyses. When the control group was shared by the two study arms, we divided the control group between relevant subgroup categories to avoid double counting of participants (for dichotomous data we divided the events and the total population, and for continuous data we assumed the same mean and standard deviation (SD) but divided the total population). In future updates, when we cannot include the data in separate comparisons, we will combine them to create a single pair-wise comparison (Higgins 2011). We will describe details in the Characteristics of included studies tables.

\section{Other unit of analysis issues}

One trial included 35 women with twin pregnancies (Mexico 2011). Effects on outcomes of different strategies for diagnosing GDM may differ between singleton and multiple pregnancies; therefore caution should be taken when the results of analyses that include data from this trial are considered.

\section{Dealing with missing data}

For included studies, levels of attrition were noted. In future updates, if more eligible studies are included, the impact of including studies with high levels of missing data in the overall assessment of treatment effect will be explored by performing sensitivity analysis.

For all outcomes, analyses were carried out, as far as possible, on an intention-to-treat basis (i.e. we attempted to include in the analyses all participants randomly assigned to each group). The denominator for each outcome in each trial was the number randomly assigned minus any participants whose outcomes were known to be missing.

\section{Assessment of heterogeneity}

We assessed statistical heterogeneity in each meta-analysis using $\mathrm{Tau}^{2}, \mathrm{I}^{2}$ and $\mathrm{Chi}^{2}$ statistics and regarded heterogeneity as substantial if $\mathrm{I}^{2}$ was greater than $30 \%$ and either $\mathrm{Tau}^{2}$ was greater than zero or the $\mathrm{P}$ value was low $(<0.10)$ in the $\mathrm{Chi}^{2}$ test for heterogeneity. If we identified substantial heterogeneity (> 30\%), we planned to explore this by performing prespecified subgroup analysis.

\section{Assessment of reporting biases}

In future updates, if 10 or more studies are included in the metaanalysis, we will investigate reporting biases (such as publication bias) by using funnel plots. We will assess funnel plot asymmetry visually. If asymmetry is suggested by visual assessment, we will perform exploratory analyses to investigate this.

\section{Data synthesis}

We carried out statistical analysis using Review Manager software (RevMan 2014). We used fixed-effect meta-analysis for combining data when it was reasonable to assume that studies were estimating the same underlying treatment effect (i.e. when trials were examining the same intervention and the trials' populations and methods were judged sufficiently similar).
If clinical heterogeneity had been sufficient to suggest that underlying treatment effects differed between trials, or if substantial statistical heterogeneity was detected, we planned to use random-effects meta-analysis to produce an overall summary if an average treatment effect across trials was considered clinically meaningful. In this update, random-effects meta-analysis was not performed. In future updates, if we conduct random-effects analysis, this will be treated as the average range of possible treatment effects, and we will discuss the clinical implications of differing treatment effects between trials. If the average treatment effect is not clinically meaningful, we will not combine trials. If we use random-effects analyses, results will be presented as the average treatment effect with $95 \% \mathrm{Cls}$, along with estimates of $\mathrm{Tau}^{2}$ and $\mathrm{I}^{2}$.

\section{Subgroup analysis and investigation of heterogeneity}

It was not possible to carry out any subgroup analyses because data were insufficient. In future updates, if we identify substantial heterogeneity, we will investigate this by using subgroup analyses and sensitivity analyses. We will consider whether an overall summary is meaningful, and if it is, we will use random-effects analysis to produce it.

We will carry out the following subgroup analyses in future updates.

1. Ethnicity.

2. Body mass index (underweight, normal weight, overweight and obese).

The following outcomes will be used in subgroup analyses in future updates.

1. Mode of birth: normal, caesarean section, instrumental delivery.

2. Diagnosis of gestational diabetes - as assessed by need for treatment, such as diet or insulin.

3. Macrosomia: birthweight greater than $4.5 \mathrm{~kg}$, or however defined in the trial.

We will assess subgroup differences by performing interaction tests available within RevMan (RevMan 2014). We will report the results of subgroup analyses by quoting the $\mathrm{Chi}^{2}$ statistic and the $\mathrm{P}$ value, and those of the interaction test by providing the $\mathrm{I}^{2}$ value.

\section{Sensitivity analysis}

If relevant to future updates, we will carry out sensitivity analyses to explore the effects of trial quality assessed by concealment of allocation, high attrition rates or both, with poor quality studies excluded from the analyses to permit assessment of whether this makes any difference in the overall result. This was not possible in this update because included data were insufficient.

\section{RE S U L T S}

\section{Description of studies}

Results of the search

See Figure 1. 
Figure 1. Study flow diagram.

6 trials included in the previous version of the review

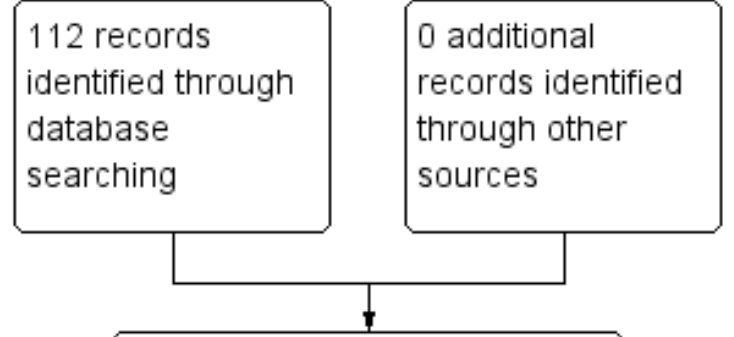

111 after duplicates removed

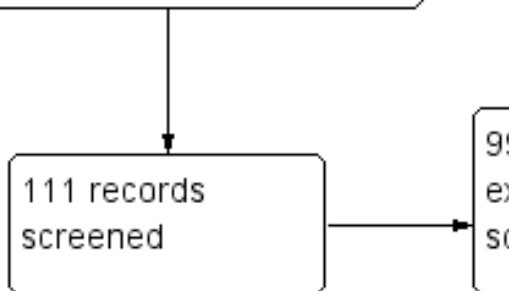

99 records excluded (not scope, not a trial)

One new trial excluded with reasons.

Five reports added to a previously excluded study.

One trial is awaiting further classification.

12 full-text articles assessed for eligibility Two trials (four reports) are ongoing. 
The updated search in January 2017 search retrieved 12 potentially eligible trial reports. One trial was included (Turkey 2014). One trial is awaiting classification (China 2013). One trial was excluded (USA 2015) and a further five trial reports were added to a previously excluded trial (Ireland 2014a). Two trials (four reports) are ongoing (Ireland 2014b; USA 2014).

\section{Included studies}

We included seven trials with 1420 women. One new trial including 736 women was included in this update (Turkey 2014). One trial (Nigeria 2004) compared $75 \mathrm{~g}$ with $100 \mathrm{~g}$ oral glucose tolerance test (OGTT) using World Health Organization (WHO) and National Diabetes Data Group (NDDG) criteria for diagnosis of gestational diabetes mellitus (GDM) (NDDG 1997). One trial (USA 1994) compared a candy bar and glucose polymer and glucose monomer drinks. Glucose monomer, referred to as d-glucose, was defined as the 'standard' intervention; therefore, data related to this group were divided for comparison with the two remaining intervention groups. One trial compared $50 \mathrm{~g}$ glucose food with a 50 g glucose drink (Mexico 2003). Another trial (Mexico 2011) included three comparison groups: $75 \mathrm{~g}$ OGTT using WHO criteria; $75 \mathrm{~g}$ OGTT using American Diabetes Association (ADA) criteria; and $100 \mathrm{~g}$ OGTT using ADA criteria. Non-randomised participants were included in the $100 \mathrm{~g}$ OGTT group (ADA criteria); therefore data for this group were not included in this review. Two trials compared a glucose polymer drink with a glucose monomer drink (New Zealand 1985; USA 1992). One trial compared the two-step (50 g OGCT and 100 g OGTT, diagnosis based on the Carpenter and Coustan criteria) with the one-step (75 g OGTT, diagnosis based on the WHO (1999) criteria) approach (Turkey 2014).

Three trials (Mexico 2011; Nigeria 2004; Turkey 2014) reported maternal primary outcomes while only one trial (Mexico 2011) reported neonatal primary outcomes. Another trial (New Zealand
1985) reported macrosomia, but only for women who were subsequently diagnosed with GDM rather than for all women who were randomly assigned. The remaining three trials (Mexico 2003; USA 1992; USA 1994) only reported secondary outcomes. Infant outcomes were reported in three trials (Mexico 2011; New Zealand 1985; Nigeria 2004). Mexico 2011 reported macrosomia and stillbirth. Nigeria 2004 reported difference in mean birthweight, which was not one of our prespecified outcomes. The duration of follow-up for all trials was short; lasting only one hour in three trials (Mexico 2003; USA 1992; USA 1994) and three hours in two trials (New Zealand 1985; Nigeria 2004). In Turkey 2014 there was no follow up because of the limited data that could be included, in Mexico 2011 follow up lasted up until birth.

\section{Excluded studies}

We excluded 30 trials, of which 15 used cross-over designs (Austria 1994; Austria 1998; Germany 2004; Hong Kong 1993; Iran 2007; Iran 2008; New Zealand 1984a; New Zealand 1984b; Singapore 1992; Thailand 2003; Tunisia 2001; USA 1993a; USA 1993b; USA 1995; USA 1999); five did not randomise allocation (China 1995; China 1995a; Greece 2004; Thailand 1995; USA 1993c); two used quasirandomisation techniques (USA 1989; USA 1991); two did not meet our participant inclusion criteria (known non-GDM and known GDM respectively at recruitment) (Thailand 2008; USA 2001); two did not provide the correct intervention (Canada 1999; Ireland 2000); two did not report outcomes in a form that allowed inclusion in the analyses (Canada 2005; USA 1995a); and one did not report sufficient data (USA 2015).

\section{Risk of bias in included studies}

All trials were relatively small and had several aspects of unclear quality with few outcomes reported. See Figure 2 and Figure 3 for a summary of risk of bias assessments.

\section{Figure 2. Risk of bias graph: review authors' judgements about each risk of bias item presented as percentages across all included studies.}

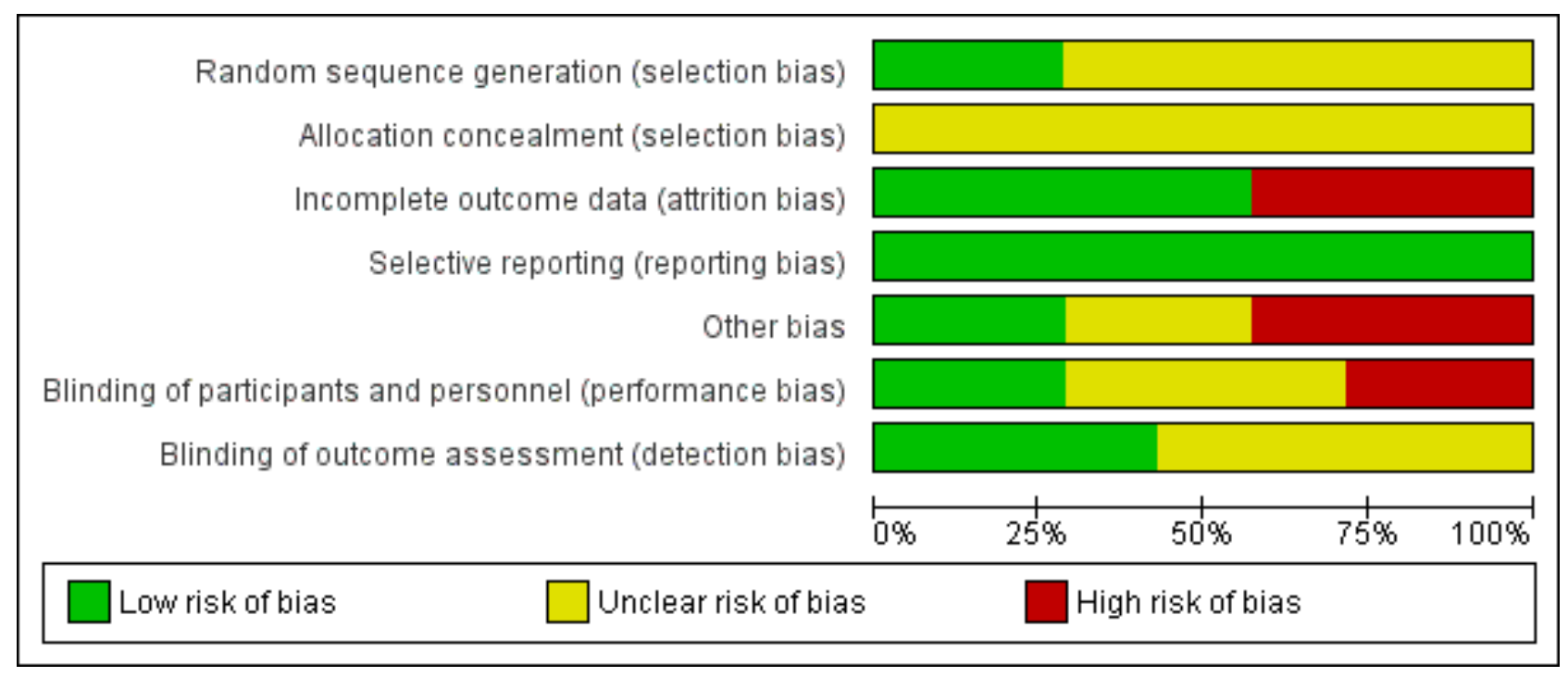


Figure 3. Risk of bias summary: review authors' judgements about each risk of bias item for each included study.

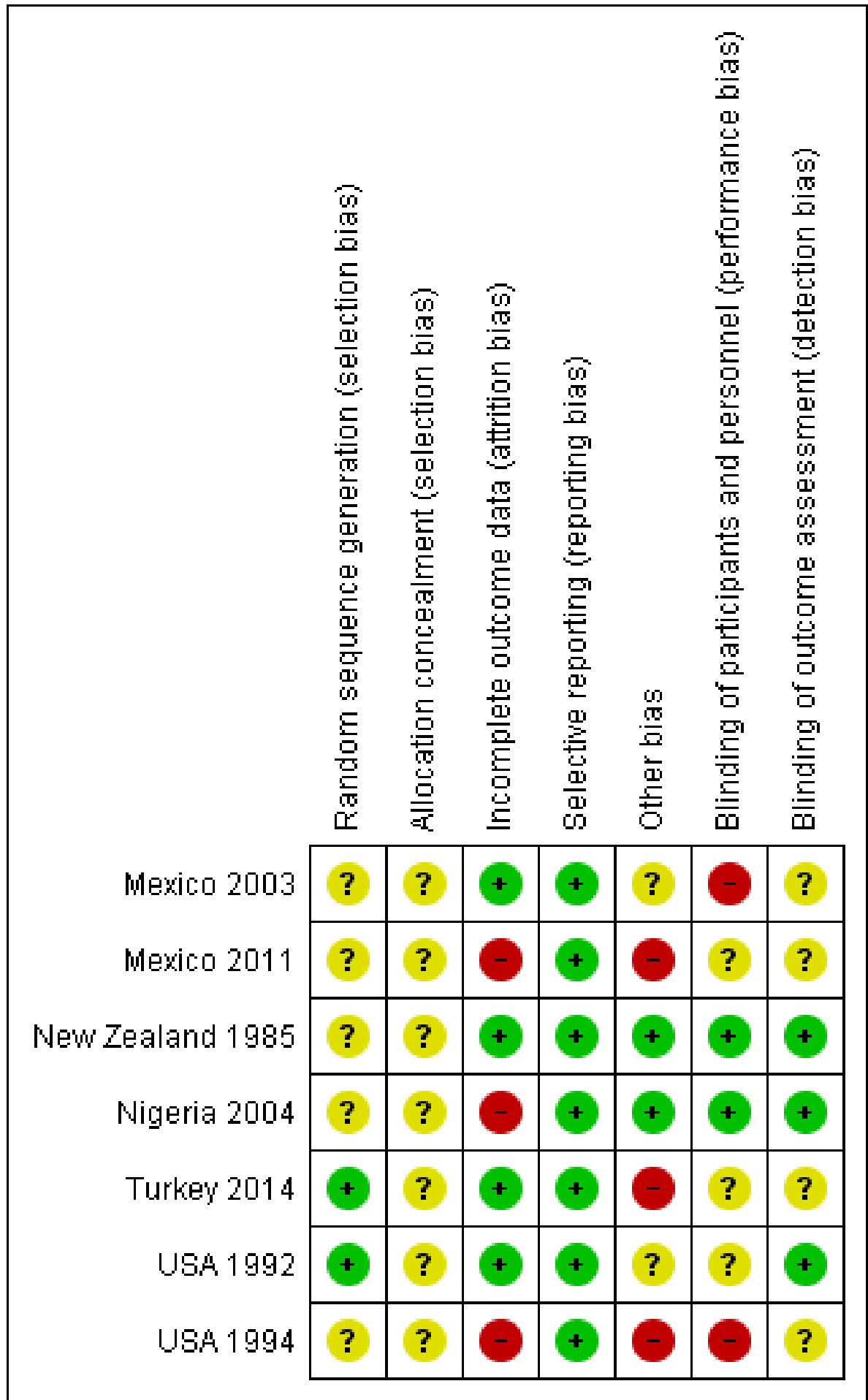

\section{Allocation}

Two trials ( Turkey 2014; USA 1992) were judged as low risk of bias for sequence generation as they used computer generated random numbers and a random number table. It was unclear in the remaining five trials (Mexico 2003; Mexico 2011; New Zealand 1985; Nigeria 2004; USA 1994). All of the trials were judged as unclear risk of bias for allocation concealment.

\section{Blinding}

Two trials (New Zealand 1985; Nigeria 2004) were judged low risk for performance bias and detection bias: blinding of personnel and participants was not reported but this was possible because the tests consisted of glucose drinks that appeared to be identical and the outcomes were objective, for example, plasma glucose value and of birthweight, and would not have been affected 
by knowledge of treatment groups. Two trials were assessed as being at high risk for performance bias (Mexico 2003; USA 1994) and unclear for detection bias: blinding of participants and personnel was not reported but the reporting of side effects may have been influenced by knowledge of the treatment and it is unclear whether knowledge of side effects would have influenced outcome assessment. Two trials (Mexico 2011; USA 1992) were judged as unclear risk for performance bias: in one (Mexico 2011), blinding of personnel and participants was not reported but would have been possible because the tests consisted of glucose drinks that could have appeared to be identical. Blood glucose levels, birthweight and ruptured membranes would not have been affected by knowledge of treatment groups, but outcomes such as caesarean birth may have been affected. Outcome assessment was not reported and so was also assessed as being unclear (Mexico 2011). In the other trial, (USA 1992), it was described as double blind, which is possible as test drinks may have appeared identical, however, the outcome of side effects could have been affected by knowledge of treatment groups, although the plasma glucose value would not have been affected. For outcome assessment, USA 1992, was assessed as being at low risk, because side effects were selfreported on a questionnaire and thus were not subject to assessor bias and plasma glucose values would not have been affected by lack of blinding on the part of assessors. The final trial, Turkey 2014, was assessed as being at unclear risk for both performance and detection bias: the tests were clearly different, but the outcome of GDM diagnosis is a biochemical assessment and so this would not have been influenced by lack of blinding; outcome assessment was not reported.

\section{Incomplete outcome data}

Four trials (Mexico 2003; New Zealand 1985; Turkey 2014; USA 1992) were judged as low risk of attrition bias with no loss to follow-up described. The three remaining trials (Mexico 2011; Nigeria 2004; USA 1994) were judged as having high risk of attrition bias: loss to follow-up was reported in up to $11 \%$ of participants in (USA 1994); loss of follow-up was reported up to $15 \%$ in another (Nigeria 2004); and seven women were excluded because they could not tolerate the $75 \mathrm{~g}$ diagnostic test given in Mexico 2011, suggesting that this trial did not analyse data using intention-to-treat methodology.

\section{Selective reporting}

All seven included trials (Mexico 2003; Mexico 2011; New Zealand 1985; Nigeria 2004; Turkey 2014; USA 1992; USA 1994) were judged as low risk for reporting bias, however it is possible that not all outcomes were reported as no protocols were available.

\section{Other potential sources of bias}

Two trials (New Zealand 1985; Nigeria 2004) were judged as having low risk of bias, with no other potential sources of bias identified. Another three trials (Mexico 2011; Turkey 2014; USA 1994) were assessed as being at high risk of bias for this domain. Turkey 2014 only reported characteristics of women included in their final analysis 486/726; therefore the effectiveness of the randomisation process could not be assessed. Significant group differences were reported with respect to age and parity in USA 1994, which may be due to inadequate randomisation or small sample size. Inclusion of non-randomised participants and unclear reporting of methods and outcomes suggest potential for 'other' bias in Mexico 2011. It was unclear in the remaining two trials (Mexico 2003; USA 1994).

\section{Effects of interventions}

See: Summary of findings for the main comparison $75 \mathrm{~g}$ OGTT versus $100 \mathrm{~g}$ OGTT for diagnosing GDM to improve maternal and infant health

\section{Comparison $1.75 \mathrm{~g}$ OGTT versus $100 \mathrm{~g}$ OGTT}

We included one trial with 248 women in this comparison.

\section{Primary outcomes}

\section{Diagnosis of gestational diabetes}

Use of a $75 \mathrm{~g}$ OGTT rather than a $100 \mathrm{~g}$ OGTT was associated with increased risk of being diagnosed with GDM (RR 2.55, 95\% Cl 0.96 to 6.75 ; 1 trial, 248 women; Analysis 1.1; very low-quality evidence). No other primary outcomes for mother or baby were reported in this trial.

\section{Secondary outcomes}

No clear differences in blood glucose levels at one hour (MD -0.11, $90 \% \mathrm{Cl}-0.44$ to $0.22 ; 1$ trial, 248 women; Analysis 1.2) and at two hours (MD $-0.31,90 \% \mathrm{Cl}-0.64$ to $0.02 ; 1$ trial, 248 women; Analysis 1.2) were observed between groups. At three hours women allocated $75 \mathrm{~g}$ OGTT had lower blood glucose than those allocated a $100 \mathrm{~g}$ test (MD $-1.08 \mathrm{mmol} / \mathrm{L}, 95 \% \mathrm{Cl}-1.55$ to $-0.61 ; 1$ trial, 248 women; Analysis 1.2). No other maternal nor neonatal outcomes were reported.

\section{Comparison 2. $50 \mathrm{~g}$ glucose polymer drink versus $50 \mathrm{~g}$ glucose monomer drink}

We included three trials with 239 women in this comparison.

\section{Primary outcomes}

No primary outcomes were reported.

\section{Secondary outcomes}

Two trials with 131 women reported side effects. Total reported side effects were less common with the glucose polymer (RR 0.21, 95\% $\mathrm{Cl} 0.07$ to $0.59 ; 1$ trial, 63 women; Analysis 2.1). Side effects reported were bloating, pain, nausea, headache, dizziness, tiredness and vomiting. Each reported side effect tended to be less common for women given the glucose polymer drink, with the exception of vomiting, which was not reported by either group. Nausea (RR 0.29, $95 \% \mathrm{Cl} 0.11$ to $0.78 ; 1$ trial, 66 women) was reported more often by women given the glucose monomer drink. There was no clear difference between groups for headache (RR $0.20,95 \% \mathrm{Cl} 0.02$ to 1.62; 1 trial, 66 women); bloating (RR $0.41,95 \% \mathrm{Cl} 0.15$ to $1.12 ; 2$ trials, 131 women; $\mathrm{I}^{2}=49 \%$ ); dizziness (RR $0.40,95 \% \mathrm{Cl} 0.08$ to 1.92 ; 1 trial, 66 women); tiredness (RR 1.33, 95\% Cl 0.32 to 5.50; 1 trial, 66 women); pain (RR $0.14,95 \% \mathrm{Cl} 0.02$ to $1.12 ; 2$ trials, 129 women; $\mathrm{I}^{2}=$ $0 \%$ ); and taste acceptability (RR $1.05,95 \% \mathrm{Cl} 0.37$ to $3.00 ; 1$ trial, 63 women). No other maternal outcomes were reported (see Analysis 2.1).

Three trials (239 women) reported one-hour glucose levels (MD $-0.27 \mathrm{mmol} / \mathrm{L}, 95 \% \mathrm{Cl}-0.56$ to 0.03 ), and one trial reported two-hour (MD $-0.40 \mathrm{mmol} / \mathrm{L}, 95 \% \mathrm{Cl}-0.85$ to $0.05 ; 100$ women) and three-hour (MD $0.00 \mathrm{mmol} / \mathrm{L}, 95 \% \mathrm{Cl}-0.45$ to $0.45 ; 100$ women) glucose levels. No clear difference in glucose levels was noted between the groups (see Analysis 2.2). 
Infants in the glucose polymer group had lower gestational age at birth compared with those in the glucose monomer group (MD - 0.80 weeks, $95 \% \mathrm{Cl}-1.69$ to $0.09 ; 1$ trial, 100 women; Analysis 2.3), but it should be noted that the $\mathrm{Cls}$ ranged from a 1.69-week reduction to a 0.09-week increase.

No outcomes were reported for the baby.

\section{Comparison 3. Candy bar versus $\mathbf{5 0} \mathrm{g}$ glucose monomer drink}

We included one trial with 60 women in this comparison.

\section{Primary outcomes}

No primary outcomes were reported.

\section{Secondary outcomes}

Reported side effects were pain, bloating and total side effects. No difference in total side effects was noted between women receiving the candy bar and women receiving the glucose monomer drink (RR $1.03,95 \% \mathrm{Cl} 0.58$ to 1.82 ). There was also no clear difference between the groups for pain (RR $0.17,95 \% \mathrm{Cl} 0.01$ to 3.91 ; 1 trial, 58 women), and bloating (RR $1.08,95 \% \mathrm{Cl} 0.21$ to 5.40; 1 trial, 60 participants). Nevertheless, there was evidence to suggest that women preferred the taste of the candy bar (RR $0.60,95 \% \mathrm{Cl} 0.42$ to 0.86; 1 trial, 59 women; Analysis 3.1).

The one-hour serum glucose level was lower for women taking the candy bar than for those taking a glucose monomer drink (MD -1.0 $\mathrm{mmol} / \mathrm{L}, 95 \% \mathrm{Cl}-1.13$ to $-0.87 ; 1$ trial, 59 women; Analysis 3.2). It should be noted that the authors report 'serum' glucose as opposed to 'plasma' glucose (our prespecified outcome) although glucose levels are likely to be similar using either plasma or serum glucose it would be incorrect to report them as one and the same. No other maternal outcomes were reported.

No outcomes were reported for the baby.

\section{Comparison 4. $50 \mathrm{~g}$ glucose food versus $50 \mathrm{~g}$ glucose drink}

We included one trial with 30 women in this comparison.

\section{Primary outcomes}

No primary outcomes were reported.

\section{Secondary outcomes}

Women receiving glucose in their food, rather than as a drink, reported fewer side effects (RR $0.08,95 \% \mathrm{Cl} 0.01$ to $0.56 ; 1$ trial, 30 women; Analysis 4.1). No difference was reported in the number of women requiring repeat testing by the same or an alternative method (RR 0.14, $95 \% \mathrm{Cl} 0.01$ to 2.55; 1 trial, 30 women; Analysis 4.2).

No other maternal outcomes nor neonatal outcomes were reported.

\section{Comparison 5.75 g OGTT (WHO criteria) versus 75 g OGTT (ADA criteria)}

We included one trial with 116 women in this comparison. No differences between treatment groups were observed for any outcome.

\section{Primary outcomes}

Birth outcomes for women were similar among treatment groups for caesarean birth (RR 1.07, 95\% Cl 0.85 to 1.35; Analysis 5.1) and instrumental birth (RR $0.21,95 \% \mathrm{Cl} 0.01$ to 3.94; Analysis 5.2). Diagnosis of gestational diabetes (RR $1.47,95 \% \mathrm{Cl} 0.66$ to 3.25 ; Analysis 5.3) and macrosomia (> 90th percentile by ultrasound or birthweight $\geq 4000 \mathrm{~g})(\mathrm{RR} 0.73,95 \% \mathrm{Cl} 0.19$ to 2.79 ; Analysis 5.4) were also similar between treatment groups.

\section{Secondary outcomes}

No differences between treatment groups were reported for the infant outcome stillbirth (RR 0.49, 95\% Cl 0.02 to 11.68; Analysis 5.5).

Two-step approach ( $50 \mathrm{~g}$ oral glucose challenge test (OGCT) followed by selective $100 \mathrm{~g}$ OGCT, Carpenter and Coustan criteria) versus one-step approach (universal $75 \mathrm{~g}$ OGTT, ADA criteria)

\section{Primary outcomes}

We included one trial with 726 women. Risk of being diagnosed with GDM at 11 to 14 weeks' gestation (RR $0.51,95 \% \mathrm{Cl} 0.28$ to 0.95 ) was lower with the two-step compared to the one-step approach. No other outcomes were reported (Analysis 6.1).

\section{Secondary outcomes}

No secondary outcomes were reported.

\section{DISCUSSION}

Five included trials compared different ways of giving a glucose load (Mexico 2003; New Zealand 1985; Nigeria 2004; USA 1992; USA 1994), one compared outcomes when two different criteria were used to diagnose gestational diabetes mellitus (GDM) with the $75 \mathrm{~g}$ oral glucose tolerance test (OGTT) (Mexico 2011) and one compared the two and one-step approaches (Turkey 2014). None evaluated the more important question of when is the best time during pregnancy to test women for GDM, and none compared the standard OGTT, which requires women to fast overnight, with a test that does not require an overnight fast. No comprehensive comparisons examined healthcare service costs associated with different test strategies. We excluded Canada 2005 from this review because the data were reported as percentages only; however, Meltzer 2010b used a subset of participants from Canada 2005 to conduct a simple analysis of laboratory and transportation costs associated with carrying out the one-step or the two-step method and with using the $75 \mathrm{~g}$ or $100 \mathrm{~g}$ OGTT. The two-step approach was reported to be less expensive than the one-step approach.

\section{Summary of main results}

We included seven small trials that included a total of 1420 women. Primary outcomes reported were diagnosis of GDM, macrosomia, caesarean section and instrumental birth (Mexico 2011; Nigeria 2004 Turkey 2014). Nigeria 2004 compared use of a 75 g OGTT versus a $100 \mathrm{~g}$ OGTT and reported results for the diagnosis of GDM. Women who received the $75 \mathrm{~g}$ OGTT had greater relative risk of being diagnosed with GDM. Although the point estimate suggests a two-fold to three-fold increase in relative risk, the Cls are wide and ranged from a 6.75 increase to a 0.04 reduction. Furthermore, evidence for this outcome was assessed as very low-quality. Mexico 2011 compared use of the $75 \mathrm{~g}$ OGTT (WHO criteria) versus the $75 \mathrm{~g}$ OGTT (ADA criteria) and reported results for the diagnosis of 
GDM, macrosomia, caesarean section and instrumental birth. None of these results showed differences between treatment groups. No trial has yet evaluated the effectiveness of the International Association of Diabetes and Pregnancy Study Groups diagnostic criteria for reducing the risk of adverse perinatal outcomes; the $75 \mathrm{~g}$ OGTT is recommended (GDM diagnosis is made if any one glucose level is equal to or greater than fasting $5.1 \mathrm{mmol} / \mathrm{L}$, one hour post load $10.0 \mathrm{mmol} / \mathrm{L}$ or two hours post load $8.5 \mathrm{mmol} / \mathrm{L}$ ). Turkey 2014 compared the two-step (50 g OGCT followed by $100 \mathrm{~g}$ OGTT, Carpenter and Coustan criteria) with the one-step (75 g OGTT, ADA criteria) approach. This trial was conducted to evaluate the performance characteristics of the two approaches, no maternal or infant outcomes were reported with the exception of GDM diagnosis (other outcomes included sensitivity and specificity and positive and negative predicted value). Results suggest a lower risk of being diagnosed with GDM if the two-step compared to the one-step approach was used (RR $0.51,95 \% \mathrm{Cl} 0.28$ to 0.95 ).

Overall, few secondary outcomes were reported. However, trials assessing ways of giving a glucose load that are likely to be more palatable to women tended to report that these alternatives were associated with fewer side effects and that women preferred their taste.

\section{Overall completeness and applicability of evidence}

Data in this review are incomplete in two key areas. The first is that no trials have evaluated the important questions, such as when is the best time during pregnancy to test women for GDM, and whether women need to fast overnight before testing. The second is that trials included in this review have not reported data for most of the substantive outcomes. Data are therefore missing for most of the prespecified primary and secondary outcomes. Two trials reported outcomes for infants, but these data were incomplete or were not related to one of our prespecified outcomes and so could not be included in the review.

Studies were conducted in various countries, including Mexico, New Zealand, Nigeria, Turkey and the USA, increasing the generalisability of the findings. Most women were between 24 and 28 weeks' gestation, one trial however reported GDM diagnosis at 11 to 14 weeks' gestation. Some women were classed as being at 'high' risk for GDM, but risk for most was unclear.

\section{Quality of the evidence}

None of the trials in this review adequately reported all aspects of the methods used and so the risk of bias of the included studies is generally unclear or high. Five trials were judged as having high risk of bias in at least one domain. Only two of the seven trials reported sequence generation, and concealment of allocation was not clearly reported in any of the trials. Blinding of the participant and the clinician to the intervention would not have been possible for most of these trials, but it would have been possible for the glucose monomer and polymer drinks. In three trials blinding of outcome assessors would have been possible. Losses to follow-up were variable, and in studies that asked women to complete questionnaires, data are missing for women who did not return the completed questionnaire. One trial suffered a $30 \%$ loss of participants which is considerable particularly given the women were still pregnant and therefore still receiving care, reasons for these losses were not provided by the authors. One trial included women with twin pregnancies, but did not report whether investigators accounted for this in their analyses, or to how many and to which comparison groups the twin pregnancies were allocated. Three trials reported that some women did not complete testing because of side effects.

We prespecified six outcomes to be assessed for quality using the GRADE (Grades of Recommendation, Assessment, Development and Evaluation) method. Data for assessment were provided for only one outcome - diagnosis of gestational diabetes for the comparison of $75 \mathrm{~g}$ OGTT versus $100 \mathrm{~g}$ OGTT and the evidence was considered to be of very low quality when assessed by GRADE due to design limitations, wide confidence intervals crossing the line of no effect, few events and small sample size. No data were reported for the following additional outcomes prespecified for assessment in GRADE: caesarean section, macrosomia $>4.5 \mathrm{~kg}$, long-term type 2 diabetes maternal, long-term type 2 diabetes infant and economic costs.

\section{Potential biases in the review process}

We conducted an extensive search, but it remains possible that studies may have been missed. If we identify any such studies in future searches, we will assess them for potential inclusion in this review.

As the quality of the included trials is unclear, the potential for bias is present. Another significant source of potential bias is missing outcome data. Therefore study results should be interpreted with caution.

\section{Agreements and disagreements with other studies or reviews}

To our knowledge one other review has been published to evaluate methods of diagnosing gestational diabetes mellitus (Scott 2002). This review included primary studies that were unrestricted by study design and therefore were more susceptible to bias. Review authors concluded that high-quality evidence is insufficient to guide practice, and that randomised trials of alternative screening and diagnostic tests should be undertaken.

A recently published report funded by the UK National Institute for Health Research, Health Technology Assessment programme provides a comprehensive assessment of evidence related to the identification and treatment of hyperglycaemia in pregnancy, including analyses of individual participant data from two large UK based contemporary cohorts, systematic reviews and a comprehensive economic analysis (Farrar 2016). Findings reported include differences in glucose and associated maternal and infant outcome prevalence by ethnic group, highlighting the need for further population-based epidemiological surveys that include ethnically diverse women. The report concluded that given the lack of longer-term evidence of effectiveness (and using the NICE recommended QALY threshold), the identification and treatment of hyperglycaemia in pregnancy is not cost-effective.

\section{AUTHORS' CONCLUSIONS}

\section{Implications for practice}

The incidence of gestational diabetes mellitus (GDM) is rising throughout the world. Evidence suggests that treatment of women with GDM improves some short-term perinatal outcomes (Crowther 2005; Landon 2009) strengthening the rationale for identifying 
women who have GDM. Strategies to diagnose GDM therefore need to be accurate, acceptable to women and affordable and demonstrate a clinically relevant reduction in risk of important adverse maternal and infant outcomes. Given that the International Association of Diabetes and Pregnancy Study Group's (IADPSG) recommended criteria aim to reduce the risk of infant obesity through its association with macrosomia, the challenge is not only to report short term outcomes, but to conduct adequate follow up so that longer-term health can be assessed, though limited evidence suggest offspring adiposity at five to 10 years is similar irrespective of whether mother was treated or not treated (Gillman 2010; Landon 2015), this does not exclude the possibility however that an effect may be seen as these infants age.

There is limited evidence to suggest which approach is superior to diagnose GDM, this includes those strategies (universal/selective) tests (glucose loads) and criteria (Carpenter and Coustan, NDDG, NICE, IADPSG) that have been used in clinical practise for several decades (Carpenter 1982) or are more recent additions (IADPSG 2010).

Until well-designed trials have been conducted that evaluate different approaches to diagnosing GDM, clinicians and those commissioning services should consider the available evidence and base their decisions on this, their population and their resources.

\section{Implications for research}

Large randomised trials are required to establish the best strategy for correctly identifying women with GDM. Information on when women should be tested is needed, as is information on the optimal criteria such as the IADPSG 2010 and WHO 1999 criteria and tests such as $75 \mathrm{~g}$ and $100 \mathrm{~g}$ oral glucose tolerance tests or alternative glucose loads (jelly beans, etc).

Studies should be of high quality and should report methods clearly. Outcomes should include measures of morbidity and mortality for the baby, as well as substantive outcomes for the mother. Follow-up of women and their offspring should be conducted for several years (Meltzer 2010a) or ideally until offspring are adults.

\section{ACKNOWLEDGEMENTS}

Thank you to Sabina Abbas for transcribing Weiss (Austria 1994) from German to English, and thank you to Ana Duarte for translating Dueñas (Mexico 2011) from Portuguese to English.

Nancy Medley was an author on the previous 2015 update. Her work was financially supported by the UNDP/UNFPA/UNICEF/WHO/ World Bank Special Programme of Research, Development and Research Training in Human Reproduction (HRP), Department of Reproductive Health and Research (RHR), World Health Organization. The named review authors alone are responsible for the views expressed in this publication.

This project was supported by the National Institute for Health Research, via Cochrane Programme Grant funding to Cochrane Pregnancy and Childbirth. The views and opinions expressed therein are those of the authors and do not necessarily reflect those of the Systematic Reviews Programme, NIHR, NHS or the Department of Health.

Therese Dowswell is supported by the NIHR Cochrane Programme Grant Project: 13/89/05 - Pregnancy and childbirth systematic reviews to support clinical guidelines. 


\section{RE F E R E N C E S}

\section{References to studies included in this review}

\section{Mexico 2003 \{published data only\}}

Martínez Collado JH, Alvarado Gay FJ, Danel Beltrán JA, González Martinez E. Glucose screening test in pregnant women. A comparison between the traditional glucose load and diet [Tamiz de glucosa en embarazadas. Comparación de la carga tradicional contra la dieta]. Medicina Interna de México 2003;19(5):286-8.

\section{Mexico 2011 \{published data only\}}

Dueñas-García OF, Ramírez-Torres A, Diaz-Sotomayo M, RicoOlvera H. Perinatal outcome of patients with gestational diabetes diagnosed with three different methods. Ginecología y Obstetricia de México 2011;79(7):411-8.

\section{New Zealand 1985 \{published data only\}}

Court DJ, Mann SL, Stone PR, Goldsbury SM, Dixon-Mclvor D, Baker JR. Comparison of glucose polymer and glucose for screening and tolerance tests in pregnancy. Obstetrics and Gynecology 1985;66(4):491-9.

Nigeria 2004 \{published data only\}

Olarinoye JK, Ohwovoriole AE, Ajayi GO. Diagnosis of gestational diabetes mellitus in Nigerian pregnant women comparison between $75 \mathrm{~g}$ and $100 \mathrm{~g}$ oral glucose tolerance tests. West African Journal of Medicine 2004;23(3):198-201.

Turkey 2014 \{published data only\}

Yeral MI, Ozgu-Erdinc AS, Uygur D, Seckin KD, Karsli MF, Danisman AN. Prediction of gestational diabetes mellitus in the first trimester, comparison of fasting plasma glucose, two-step and one-step methods: a prospective randomized controlled trial. Endocrine 2014;46(3):512-8.

\section{USA 1992 \{published data only\}}

Bergus GR, Murphy NJ. Screening for gestational diabetes mellitus: comparison of a glucose polymer and a glucose monomer test beverage. Journal of the American Board of Family Practice 1992;5(3):241-7.

\section{USA 1994 \{published data only\}}

Murphy NJ, Meyer BA, O'Kell RT, Hogard ME. Carbohydrate sources for gestational diabetes mellitus screening. A comparison. Journal of Reproductive Medicine 1994;39(12):977-81.

\section{References to studies excluded from this review}

\section{Austria 1994 \{published data only\}}

Weiss PA, Kainer F, Haeusler MC, Pürstner P, Urasch R. A rapid method for diabetes screening in pregnancy [Schnellmethode zum Diabetesscreening in der Schwangerschaft]. Geburtshilfe und Frauenheilkunde 1994;54(12):697-701.

\section{Austria 1998 \{published data only\}}

Weiss PA, Haeusler M, Kainer F, Pürstner P, Haas J. Toward universal criteria for gestational diabetes: relationships between seventy-five and one hundred gram glucose loads and between capillary and venous glucose concentrations. American Journal of Obstetrics and Gynecology 1998;178(4):830-5.

\section{Canada 1999 \{published data only\}}

Bebbington MW, Milner R, Wilson RD, Harris S. A randomized controlled trial comparing routine screening vs selected screening for gestational diabetes in low risk population. American Journal of Obstetrics and Gynecology 1999;180(1 Pt 2):S36.

\section{Canada 2005 \{published data only\}}

Meltzer SJ, Snyder J, Morin L, Nudi M, Karalis A. Prevalence of gestational diabetes mellitus (GDM) among 5489 multiethnic pregnant women in Montreal using a randomized trial of a 75 vs 100 g glucose load. Diabetologia 2005;48(Suppl 1):A23.

Meltzer SJ, Snyder J, Penrod JR, Nudi M, Morin L. Gestational diabetes mellitus screening and diagnosis: prospective randomised controlled trial comparing costs of one-step and two-step methods. BJOG: an international journal of obstetrics and gynaecology 2010;117(4):407-15.

China 1995 \{published data only\}

Zhang Y, Xu H. Screening for gestational diabetes with capillary blood glucose. Zhonghua Fu Chan Ke Za Zhi [Chinese Journal of Obstetrics and Gynecology] 1995;30(5):287-9.

China 1995a \{published data only\}

Sun B, Wang X, Song Q, Wang Y, Xue L, Wang C, et al. Prospective studies on the relationship between the $50 \mathrm{~g}$ glucose challenge test and pregnant outcome. Chinese Medical Journal 1995; Vol. 108, issue 12:910-3.

Germany 2004 \{published data only\}

Buhling KJ, Elsner E, Wolf C, Harder T, Engel B, Wascher C, et al. No influence of high- and low-carbohydrate diet on the oral glucose tolerance test in pregnancy. Clinical Biochemistry 2004;37(4):323-7.

\section{Greece 2004 \{published data only\}}

Stavrianos C, Anastasiou E. Oral glucose tolerance test evaluation with forearm and fingertip glucose measurements in pregnant women. Diabetes Care 2004;27(2):627-8.

\section{Hong Kong 1993 \{published data only\}}

Fung $\mathrm{H}$, Baldwin S, Rogers M. The influence of a glucose load on subsequent carbohydrate metabolism in pregnancy. Australian and New Zealand Journal of Obstetrics and Gynaecology 1993;33(2):118-21.

Iran 2007 \{published data only\}

Eslamian L, Ramezani Z. Breakfast as a screening test for gestational diabetes. International Journal of Gynaecology and Obstetrics 2007;96(1):34-5.

\section{Iran 2008 \{published data only\}}

Eslamian L, Ramezani Z. Evaluation of a breakfast screening test for the detection of gestational diabetes. Acta Medica Iranica 2008;46(1):43-6. 
Ireland 2000 \{published data only\}

Griffin ME, Coffey M, Johnson H, Scanlon P, Foley M, Stronge J, et al. Universal vs risk factor-based screening for gestational diabetes mellitus: detection rates, gestation at diagnosis and outcome. Diabetic Medicine 2000;17(1):26-32.

Ireland 2014a \{published data only\}

O'Dea A, Infanti JJ, Gillespie P, Tummon O, Fanous S, Glynn LG, et al. Screening uptake rates and the clinical and cost effectiveness of screening for gestational diabetes mellitus in primary versus secondary care: study protocol for a randomised controlled trial. Trials 2014;15:27.

O'Dea A, Tierney M, Glynn L, Danyliv A, Carmody L, McGuire B, et al. The clinical effectiveness of screening for gestational diabetes mellitus in primary vs secondary care: results of a randomised controlled trial. Endocrine Abstracts 2015;37:EP377.

Tierney M, O'Dea A, Danyliv A, Glynn L, McGuire B, Carmody L, et al. Feasibility, acceptability, and uptake rates of gestational diabetes mellitus screening in primary care vs secondary care: Findings from a randomised controlled mixed methods trial. Endocrine Abstracts 2015;37:EP497.

Tierney M, O'Dea A, Danyliv A, Glynn L, Mcguire B, Carmody L, et al. The rate of uptake and clinical effectiveness of gestational diabetes mellitus screening in primary vs. secondary care. Diabetes 2015;64:A676.

Tierney M, O'Dea A, Danyliv A, Glynn LG, McGuire BE, Carmody LA, et al. Feasibility, acceptability and uptake rates of gestational diabetes mellitus screening in primary care vs secondary care: findings from a randomised controlled mixed methods trial. Diabetologia 2015;58(11):2486-93.

Tierney M, O'Dea A, Glynn L, Carmody L, McGuire B, Dunne F. The prevalence rate and rate of uptake of screening for gestational diabetes mellitus (GDM) in primary versus secondary care. Irish Journal of Medical Science 2014;183(Suppl 9):S447.

\section{New Zealand 1984a \{published data only\}}

Court DJ, Stone PR, Killip M. Comparison of glucose and a glucose polymer for testing oral carbohydrate tolerance in pregnancy. Obstetrics and Gynecology 1984; Vol. 64, issue 2:251-5.

\section{New Zealand 1984b \{published data only\}}

Court DJ, Stone PR, Killip M. Comparison of glucose and a glucose polymer for testing oral carbohydrate tolerance in pregnancy. Obstetrics and Gynecology 1984; Vol. 64, issue 2:251-5.

\section{Singapore 1992 \{published data only\}}

Cheng LC, Salmon YM, Chen C. A double-blind, randomised, cross-over study comparing the 50g OGTT and the $75 \mathrm{~g}$ OGTT for pregnant women in the third trimester. Annals of the Academy of Medicine 1992; Vol. 21, issue 6:769-72.

\section{Thailand 1995 \{published data only\}}

Deerochanawong C, Putiyanun C, Wongsuryrat M, Serirat S. Comparison of the diagnosis of GDM between NDDG and WHO criteria. Diabetologia 1995;38(Suppl 1):A36.

\section{Thailand 2003 \{published data only\}}

Soonthornpun S, Soonthornpun K, Aksonteing J, Thamprasit A. A comparison between a $75-g$ and $100-$ g oral glucose tolerance test in pregnant women. International Journal of Gynaecology and Obstetrics 2003;81(2):169-73.

\section{Thailand 2008 \{published data only\}}

Soonthornpun K, Soonthornpun S, Thamprasit A, Aksonteing J. Differences in postload plasma glucose levels between 100$\mathrm{g}$ and 75 -g oral glucose tolerance tests in normal pregnant women: a potential role of early insulin secretion. Journal of the Medical Association of Thailand 2008;91(3):277-81.

\section{Tunisia 2001 \{published data only\}}

Hidar S, Chaïeb A, Baccouche S, Laradi S, Fkih M, Milled A, et al. Post-prandial plasma glucose test as screening tool for gestational diabetes. A prospective randomized trial [Apport de la mesure de la glycemie post-prandiale dans le depistage du diabete gestationnel. Etude prospective randomisee]. Journal de Gynecologie, Obstetrique et Biologie de la Reproduction 2001;30(4):344-7.

\section{USA 1989 \{published data only\}}

Helton DG, Martin RW, Martin JN Jr, Meeks GR, Morrison JC. Detection of glucose intolerance in pregnancy. Journal of Perinatology 1989;9(3):259-61.

\section{USA 1991 \{published data only\}}

Harlass FE, McClure GB, Read JA, Brady K. Use of a standard preparatory diet for the oral glucose tolerance test. Is it necessary?. Journal of Reproductive Medicine 1991;36(2):147-50.

\section{USA 1993a \{published data only\}}

Jones JS, Horger E. A comparative study of the standard oral and intravenous glucose tolerance tests in pregnancy. American Journal of Obstetrics and Gynecology 1993;168:407.

USA 1993b \{published data only\}

Sammarco MJ, Mundy DC, Riojas JE. Glucose tolerance in pregnancy. Proceedings of 41st Annual Clinical Meeting of The American College of Obstetricians and Gynecologists; 1993 May 3-6; Washington DC, USA. 1993:10-1.

\section{USA 1993c \{published data only\}}

Lewis GF, McNally C, Blackman JD, Polonsky KS, Barron WM. Prior feeding alters the response to the 50 -g glucose challenge test in pregnancy. The Staub-Traugott Effect revisited. Diabetes Care 1993;16(12):1551-6.

\section{USA 1995 \{published data only\}}

Brustman LE, Gela BD, Moore M, Reilly KD, Langer O. Variations in oral glucose tolerance tests: the 100-versus 75-g controversy. Journal of the Association for Academic Minority Physicians 1995;6(2):70-2. 
USA 1995a \{published data only\}

Berkus MD, Langer O. Glucose tolerance test periodicity: the effect of glucose loading. Obstetrics and Gynecology 1995;85(3):423-7.

\section{USA 1999 \{published data only\}}

Dornhorst A, Frost G. Jelly-beans, only a colourful distraction from gestational glucose-challenge tests. Lancet 2000; Vol. 355, issue 9205:674.

Lamar ME, Allen SR, Cooney AT, Gayle LJ, Holleman S, Kuehl TJ. Jelly beans as an alternative to the glucola for gestational diabetes screening. American Journal of Obstetrics and Gynecology 1999;180(1 Pt 2):S36.

* Lamar ME, Kuehl TJ, Cooney AT, Gayle LJ, Holleman S, Allen SR. Jelly beans as an alternative to a fifty-gram glucose beverage for gestational diabetes screening. American Journal of Obstetrics and Gynecology 1999;181(5 Pt 1):1154-7.

\section{USA 2001 \{published data only\}}

Kjos SL, Schaefer-Graf U, Sardesi S, Peters RK, Buley A, Xiang AH, et al. A randomized controlled trial using glycemic plus fetal ultrasound parameters versus glycemic parameters to determine insulin therapy in gestational diabetes with fasting hyperglycemia. Diabetes Care 2001;24(11):1904-10.

USA 2015 \{published data only\} Upadhyaya NB, Bryant SB, Heidel RE, Hennessey MD, Howard BC, Rodriguez H. Early diagnosis of gestational diabetes mellitus in patients with elevated body mass index. Obstetrics and Gynecology 2015;125:965.

\section{References to studies awaiting assessment}

\section{China 2013 \{published data only\}}

ChiCTR-TRC-13003495. A prospective study of the risk factors of gestational diabetes in patients with early screening and intensive insulin intervention. chictr.org.cn/showproj.aspx? proj=6065 (first received 20 February 2013).

\section{References to ongoing studies}

Ireland 2014b \{published data only\}

Ahern T, Collins C, Gannon M, Hoashi S. Comparing the glucose challenge test and the oral glucose tolerance test in screening for gestational diabetes: A randomised clinical trial. Irish Journal of Medical Science 2014;183(Suppl 9):S457.

\section{USA 2013 \{published data only\}}

NCT01864564. Early gestational diabetes screening in the gravid obese woman. clinicaltrials.gov/ct2/show/NCT01864564 (first received 22 May 2013).

\section{USA 2014 \{published data only\}}

NCT01540396. GD2M study: gestational diabetes diagnostic methods. clinicaltrials.gov/ct2/show/NCT01540396 (first received 15 February 2012).
NCT02309138. Gestational diabetes diagnostic methods (gd2m) study: comparison of two screening strategies for gestational diabetes. clinicaltrials.gov/ct2/show/NCT02309138 (first received 25 November 2014).

Scifres CM, Abebe KZ, Jones KA, Comer DM, Costacou T, Freiberg MS, et al. Gestational Diabetes Diagnostic Methods (GD2M) pilot randomized trial. Maternal and Child Health Journal 2015;19(7):1472-80.

\section{Additional references}

\section{ADA 2010}

American Diabetes Association. Diagnosis and classification of diabetes mellitus. Diabetes Care 2010;33(Suppl 1):S62-S69.

\section{ADA 2017}

American Diabetes Association. Standards of medical care in diabetes. Diabetes Care 2017;40(Suppl 1):S1-S135.

\section{ADIPS 1998}

Hoffman L, Nolan C, Wilson JD, Oats JJ, Simmons D. Gestational diabetes mellitus - management guidelines. The Australasian Diabetes in Pregnancy Society. Medical Journal of Australia 1998;169(2):93-7.

\section{Akisü 1999}

Akisü M, Darcan S, Oral R, Kültürsay N. Serum lipid and lipoprotein composition in infants of diabetic mothers. Indian Journal of Pediatrics 1999;66(3):381-6.

\section{Bitó 2005}

Bitó T, Földesi I, Nyári T, Pál A. Prediction of gestational diabetes mellitus in a high risk group by insulin measurement in early pregnancy. Diabetic Medicine 2005;22(10):1434-9.

\section{Brown 2017}

Brown J, Alwan NA, West J, Brown S, McKinlay CJD, Farrar D, et al. Lifestyle interventions for the treatment of women with gestational diabetes. Cochrane Database of Systematic Reviews 2017, Issue 5. [DOI: 10.1002/14651858.CD011970.pub2]

\section{Carpenter 1982}

Carpenter MW, Coustan DR. Criteria for screening tests for gestational diabetes. American Journal of Obstetrics and Gynecology 1982;144(7):768-73.

\section{Catalano 2011}

Catalano PM, Hauguel-De Mouzon S. Is it time to revisit the Pedersen hypothesis in the face of the obesity epidemic?. American Journal of Obstetrics and Gynecology 2011;204(6):479-87.

\section{Ceysens 2006}

Ceysens G, Rouiller D, Boulvain M. Exercise for diabetic pregnant women. Cochrane Database of Systematic Reviews 2006, Issue 3. [DOI: 10.1002/14651858.CD004225.pub2]

\section{Crowther 2005}

Crowther CA, Hiller JE, Moss JR, McPhee AJ, Jeffries WS, Robinson JS, for the Australian Carbohydrate Intolerance Study 
in Pregnant Women (ACHOIS) Trial Group. Effect of treatment of gestational diabetes mellitus on pregnancy outcomes. New England Journal of Medicine 2005;352(24):2477-546.

\section{Dabelea 2000}

Dabelea D, Knowler, Pettitt DJ. Effect of Diabetes in Pregnancy on Offspring: Follow-up Research in the Pima Indians. Journal of Maternal-Fetal Medicine 2000;9:83-8.

\section{Expert 2000}

Expert Committee on the Diagnosis and Classification of Diabetes Mellitus. Report of the expert committee on the diagnosis and classification of diabetes mellitus. Diabetes Care 2003;26(Suppl):S5-S20.

\section{Farrar 2014}

Farrar D, Fairley L, Wright J, Tuffnell D, Whitelaw D, Lawlor DA. Evaluation of the impact of universal testing for gestational diabetes mellitus on maternal and neonatal health outcomes: a retrospective analysis. BMC Pregnancy and Childbirth 2014;14(317):1-347.

\section{Farrar 2015a}

Farrar D, Fairley L, Santorelli G, Tuffnell D, Sheldon TA, Wright J, et al. Association between hyperglycaemia and adverse perinatal outcomes in south Asian and white British women: analysis of data from the Born in Bradford cohort. Lancet. Diabetes \& Endocrinology 2015;3(10):795-804.

\section{Farrar 2016}

Farrar D, Fairley L, Tuffnell D, Wright J, Sheldon T, Bland M, et al. The identification and treatment of women with hyperglycaemia in pregnancy: an analysis of individual participant data, systematic reviews, meta-analyses and an economic evaluation. Health Technology Assessment 2016;20(86):1-348.

\section{Fonseca 2009}

Fonseca, V, Inzucchi, SE, Ferrannini, E. Redefining the diagnosis of diabetes using glycated hemoglobin. Diabetes Care 2009;32(7):1344-5.

\section{Gillman 2003}

Gillman MW, Rifas-Shiman S, Berkey CS, Field AE, Colditz GA. Maternal gestational diabetes, birth weight, and adolescent obesity. Pediatrics 2003;111(3):e221-e226.

\section{Gillman 2010}

Gillman MW, Oakey H, Baghurst PA, Volkmer RE, Robinson JS, Crowther CA. Effect of treatment of gestational diabetes mellitus on obesity in the next generation. Diabetes Care 2010;33(5):964-8.

\section{Hanna 2008}

Hanna FW, Peters JR, Harlow J, Jones PW. Gestational diabetes screening and glycaemic management; national survey on behalf of the Association of British Clinical Diabetologists. QJM 2008;101(10):777-84.

\section{HAPO Study Cooperative Research Group 2008}

HAPO Study Cooperative Research Group, Metzger BE, Lowe LP, Dyer AR, Trimble ER, Chaovarindr U, Coustan DR, et al. Hyperglycaemia and adverse pregnancy outcomes. New England Journal of Medicine 2008;358(19):1991-2002.

\section{Higgins 2011}

Higgins JPT, Green S, editors. Cochrane Handbook for Systematic Reviews of Interventions Version 5.1.0 [updated March 2011]. The Cochrane Collaboration, 2011. Available from handbook.cochrane.org.

\section{IADPSG 2010}

International Association of Diabetes and Pregnancy Study Groups Consensus panel. International Association of Diabetes and Pregnancy Study Groups recommendations on the diagnosis and classification of hyperglycemia in pregnancy. Diabetes Care 2010;33(7):676-82.

\section{Jovanovic 2001}

Jovanovic L, Pettitt D. Gestational diabetes mellitus. JAMA 2001;286(20):2516-8.

\section{Jovanovic 2004}

Jovanovic L. Achieving euglycaemia in women with gestational diabetes mellitus: current options for screening, diagnosis and treatment. Drugs 2004;64(13):1401-17.

\section{Kanguru 2014}

Kanguru L, Bezawada N, Hussein J, Bell JS. The burden of diabetes mellitus during pregnancy in low- and middleincome countries: a systematic review. Global Health Action 2014;7:23987. [DOI: 10.3402/gha.v7.23987]

\section{$\operatorname{Kim} 2002$}

Kim HS, Chang KH, Tang JI, Yang SC, Lee HJ, Ryu HS. Clinical outcomes of pregnancy with one elevated glucose tolerance test value. International Journal of Gynaecology and Obstetrics 2002;78(2):131-8.

\section{Kjos 1999}

Kjos SL, Buchanan TA. Gestational diabetes mellitus. New England Journal of Medicine 1999;341(23):1749-56.

\section{Kostalova 2001}

Kostalova L, Lesková L, Kapellerová A, Strbák V. Body mass, plasma leptin, glucose, insulin and C-peptide in offspring of diabetic and non-diabetic mothers. Journal of Endocrinology 2001;145(1):53-8.

\section{Landon 2009}

Landon MB, Spong CY, Thom E, Carpenter MW, Ramin SM, Casey B, et al. A multicenter, randomized trial of treatment for mild gestational diabetes. New England Journal of Medicine 2009;361(14):1339-48.

\section{Landon 2015}

Landon MB, Rice MM, Varner MIW, Casey BM, Reddy UM, Wapner RJ, et al. Mild gestational diabetes mellitus and longterm child health. Diabetes Care 2015;38(3):445-52. 


\section{Martis 2016}

Martis R, Brown J, Alsweiler J, Downie MR, Crowther CA. Treatments for women with gestational diabetes mellitus: an overview of Cochrane systematic reviews. Cochrane Database of Systematic Reviews 2016, Issue 8. [DOI: 10.1002/14651858.CD012327]

\section{McElduff 1994}

McElduff A, Goldring J, Gordon P, Wyndham L. A direct comparison of the measurement of a random plasma glucose and a post-50 g glucose load glucose, in the detection of gestational diabetes. Australian and New Zealand Journal of Obstetrics and Gynaecology 1994;34(1):28-30.

\section{Meltzer 2010a}

Meltzer SJ. Treatment of gestational diabetes. BMJ 2010;340:1708.

\section{Meltzer 2010b}

Meltzer SJ, Snyder J, Penrod JR, Nudi M, Morin L. Gestational diabetes mellitus screening and diagnosis: a prospective randomised controlled trial comparing costs of one-step and two-step methods. BJOG: an international journal of obstetrics and gynaecology 2010;117(4):407-15.

\section{Metzger 2010}

Metzger BE, Gabbe SG, Persson B, Buchanan TA, Catalano PA Damm $P$, et al. International association of diabetes and pregnancy study groups recommendations on the diagnosis and classification of hyperglycemia in pregnancy. Diabetes Care 2010;33(3):676-82. [PUBMED: 20190296]

\section{NDDG 1979}

National Diabetes Data Group. Classification and diagnosis of diabetes mellitus and other categories of glucose intolerance. Diabetes 1979;28(12):1039-57.

\section{NDDG 1997}

National Diabetes Data Group. Report of the Expert Committee on the diagnosis and classification of diabetes mellitus. Diabetes Care 1997;20(7):1183-97.

\section{NICE 2008}

NICE. NICE Clinical Guideline 62. Antenatal Care: Routine Care for the Healthy Pregnant Woman. www.nice.org.uk/guidance/ cg62/resources/antenatal-care-for-uncomplicated-pregnanciespdf-975564597445. London: NICE, accessed 15 August 2017.

\section{NICE 2015}

National Institute for Health and Care Excellence. NICE Guideline. Diabetes in pregnancy: Management from preconception to the postnatal period (NG3). www.nice.org.uk/ guidance/ng3/resources/diabetes-in-pregnancy-managementof-diabetes-and-its-complications-from-preconception-to-thepostnatal-period-51038446021. London: NICE, (accessed prior to 23 July 2017).

\section{NIH 2013}

National Institutes of Health. National Institutes of Health consensus development conference statement: diagnosing gestational diabetes mellitus, March 4-6, 2013. Obstetrics and Gynecology 2013;122(2 Pt 1):358-69.

\section{O'Sullivan 1964}

O'Sullivan JB, Mahan CM. Criteria for the oral glucose tolerance test in pregnancy. Diabetes 1964;13:278-85.

\section{O'Sullivan 1973}

O'Sullivan JB, Mahan CM, Charles D, Dandrow RV. Screening criteria for high risk gestational diabetic patients. American Journal of Obstetrics and Gynecology 1973;116(7):895-900.

\section{Perucchini 1999}

Perucchini D, Fischer U, Spinas GA, Huch R, Huch A, Lehmann R. Using fasting plasma glucose concentrations to screen for gestational diabetes mellitus: prospective population based study. BMJ 1999;319(7213):812-5.

\section{Pettitt 1983}

Pettitt DJ, Baird HR, Aleck KA, Bennett PH, Knowler WC. Excessive obesity in offspring of Pima Indian women with diabetes during pregnancy. New England Journal of Medicine 1983;308(5):242-5.

\section{Pribylová 1996}

Pribylová H, Dvoráková L. Long-term prognosis of infants of diabetic mothers. Relationship between metabolic disorders in newborns and adult offspring. Acta Diabetologica 1996;33(1):30-4.

\section{RANZCOG 2014}

Royal Australian and New Zealand College of Obstetricians and Gynaecologists. Diagnosis of Gestational Diabetes Mellitus (GDM) and Diabetes Mellitus in Pregnancy. RANZCOG, 2014.

\section{RevMan 2014 [Computer program]}

The Nordic Cochrane Centre, The Cochrane Collaboration. Review Manager (RevMan). Version 5.3. Copenhagen: The Nordic Cochrane Centre, The Cochrane Collaboration, 2014.

\section{Schytte 2004}

Schytte T, Jørgensen LG, Brandslund I, Petersen PH, Andersen B. The clinical impact of screening for gestational diabetes. Cinical Chemistry and Laboratory Medicine 2004;42(9):1036-42.

\section{Scott 2002}

Scott DA, Loveman E, McIntyre L, Waugh N. Screening for gestational diabetes: a systematic review and economic evaluation. Health Technology Assessment 2002;6(11):1-161.

\section{Silverman 1995}

Silverman BL, Metzger BE, Cho NH, Loeb CA. Impaired glucose tolerance in adolescent offspring of diabetic mothers. Relationship to fetal hyperinsulinism. Diabetes Care 1995;18(5):611-7.

\section{Simmons 2011}

Simmons D. Diabetes and obesity in pregnancy. Best Practice \& Research. Clinical Obstetrics \& Gynaecology 2011;25(1):25-36. 


\section{Thomas 2005}

Thomas MC, Walker MK, Emberson JR, Thomson AG, Lawlor DA, Ebrahim S, et al. Prevalence of undiagnosed type 2 diabetes and impaired fasting glucose in an older British men and women. Diabetic Medicine 2005;22(6):789-93.

\section{Tieu 2014}

Tieu J, McPhee AJ, Crowther CA, Middleton P. Screening and subsequent management for gestational diabetes for improving maternal and infant health. Cochrane Database of Systematic Reviews 2014, Issue 2. [DOI: 10.1002/14651858.CD007222.pub2]

\section{Tieu 2017}

Tieu J, Shepherd E, Middleton P, Crowther CA. Dietary advice interventions in pregnancy for preventing gestational diabetes mellitus. Cochrane Database of Systematic Reviews 2017, Issue 1. [DOI: 10.1002/14651858.CD006674.pub3]

\section{WHO 1980}

World Health Organization. WHO Expert Committee on Diabetes Mellitus. Second Report. Technical Report Series 646 (1980). apps.who.int/iris/bitstream/10665/41399/1/WHO_TRS_646.pdf (accessed prior to 23 July 2017).

\section{WHO 1999}

World Health Organization. Definition, Diagnosis and Classification of Diabetes Mellitus and Its Complications. Report of a WHO Consultation. Part 1: Diagnosis and Classification of Diabetes Mellitus (1999). apps.who.int/iris/ bitstream/10665/66040/1/WHO_NCD_NCS_99.2.pdf. Geneva: WHO, (accessed prior to 23 July 2017).

\section{WHO 2013}

World Health Organization. Diagnostic criteria and classification of hyperglycaemia first detected in pregnancy (2013). www.who.int/diabetes/publications/Hyperglycaemia_In Pregnancy/en/. Geneva: WHO, (accessed prior to 23 July 2017).

\section{Williams 2003}

Williams R, Wild S. Diabetes prevalence data for the United Kingdom - what do we have and what do we need?. Diabetic Medicine 2003;20(6):505-9.

\section{References to other published versions of this review \\ Farrar 2008}

Farrar D, Duley L, Lawlor DA. Alternative strategies for diagnosing gestational diabetes mellitus to improve maternal and infant health. Cochrane Database of Systematic Reviews 2008, Issue 2. [DOI: 10.1002/14651858.CD007122]

\section{Farrar 2011}

Farrar D, Duley L, Lawlor DA. Different strategies for diagnosing gestational diabetes to improve maternal and infant health. Cochrane Database of Systematic Reviews 2011, Issue 10. [DOI: 10.1002/14651858.CD007122.pub2]

\section{Farrar 2015}

Farrar D, Duley L, Medley N, Lawlor DA. Different strategies for diagnosing gestational diabetes to improve maternal and infant health. Cochrane Database of Systematic Reviews 2015, Issue 1. [DOI: 10.1002/14651858.CD007122.pub3]

* Indicates the major publication for the study

\section{CHARACTERISTICS OFSTUDIES}

Characteristics of included studies [ordered by study ID]

Mexico 2003

Methods 'Randomly assigned'; no further information was given.

No losses to follow-up were reported.

Participants 30 women at 24 to 28 weeks' gestation, defined as 'high risk'; no further information was reported regarding criteria for being high-risk or criteria for GDM diagnosis.

Settings: Hospital, Mexico.

Interventions

Experimental: 15 women; diet of carbohydrates, proteins and fats including $50 \mathrm{~g}$ of glucose.

Control: 15 women; $50 \mathrm{~g}$ of glucose in solution.

Outcomes Women: side effects (nausea, sickness, migraine, diarrhoea), screen positive 1-hour serum glucose > $140 \mathrm{mg} / \mathrm{dL}$.

Babies: none reported.

Notes Women with serum glucose above $140 \mathrm{mg} / \mathrm{dL}$ were offered further testing. Study dates: not reported. 
Mexico 2003 (Continued)

Funding sources: not reported; declarations of interest: not reported.

\section{Risk of bias}

\begin{tabular}{|c|c|c|}
\hline Bias & Authors' judgement & Support for judgement \\
\hline $\begin{array}{l}\text { Random sequence genera- } \\
\text { tion (selection bias) }\end{array}$ & Unclear risk & $\begin{array}{l}\text { 'Randomly assigned' is stated in the abstract. No further information is given } \\
\text { in the main text. }\end{array}$ \\
\hline $\begin{array}{l}\text { Allocation concealment } \\
\text { (selection bias) }\end{array}$ & Unclear risk & Concealment of allocation was not reported. \\
\hline $\begin{array}{l}\text { Incomplete outcome data } \\
\text { (attrition bias) } \\
\text { All outcomes }\end{array}$ & Low risk & No losses to follow-up were reported. \\
\hline $\begin{array}{l}\text { Selective reporting (re- } \\
\text { porting bias) }\end{array}$ & Low risk & $\begin{array}{l}\text { Prespecified outcomes of side effects and serum glucose }>140 \mathrm{mg} / \mathrm{dL} \text { at } 1 \\
\text { hour were reported. }\end{array}$ \\
\hline Other bias & Unclear risk & $\begin{array}{l}\text { No table of participants' baseline characteristics was provided to permit } \\
\text { judgement of the effectiveness of randomisation. }\end{array}$ \\
\hline $\begin{array}{l}\text { Blinding of participants } \\
\text { and personnel (perfor- } \\
\text { mance bias) } \\
\text { All outcomes }\end{array}$ & High risk & $\begin{array}{l}\text { Blinding of participants and personnel was not reported. Reporting of side ef- } \\
\text { fects may be influenced by knowledge of treatment. }\end{array}$ \\
\hline $\begin{array}{l}\text { Blinding of outcome as- } \\
\text { sessment (detection bias) } \\
\text { All outcomes }\end{array}$ & Unclear risk & $\begin{array}{l}\text { Blinding of outcome assessment was not reported. Unclear risk because re- } \\
\text { porting of side effects may have been influenced by knowledge of treatment, } \\
\text { but the outcome of serum glucose }>140 \mathrm{mg} / \mathrm{dL} \text { would not have been influ- } \\
\text { enced. }\end{array}$ \\
\hline
\end{tabular}

\section{Mexico 2011}

$\begin{array}{ll}\text { Methods } & \begin{array}{l}\text { 'Randomised by a computer programme'; no other information was given (see notes below and risk of } \\ \text { bias table). }\end{array}\end{array}$

\section{Participants}

386 women at 12 to 28 weeks' gestation were attending for care at the National Institute of Perinatology Isidro Espinosa de los Reyes, Mexico, 116 of whom were included in this review.

Settings: National Institute of Perinatology Isidro Espinosa de los Reyes, Mexico.

\section{Interventions}

Outcomes
75 g OGTT WHO 1999 criteria, 75 g OGTT ADA 2010 criteria and 100 g OGTT O'Sullivan 1973 criteria.

GDM diagnosis, stillbirth, macrosomia, threat of preterm birth, caesarean and instrumental birth, pregnancy-induced hypertension, preterm rupture of membranes, oligohydramnios, polyhydramnios.

Notes Non-randomised participants included in the group were allocated $100 \mathrm{~g}$ OGTT with ADA criteria; therefore this group was not included in any analysis.

Study dates: 1 June 2006 to 1 September 2006.

Funding sources: not reported; declarations of interest: not reported.

\section{Risk of bias}


Mexico 2011 (Continued)

\begin{tabular}{|c|c|c|}
\hline Bias & Authors' judgement & Support for judgement \\
\hline $\begin{array}{l}\text { Random sequence genera- } \\
\text { tion (selection bias) }\end{array}$ & Unclear risk & 'Randomised by a computer programme'; no other information was given. \\
\hline $\begin{array}{l}\text { Allocation concealment } \\
\text { (selection bias) }\end{array}$ & Unclear risk & Concealment of allocation was not reported. \\
\hline $\begin{array}{l}\text { Incomplete outcome data } \\
\text { (attrition bias) } \\
\text { All outcomes }\end{array}$ & High risk & $\begin{array}{l}7 / 54(13 \%) \text { participants allocated } 75 \mathrm{~g} \text { OGTT were unable to complete and } \\
\text { were not followed up and included in the analysis. }\end{array}$ \\
\hline $\begin{array}{l}\text { Selective reporting (re- } \\
\text { porting bias) }\end{array}$ & Low risk & All prespecified outcomes seem to have been reported. \\
\hline Other bias & High risk & $\begin{array}{l}\text { The numbers for this trial are unclear. It appears that women }>28 \text { weeks who } \\
\text { were not screened or randomly assigned were included in the } 100 \mathrm{~g} \text { OGTT } \\
\text { group. Inclusion of non-randomised participants in } 1 \text { of the groups; uneven } \\
\text { numbers in the remaining groups, possibly due to the fact that study authors } \\
\text { failed to use an intention-to-treat design (see notes above regarding loss of } \\
\text { participants due to lack of completion of the test); possible 'double' counting } \\
\text { of participants in the screened tables; and lack of clarity surrounding the study } \\
\text { design suggest that extreme caution should be exercised when results from } \\
\text { this trial are interpreted. } 35 \text { twin pregnancies were included; however group } \\
\text { allocation was not reported, so they may or may not be included in the com- } \\
\text { parison groups described in this review. We have used data from } 2 \text { groups in- } \\
\text { cluding } 116 \text { randomly assigned women. }\end{array}$ \\
\hline
\end{tabular}

\begin{tabular}{|c|c|c|}
\hline $\begin{array}{l}\text { Blinding of participants } \\
\text { and personnel (perfor- } \\
\text { mance bias) } \\
\text { All outcomes }\end{array}$ & Unclear risk & $\begin{array}{l}\text { Blinding of personnel and participants is not reported but is possible because } \\
\text { the tests consisted of glucose drinks and could have appeared to be identical. } \\
\text { Blood glucose levels, birthweight and ruptured membranes would not have } \\
\text { been affected by knowledge of treatment groups, but outcomes such as cae- } \\
\text { sarean birth may have been affected. }\end{array}$ \\
\hline
\end{tabular}

Blinding of outcome as- Unclear risk Blinding of outcome assessors was not reported.

sessment (detection bias)

All outcomes

New Zealand 1985

Methods 'Randomised into two groups'; no further information was given.

No losses to follow-up were reported.

Participants 100 women at 28 weeks' gestation without pre-existing diabetes were given a $100 \mathrm{~g}$ non-fasting OGTT. NDDG 1979 criteria were used to diagnose GDM.

Settings: prenatal clinics, National Women's Hospital, Mexico.

Interventions Experimental: 52 women; $100 \mathrm{~g}$ glucose polymer screening test was given before a $100 \mathrm{~g}$ OGTT glucose polymer tolerance test was given.

Control: 48 women; $100 \mathrm{~g}$ glucose screening test was given before a $100 \mathrm{~g}$ GTT was given.

Outcomes Women: 1-, 2- and 3-hour blood glucose at GTT.

Babies: gestation at birth, mean birthweight. 
New Zealand 1985 (Continued)

Notes

Mean birthweight was reported: $3427 \mathrm{~g}$ (SD 566) for polymer screening group vs $3280 \mathrm{~g}$ (SD 739) for glucose screening group.

Report includes a case series of a further 178 women not included in this review who received a $100 \mathrm{~g}$ glucose polymer screening test followed by a $100 \mathrm{~g}$ GTT using glucose polymer.

Study dates: not reported.

Funding sources: not reported; declarations of interest: not reported.

\section{Risk of bias}

\begin{tabular}{|c|c|c|}
\hline Bias & Authors' judgement & Support for judgement \\
\hline $\begin{array}{l}\text { Random sequence genera- } \\
\text { tion (selection bias) }\end{array}$ & Unclear risk & 'Randomised'; no further information was reported. \\
\hline $\begin{array}{l}\text { Allocation concealment } \\
\text { (selection bias) }\end{array}$ & Unclear risk & Concealment of allocation was not reported. \\
\hline $\begin{array}{l}\text { Incomplete outcome data } \\
\text { (attrition bias) } \\
\text { All outcomes }\end{array}$ & Low risk & No women were lost to follow-up. \\
\hline $\begin{array}{l}\text { Selective reporting (re- } \\
\text { porting bias) }\end{array}$ & Low risk & Specified outcomes have been reported. \\
\hline Other bias & Low risk & No significant group differences in baseline characteristics were noted. \\
\hline $\begin{array}{l}\text { Blinding of participants } \\
\text { and personnel (perfor- } \\
\text { mance bias) } \\
\text { All outcomes }\end{array}$ & Low risk & $\begin{array}{l}\text { Blinding of personnel and participants was not reported but was possible be- } \\
\text { cause the tests consisted of glucose drinks and could have appeared to be } \\
\text { identical outcomes of plasma glucose value and of birthweight would not have } \\
\text { been affected by knowledge of treatment groups. }\end{array}$ \\
\hline $\begin{array}{l}\text { Blinding of outcome as- } \\
\text { sessment (detection bias) } \\
\text { All outcomes }\end{array}$ & Low risk & $\begin{array}{l}\text { Blinding of outcome assessors was not stated. Outcomes of plasma glucose } \\
\text { value and birthweight would not have been affected by knowledge of treat- } \\
\text { ment groups. }\end{array}$ \\
\hline
\end{tabular}

Nigeria 2004

Methods 'Randomly selected'; no further information was given.

45 women (15\%) were lost to follow-up.

Participants 293 consecutive women at $\geq 28$ weeks' gestation.

Excluded: women with diabetes, women taking drugs that might influence glucose tolerance.

Settings: Antenatal clinic, Lagos University Teaching Hospital, Nigeria.

Interventions Experimental: 138 women, 75 g OGTT, WHO 1980 criteria.

Control: 110 women, 100 g OGTT, NDDG 1979 criteria.

In both groups women fasted for 8 hours before they were given the GTT.

Outcomes Women: GDM, 1-, 2- and 3-hour blood glucose.


Nigeria 2004 (Continued)

Babies: macrosomia.

Notes 2 women could not tolerate the glucose drink because of vomiting and contractions. For the $75 \mathrm{~g}$ GTT, GDM was diagnosed using WHO criteria. For the $100 \mathrm{~g}$ GTT, GDM was diagnosed using National Diabetes Data Group criteria.

Attempts to contact study authors for clarification of outcomes were unsuccessful.

Study dates: November 1997 to July 1999.

Funding sources: not reported; declarations of interest: not reported.

\section{Risk of bias}

\begin{tabular}{|c|c|c|}
\hline Bias & Authors' judgement & Support for judgement \\
\hline $\begin{array}{l}\text { Random sequence genera- } \\
\text { tion (selection bias) }\end{array}$ & Unclear risk & 'Randomly selected'; no further information was given. \\
\hline $\begin{array}{l}\text { Allocation concealment } \\
\text { (selection bias) }\end{array}$ & Unclear risk & Allocation concealment was not reported. \\
\hline $\begin{array}{l}\text { Incomplete outcome data } \\
\text { (attrition bias) } \\
\text { All outcomes }\end{array}$ & High risk & $\begin{array}{l}293 \text { were recruited but only } 248 \text { completed; } 45 \text { were lost (15\%). In Table } 2 \\
\text { study authors report data for only } 25 \text { of } 138 \text { women for the } 3 \text {-hour glucose lev- } \\
\text { el in the } 75 \text { g group; no data for this outcome are missing for the } 100 \text { g group. }\end{array}$ \\
\hline $\begin{array}{l}\text { Selective reporting (re- } \\
\text { porting bias) }\end{array}$ & Low risk & Specified outcomes of blood glucose values and macrosomia were reported. \\
\hline Other bias & Low risk & No significant group differences in baseline characteristics were reported. \\
\hline $\begin{array}{l}\text { Blinding of participants } \\
\text { and personnel (perfor- } \\
\text { mance bias) } \\
\text { All outcomes }\end{array}$ & Low risk & $\begin{array}{l}\text { Blinding of participants and personnel was not reported but was possible, as } \\
\text { both tests were glucose drinks and could have appeared to be identical. Out- } \\
\text { comes would not have been affected by knowledge of treatment groups. }\end{array}$ \\
\hline $\begin{array}{l}\text { Blinding of outcome as- } \\
\text { sessment (detection bias) } \\
\text { All outcomes }\end{array}$ & Low risk & $\begin{array}{l}\text { Blinding of outcome assessors was not reported. Outcomes of blood glucose } \\
\text { values and birthweight would not have been affected by knowledge of treat- } \\
\text { ment groups. }\end{array}$ \\
\hline
\end{tabular}

Turkey 2014

Methods Prospective, non-blind, parallel-group randomised controlled trial. Block randomisation used.

Participants 736 pregnant women between 11 and 14 weeks of gestation.

Settings: Antenatal outpatient clinic, Ankara, Turkey.

Interventions

Fasting plasma glucose obtained from all women at recruitment (8 to 14 weeks).

Randomisation and intervention at 11 to 14 weeks.

Experimental intervention 1: 377 women, 2-step method: 50 g GCT \pm 100 g GTT.

Experimental intervention 2: 349 women, 1-step method: $75 \mathrm{~g}$ GTT.

All women not lost to follow-up, withdrawn or diagnosed with GDM received the allocated intervention again at 24 to 28 weeks' gestation. 
Turkey 2014 (Continued)

Outcomes GDM diagnosis.

\begin{tabular}{ll}
\hline Notes & Study dates: 31 December 2010 to 31 December 2011. \\
& Funding sources: not reported; declarations of interest: "The authors report no conflicts of interest”.
\end{tabular}

\section{Risk of bias}

\begin{tabular}{|c|c|c|}
\hline Bias & Authors' judgement & Support for judgement \\
\hline $\begin{array}{l}\text { Random sequence genera- } \\
\text { tion (selection bias) }\end{array}$ & Low risk & $\begin{array}{l}\text { Block randomisation with blocks of } 4 \text { to ensure each group consisted of an } \\
\text { equal number of participants. Blocks were chosen randomly using computer } \\
\text { generated random numbers. }\end{array}$ \\
\hline $\begin{array}{l}\text { Allocation concealment } \\
\text { (selection bias) }\end{array}$ & Unclear risk & $\begin{array}{l}\text { Unclear if allocation was concealed. Women in same block may have pre- } \\
\text { empted which group they would be in. }\end{array}$ \\
\hline $\begin{array}{l}\text { Incomplete outcome data } \\
\text { (attrition bias) } \\
\text { All outcomes }\end{array}$ & Low risk & $\begin{array}{l}7 \text { and } 4 \text { women in the } 2 \text { and 1-step groups respectively who experienced fetal } \\
\text { loss before } 24 \text { to } 28 \text { weeks were withdrawn. } 132 \text { and } 107 \text { women in the } 2 \text { - and } \\
\text { 1-step groups respectively were lost to follow-up (before } 24 \text { to } 28 \text { weeks). How- } \\
\text { ever we only include the outcome rates reported prior to losses to follow-up. }\end{array}$ \\
\hline $\begin{array}{l}\text { Selective reporting (re- } \\
\text { porting bias) }\end{array}$ & Low risk & $\begin{array}{l}\text { Protocol not available, however the aim to evaluate the performance of } \\
\text { screening tests for GDM is clearly stated. }\end{array}$ \\
\hline Other bias & High risk & $\begin{array}{l}\text { Baseline characteristics reported only for those not lost to follow up or with- } \\
\text { drawn ( } 60 \% \text { of recruited population). }\end{array}$ \\
\hline $\begin{array}{l}\text { Blinding of participants } \\
\text { and personnel (perfor- } \\
\text { mance bias) } \\
\text { All outcomes }\end{array}$ & Unclear risk & $\begin{array}{l}\text { Because the tests are clearly different the women and those administering the } \\
\text { tests can not be blinded to the intervention allocation, however as the only rel- } \\
\text { evant outcome reported (GDM diagnosis) is a biochemical assessment it is not } \\
\text { possible for this to be influenced. }\end{array}$ \\
\hline $\begin{array}{l}\text { Blinding of outcome as- } \\
\text { sessment (detection bias) } \\
\text { All outcomes }\end{array}$ & Unclear risk & Not reported. \\
\hline
\end{tabular}

USA 1992

\begin{tabular}{ll}
\hline Methods & $\begin{array}{l}\text { Consecutive numbers were obtained from a random number table. } \\
\text { No losses to follow-up were reported, although } 10 \text { women did not complete the questionnaire on side } \\
\text { effects. O'Sullivan } 1964 \text { criteria were used to diagnose GDM. }\end{array}$ \\
\hline Participants & $\begin{array}{l}76 \text { Native Alaskan women at } 24 \text { to } 28 \text { weeks' gestation without a history of diabetes. } \\
\text { Settings: Ketchikan Native Health Clinic and Mt. Edgecumbe Hospital, Alaska, USA. }\end{array}$ \\
\hline Interventions & $\begin{array}{l}\text { Experimental: } 35 \text { women; } 50 \text { g glucose polymer drink. } \\
\text { Control: } 41 \text { women; } 50 \text { g glucose monomer drink. }\end{array}$ \\
\hline Wutcomes & Babies: none reported. \\
\hline Notes & Study dates: January 1988 to May 1990.
\end{tabular}


USA 1992 (Continued)

Funding sources: grant from the Diabetes Research and Education Foundation, Bridgewater, NJ; declarations of interest: not reported.

\section{Risk of bias}

\begin{tabular}{|c|c|c|}
\hline Bias & Authors' judgement & Support for judgement \\
\hline $\begin{array}{l}\text { Random sequence genera- } \\
\text { tion (selection bias) }\end{array}$ & Low risk & Consecutive numbers from a random number table. \\
\hline $\begin{array}{l}\text { Allocation concealment } \\
\text { (selection bias) }\end{array}$ & Unclear risk & $\begin{array}{l}\text { Allocation concealment was not reported, although study was described as } \\
\text { "double blind". }\end{array}$ \\
\hline $\begin{array}{l}\text { Incomplete outcome data } \\
\text { (attrition bias) } \\
\text { All outcomes }\end{array}$ & Low risk & $\begin{array}{l}\text { No losses to follow-up were reported, although } 10 \text { women did not complete } \\
\text { the questionnaire on side effects. }\end{array}$ \\
\hline $\begin{array}{l}\text { Selective reporting (re- } \\
\text { porting bias) }\end{array}$ & Low risk & Specified outcomes of side effects and plasma glucose values were reported. \\
\hline Other bias & Unclear risk & $\begin{array}{l}\text { No table of participants' baseline characteristics was provided to permit } \\
\text { judgement of the effectiveness of randomisation. }\end{array}$ \\
\hline $\begin{array}{l}\text { Blinding of participants } \\
\text { and personnel (perfor- } \\
\text { mance bias) } \\
\text { All outcomes }\end{array}$ & Unclear risk & $\begin{array}{l}\text { Study was described as double blind, which is possible as test drinks may have } \\
\text { appeared identical. Outcomes of side effects could have been affected by } \\
\text { knowledge of treatment groups, but the plasma glucose value would not have } \\
\text { been affected. }\end{array}$ \\
\hline $\begin{array}{l}\text { Blinding of outcome as- } \\
\text { sessment (detection bias) } \\
\text { All outcomes }\end{array}$ & Low risk & $\begin{array}{l}\text { Study was described as double blind. Side effects were self-reported on a } \\
\text { questionnaire and thus were not subject to assessor bias. Plasma glucose val- } \\
\text { ues would not have been affected by lack of blinding on the part of assessors. }\end{array}$ \\
\hline
\end{tabular}

USA 1994

\begin{tabular}{ll} 
Methods & 'Prospectively enrolled and randomly assigned'; no further information was given. \\
& 3-arm comparison trial. \\
\hline Participants & $\begin{array}{l}124 \text { women having GDM screening at } 24 \text { to } 28 \text { weeks' gestation or women at high risk at initial antena- } \\
\text { tal visit; partial initial outcome data reported following screening of } 122 \text { women O'Sullivan } 1964 \text { crite- } \\
\text { ria were used to diagnose GDM. } \\
\text { Settings: Medical Education Clinics, Saint Luke's Hospital, Kansas City, Missouri, USA. }\end{array}$
\end{tabular}

Interventions

Experimental group 1: 40 women, 50 g glucose polymer.

Experimental group 2: 39 women, candy bars as a screening test.

Control: 43 women, $50 \mathrm{~g}$ standard d-glucose.

In all groups the intervention was non-fasting, regardless of when the last meal was eaten. Serum glucose at 1 hour, then $100 \mathrm{~g}$ oral GTT within 1 week, 16 were unable to complete the GTT; 5 because of vomiting and 11 for logistical or laboratory reasons.

Outcomes Women: serum glucose at 1 hour $\geq 7.5 \mathrm{mmol} / \mathrm{L}$, rating for taste and adverse symptoms (including pain, bloating, dizziness and nausea). 
USA 1994 (Continued)

Babies: none reported.

Notes 5 women required nursing assistance to complete the GTT. Control group data were divided (to prevent double counting) and were compared with data from the 2 experimental groups.

Study dates: not reported.

Funding sources: research grant from St Luke's Foundation; declarations of interest: not reported.

\section{Risk of bias}

\begin{tabular}{|c|c|c|}
\hline Bias & Authors' judgement & Support for judgement \\
\hline $\begin{array}{l}\text { Random sequence genera- } \\
\text { tion (selection bias) }\end{array}$ & Unclear risk & 'Randomly assigned'; no further information was given. \\
\hline $\begin{array}{l}\text { Allocation concealment } \\
\text { (selection bias) }\end{array}$ & Unclear risk & Concealment of allocation was not reported. \\
\hline $\begin{array}{l}\text { Incomplete outcome data } \\
\text { (attrition bias) } \\
\text { All outcomes }\end{array}$ & High risk & $\begin{array}{l}16 / 124(13 \%) \text { did not have a GTT ( } 5 \text { because of vomiting, } 11 \text { for 'logistical' rea- } \\
\text { sons or because of incomplete laboratory data). } 14 / 108(13 \%) \text { women did not } \\
\text { complete the post-test questionnaire. }\end{array}$ \\
\hline $\begin{array}{l}\text { Selective reporting (re- } \\
\text { porting bias) }\end{array}$ & Low risk & $\begin{array}{l}\text { Specified outcomes of serum glucose at } 1 \text { hour and questionnaire for taste and } \\
\text { symptoms were reported. }\end{array}$ \\
\hline Other bias & High risk & $\begin{array}{l}\text { Differences in group characteristics were significant for age and parity } \\
\text { (younger and lower parity women received candy bars). }\end{array}$ \\
\hline $\begin{array}{l}\text { Blinding of participants } \\
\text { and personnel (perfor- } \\
\text { mance bias) } \\
\text { All outcomes }\end{array}$ & High risk & $\begin{array}{l}\text { Blinding was not reported, but treatments were visibly different (candy bar vs } \\
\text { solution). Reporting of side effects could have been affected by knowledge of } \\
\text { treatment groups, but serum glucose value would not have been affected. }\end{array}$ \\
\hline $\begin{array}{l}\text { Blinding of outcome as- } \\
\text { sessment (detection bias) } \\
\text { All outcomes }\end{array}$ & Unclear risk & $\begin{array}{l}\text { Blinding was not reported. Symptoms were self-reported on a questionnaire } \\
\text { and were not subject to assessor bias. Plasma glucose values would not have } \\
\text { been affected by lack of blinding on the part of assessors. }\end{array}$ \\
\hline
\end{tabular}

ADA: American Diabetes Association

d-glucose: glucose monomer

GDM: gestational diabetes mellitus

GTT: glucose tolerance test

OGTT: oral glucose tolerance test

SD: standard deviation

vs: versus

WHO: World Health Organization

Characteristics of excluded studies [ordered by study ID]

\begin{tabular}{ll}
\hline Study & Reason for exclusion \\
\hline Austria 1994 & $\begin{array}{l}\text { Not a randomised trial; cross-over design and comparison of different ways of measuring blood } \\
\text { glucose. } \\
\text { Participants: } 500 \text { women having an OGTT, usually at } 24 \text { to } 28 \text { weeks' gestation, but some earlier and } \\
\text { a few later or postpartum. }\end{array}$ \\
\hline
\end{tabular}




\begin{tabular}{|c|c|}
\hline Study & Reason for exclusion \\
\hline \multirow[t]{3}{*}{ Austria 1998} & $\begin{array}{l}\text { Cross-over study of response to different glucose loads in those with a diagnosis of GDM and those } \\
\text { without. }\end{array}$ \\
\hline & $\begin{array}{l}\text { Participants: } 60 \text { women, } 30 \text { with GDM and willing to undergo a second GTT and } 30 \text { healthy pregnant } \\
\text { women. }\end{array}$ \\
\hline & Interventions: 75 g OGTT vs 100 g OGTT. \\
\hline \multirow[t]{4}{*}{ Canada 1999} & $\begin{array}{l}\text { Wrong intervention: routine screening of all women vs selective screening for clinical indications of } \\
\text { GDM. }\end{array}$ \\
\hline & $\begin{array}{l}\text { Participants: } 2401 \text { low-risk women randomly assigned to screening, or screening only if a clinical } \\
\text { indication arose during pregnancy. }\end{array}$ \\
\hline & Interventions: routine screening with $50 \mathrm{~g}$ OGTT vs screening with $100 \mathrm{~g}$ OGTT only if indicated. \\
\hline & Outcome: macrosomia rate. \\
\hline
\end{tabular}

\section{Canada 2005}

Outcomes reported as percentage rates.

Participants: 5489 women.

Interventions: $50 \mathrm{~g}$ OGTT and $100 \mathrm{~g}$ OGTT vs $50 \mathrm{~g}$ OGTT and $75 \mathrm{~g}$ OGTT vs $75 \mathrm{~g}$ OGTT.

Canada 2010 subset of Canada 2005.

Outcomes: economic evaluation of 1-step and 2-step screening and diagnostic approaches, no evaluation of maternal and infant outcomes.

Participants: 1594 women.

Intervention: as above.

China 1995 Not a randomised trial; women 'randomly selected' for a $50 \mathrm{~g}$ OGTT.

Participants: 220 women in the third trimester.

Interventions: comparison of capillary vs venous blood samples.

Participants: 622 women at 28 to 32 weeks.

Interventions: $50 \mathrm{~g}$ OGTT if results $>7.78 \mathrm{mmol} / \mathrm{L}$, then $75 \mathrm{~g}$ OGTT.

Cross-over trial; no clinical outcomes reported.
Participants: 34 women at around 30 weeks' gestation, unselected.
Interventions: low- vs high-carbohydrate diet before OGTT.

Greece 2004 Not a randomised trial: 2 groups matched for key characteristics. No clinical outcomes reported. Participants: 47 women undergoing $100 \mathrm{~g}$ OGTT at 24 to 28 weeks. Interventions: fingertip vs forearm blood sample. 


\begin{tabular}{ll}
\hline Study & Reason for exclusion \\
\hline Iran 2007 & Cross-over trial. \\
& Participants: 141 women at 24 to 28 weeks' gestation if low risk. \\
& Interventions: breakfast containing 50 g simple glucose vs 50 g glucose challenge. \\
\hline Iran 2008 & Cross-over trial. \\
& Participants: 138 women. \\
Intervention: 50 g OGTT vs breakfast (includes 50 g sugar or jam).
\end{tabular}

Participants: 3742 women at booking visit.

Interventions: universal vs selective screening for GDM.

\begin{tabular}{ll}
\hline Ireland 2014a & $\begin{array}{l}\text { Trial comparing identification of gestational diabetes using OGTT in primary and secondary care } \\
\text { settings. }\end{array}$
\end{tabular}

New Zealand 1984a Cross-over trial; 2 studies reported in the same paper.

Participants: 26 women; consecutive referrals for carbohydrate tolerance testing because of risk factors for GDM.

Interventions: $50 \mathrm{~g}$ OGTT vs $50 \mathrm{~g}$ glucose polymer tolerance test.

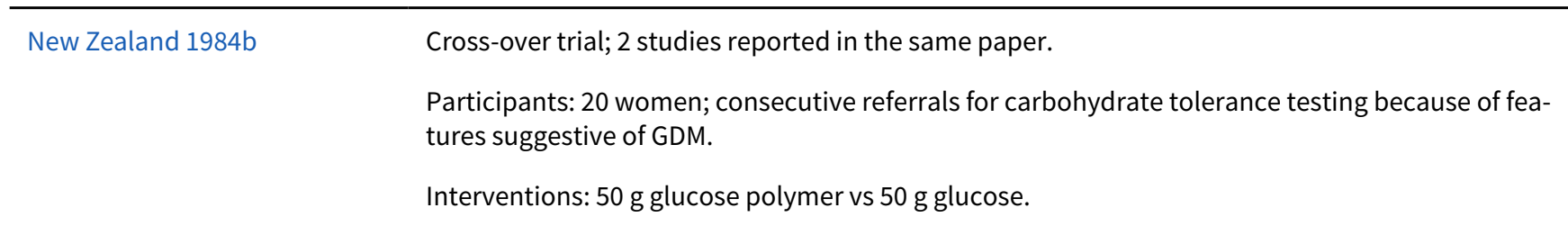

\begin{tabular}{ll}
\hline Singapore 1992 & Cross-over trial. \\
& Participants: 56 women in the third trimester. \\
Interventions: $50 \mathrm{~g}$ OGTT vs $75 \mathrm{~g}$ OGTT.
\end{tabular}

Thailand $1995 \quad \begin{aligned} & \text { Not a randomised trial. } \\ & \text { Participants: } 709 \text { women. } \\ & \text { Interventions: } 50 \mathrm{~g} \text { OGTT and } 75 \mathrm{~g} \text { OGTT within a week, then } 100 \mathrm{~g} \text { if } 50 \mathrm{~g} \text { OGTT blood sugar } \geq 7.8 \\ & \text { within a week of the } 75 \mathrm{~g} \text { OGTT. }\end{aligned}$

Participants: 42 women with a positive $50 \mathrm{~g}$ glucose challenge test at 14 to 36 weeks.

Interventions: $75 \mathrm{~g}$ OGTT vs $100 \mathrm{~g}$ OGTT. 


\begin{tabular}{|c|c|}
\hline Study & Reason for exclusion \\
\hline \multirow[t]{3}{*}{ Tunisia 2001} & Cross-over trial. \\
\hline & Participants: 100 women at 24 to 28 weeks. \\
\hline & Interventions: meal and $50 \mathrm{~g}$ oral glucose as screening for GDM. \\
\hline \multirow[t]{3}{*}{ USA 1989} & $\begin{array}{l}\text { Quasi-randomised study using alternate allocations. Also, cross-over design and } 42 \% \text { lost to fol- } \\
\text { low-up. }\end{array}$ \\
\hline & Participants: 114 women $\leq 24$ weeks' gestation. \\
\hline & Interventions: $50 \mathrm{~g}$ vs $100 \mathrm{~g}$ OGTT. \\
\hline \multirow[t]{3}{*}{ USA 1991} & Quasi-randomised study using alternate allocations and a cross-over design. \\
\hline & Participants: 37 women at 10 to 38 weeks' gestation. \\
\hline & $\begin{array}{l}\text { Interventions: } 50 \mathrm{~g} \text { OGTT if result } \geq 135 \mathrm{mg} / \mathrm{dL} \text {, then } 3 \text {-day diet of }>150 \mathrm{~g} / \mathrm{d} \text { of } \mathrm{CHO} \text {, then }>1 \text { week of } \\
\text { normal diet before } 50 \mathrm{~g} \text { OGTT or }>1 \text { week of normal diet plus } 3 \text {-day diet of }>150 \mathrm{~g} / \mathrm{d} \text { of } \mathrm{CHO} \text { before } \\
50 \mathrm{~g} \text { OGTT. }\end{array}$ \\
\hline
\end{tabular}

USA 1993a Cross-over trial; published as abstract only.
Participants: 45 women with an abnormal glucose challenge screening test.
Interventions: '3-hour standard' OGTT vs intravenous GTT.

USA 1993b Cross-over trial.
Participants: 26 low-risk women at 28 to 32 weeks' gestation.
Interventions: non-fasting OGTT vs fasting OGTT.

USA 1993C Not a randomised trial. Case series in which all women were given both tests.
Participants: 32 women at 26 to 36 weeks' gestation.
Interventions: 75 g OGTT vs 100 g OGTT.

USA 1995 Not a randomised trial, cross-over design.
Participants: 32 women at 26 to 36 weeks' gestation.
Interventions: $100 \mathrm{~g}$ then $75 \mathrm{~g}$ OGTT.

USA 1995a Outcomes data reported by whether or not the women had GDM, not by allocated group.

Participants: 80 women with a positive 50 g glucose challenge test.

Interventions: $75 \mathrm{~g}$ OGTT vs $50 \mathrm{~g}$ OGTT.

\begin{tabular}{ll}
\hline USA 1999 & Cross-over trial. \\
& Participants: 160 women at 24 to 28 weeks' gestation. \\
& Interventions: 30 jelly beans vs 50 g glucose drink. \\
\hline USA 2001 & Participants were women with a diagnosis of gestational diabetes. \\
\hline USA 2015 & Brieft abstract only. \\
& Participants: women with increased BMI (> 25) at 16 weeks' gestation. \\
\hline
\end{tabular}




\section{Study Reason for exclusion}

Intervention: early testing of glucose intolerance and provision of an intervention to reduce the risk of GDM (prevention intervention).

BMI: body mass index

$\mathrm{CHO}$ : carbohydrate

GDM: gestational diabetes mellitus

GTT: glucose tolerance test

OGTT: oral glucose tolerance test

vs: versus

Characteristics of studies awaiting assessment [ordered by study ID]

China 2013

\begin{tabular}{|c|c|}
\hline Methods & Randomised parallel control trial (no details given). \\
\hline Participants & $\begin{array}{l}\text { Women at high risk of diabetes - increased BMI, relative with diabetes, polycystic ovarian syn- } \\
\text { drome, history of GDM (not clear if history of GDM was in current or previous pregnancy). }\end{array}$ \\
\hline Interventions & $\begin{array}{l}\text { Early screening then diet control vs advanced screening them insulin (not clear what advanced } \\
\text { screening is). }\end{array}$ \\
\hline \multirow[t]{14}{*}{ Outcomes } & Glycated haemoglobin (HbA1C) \\
\hline & Oral glucose tolerance \\
\hline & C-peptide \\
\hline & Low density lipoprotein \\
\hline & Triglycerides \\
\hline & Insulin \\
\hline & Homeostatic model assessment insulin resistance \\
\hline & Mean glucose value \\
\hline & Mean blood glucose \\
\hline & Body mass index \\
\hline & Post prandial glucose estimation \\
\hline & Systolic blood pressure \\
\hline & Diastolic blood pressure \\
\hline & Apgar score at 5 minutes \\
\hline
\end{tabular}

Notes

Awaiting assessment pending further publications or information from the authors.

GDM: gestational diabetes mellitus vs: versus

Characteristics of ongoing studies [ordered by study ID]

Ireland 2014b

Trial name or title Not known. Interim analysis of ongoing trial.

Different strategies for diagnosing gestational diabetes to improve maternal and infant health (Review) 
Ireland 2014b (Continued)

Methods Described as 'randomly allocated'. No further details given (conference abstract only).

\begin{tabular}{ll}
\hline Participants & Pregnant women offered universal testing for GDM. \\
\hline Interventions & Non-fasting 50 g glucose challenge test vs fasting 75 g OGTT. \\
\hline Outcomes & Number diagnosed with GDM \\
& Change in HbA1c (mmol/mol) \\
& Rise in HbAlc > 10\% \\
\hline Starting date & 2014. \\
\hline Contact information & T Ahern, Diabetes Centre, Midlands Regional Hospital, Mullingar, Co Westmeath. \\
\hline Notes &
\end{tabular}

USA 2013

\begin{tabular}{ll}
\hline Trial name or title & USA 2013. \\
\hline Methods & Randomised trial. \\
\hline Participants & 1160 obese (BMI $\geq 30)$ pregnant women. \\
\hline Interventions & $\begin{array}{l}\text { Routine (OGTT at } 24 \text { to } 28 \text { weeks) vs early (OGTT at } 14 \text { to } 18 \text { weeks with repeat testing at } 24 \text { to } 28 \\
\text { weeks for negative women) testing to identify gestational diabetes. }\end{array}$ \\
\hline Outcomes & $\begin{array}{l}\text { Composite perinatal outcome (macrosomia }>4 \text { kg, gestational hypertension, pre-eclampsia, shoul- } \\
\text { der dystocia, hyperbilirubinaemia, neonatal hypoglycaemia }<40 \text { mg } / \mathrm{dL}), \text { macrosomia }>4 \mathrm{~kg}, \text { pri- } \\
\text { mary caesarean, pregnancy-induced hypertension (gestational hypertension, pre-eclampsia), } \\
\text { shoulder dystocia, hyperbilirubinaemia, neonatal hypoglycaemia }<40 \mathrm{mg} / \mathrm{dL}, \text { preterm birth }<37 \\
\text { weeks' gestation. }\end{array}$
\end{tabular}

Starting date June 2013.

Contact information Imharper@uabmc.edu University of Alabama at Birmingham, USA.

\section{Notes}

USA 2014

\begin{tabular}{ll}
\hline Trial name or title & Not known. \\
\hline Methods & Randomised double blind trial. \\
\hline Participants & $\begin{array}{l}\text { All pregnant women who did not have a diagnosis of diabetes. Following a } 1 \text { hour } 50 \text { g glucose chal- } \\
\text { lenge test at between } 24 \text { to } 28 \text { weeks' gestation. Women with results }<20 \mathrm{mg} / \mathrm{dL} \text { randomised to } 1 \text { of } \\
2 \text { groups. }\end{array}$
\end{tabular}

Interventions Fasting 2 hour $75 \mathrm{~g}$ OGTT and the IADPSG criteria vs fasting 3 hour $100 \mathrm{~g}$ OGTT and diagnosed with Carpenter Coustan criteria. 
USA 2014 (Continued)

\begin{tabular}{ll} 
Outcomes & $\begin{array}{l}\text { Large for gestational age infant } \\
\text { Birthweight greater than the 90th percentile for gestational age } \\
\text { Caesarean delivery } \\
\text { Maternal composite morbidity - maternal pre-eclampsia, 3rd or 4th degree vaginal lacerations, } \\
\text { postpartum haemorrhage } \\
\text { Neonatal composite morbidity }\end{array}$ \\
\hline Starting date & 2014. \\
\hline Contact information & Esa Davis: davisem@upmc.edu \\
\hline Notes & Estimated primary completion date: December 2018. \\
\hline
\end{tabular}

BMI: body mass index

GDM: gestational diabetes mellitus

IADPSG: International Association of Diabetes and Pregnancy Study Group

OGTT: oral glucose tolerance test

vs: versus

\section{DATA AND ANALYSES}

\section{Comparison 1. $75 \mathrm{~g}$ OGTT versus $100 \mathrm{~g}$ OGTT}

\begin{tabular}{lllll}
\hline $\begin{array}{l}\text { Outcome or subgroup } \\
\text { title }\end{array}$ & No. of studies & $\begin{array}{l}\text { No. of partici- } \\
\text { pants }\end{array}$ & Statistical method & Effect size \\
\hline $\begin{array}{l}\text { 1 Diagnosis of gestation- } \\
\text { al diabetes }\end{array}$ & 1 & 248 & Risk Ratio (M-H, Fixed, 95\% Cl) & $2.55[0.96,6.75]$ \\
\hline $\begin{array}{l}\text { 2 Plasma glucose (mmol/ } \\
\text { L) }\end{array}$ & 1 & Mean Difference (IV, Fixed, 95\% Cl) & Subtotals only \\
\hline $\begin{array}{l}2.1 \text { At } 1 \text { hour } \\
2.2 \text { At 2 hours }\end{array}$ & 1 & Mean Difference (IV, Fixed, 95\% Cl) & $-0.11[-0.44,0.22]$ \\
\hline 2.3 At 3 hours & 1 & 248 & Mean Difference (IV, Fixed, 95\% Cl) & $-0.31[-0.64,0.02]$ \\
\hline
\end{tabular}

Analysis 1.1. Comparison $175 \mathrm{~g}$ OGTT versus $100 \mathrm{~g}$ OGTT, Outcome 1 Diagnosis of gestational diabetes.

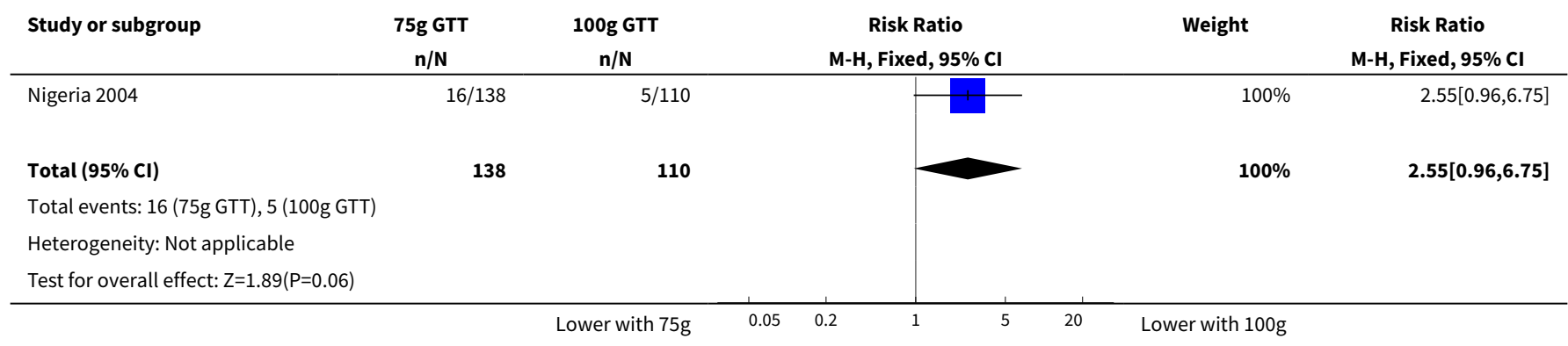


Analysis 1.2. Comparison $175 \mathrm{~g}$ OGTT versus $100 \mathrm{~g}$ OGTT, Outcome 2 Plasma glucose (mmol/L).

\begin{tabular}{|c|c|c|c|c|c|c|c|}
\hline \multirow[t]{2}{*}{ Study or subgroup } & \multicolumn{2}{|c|}{$75 \mathrm{~g}$ GTT } & \multicolumn{2}{|c|}{$100 \mathrm{~g}$ GTT } & \multirow{2}{*}{$\begin{array}{c}\text { Mean Difference } \\
\text { Fixed, } 95 \% \mathrm{Cl}\end{array}$} & \multirow[t]{2}{*}{ Weight } & \multirow{2}{*}{$\begin{array}{c}\text { Mean Difference } \\
\text { Fixed, } 95 \% \mathrm{Cl}\end{array}$} \\
\hline & $\mathbf{N}$ & $\operatorname{Mean}(\mathrm{SD})$ & $\mathbf{N}$ & $\operatorname{Mean}(\mathrm{SD})$ & & & \\
\hline \multicolumn{8}{|l|}{ 1.2.1 At 1 hour } \\
\hline Nigeria 2004 & 138 & $7.4(1.7)$ & 110 & $7.5(1.4)$ & & $100 \%$ & $-0.11[-0.5,0.28]$ \\
\hline Subtotal $* \star \star$ & 138 & & 110 & & & $100 \%$ & $-0.11[-0.44,0.22]$ \\
\hline \multicolumn{8}{|c|}{ Heterogeneity: Not applicable } \\
\hline \multicolumn{8}{|c|}{ Test for overall effect: $Z=0.56(P=0.58)$} \\
\hline \multicolumn{8}{|l|}{ 1.2.2 At 2 hours } \\
\hline Nigeria 2004 & 138 & $6.6(1.9)$ & 110 & $6.9(1.3)$ & & $100 \%$ & $-0.31[-0.71,0.09]$ \\
\hline Subtotal $\star \star \star$ & 138 & & 110 & & & $100 \%$ & $-0.31[-0.64,0.02]$ \\
\hline \multicolumn{8}{|c|}{ Heterogeneity: Not applicable } \\
\hline \multicolumn{8}{|c|}{ Test for overall effect: $Z=1.53(P=0.13)$} \\
\hline \multicolumn{8}{|l|}{ 1.2.3 At 3 hours } \\
\hline Nigeria 2004 & 138 & $5.2(2.1)$ & 110 & $6.3(1.6)$ & & $100 \%$ & $-1.08[-1.55,-0.61]$ \\
\hline Subtotal $\star \star \star$ & 138 & & 110 & & & $100 \%$ & $-1.08[-1.47,-0.69]$ \\
\hline \multicolumn{8}{|c|}{ Heterogeneity: Not applicable } \\
\hline Test for overall effect & & & & & & & \\
\hline
\end{tabular}

\section{Comparison 2. $50 \mathrm{~g}$ glucose polymer drink versus $50 \mathrm{~g}$ glucose monomer drink}

\begin{tabular}{|c|c|c|c|c|}
\hline $\begin{array}{l}\text { Outcome or subgroup } \\
\text { title }\end{array}$ & No. of studies & $\begin{array}{l}\text { No. of partici- } \\
\text { pants }\end{array}$ & Statistical method & Effect size \\
\hline 1 Maternal side effects & 2 & & Risk Ratio (M-H, Random, 95\% Cl) & Subtotals only \\
\hline 1.1 Nausea & 1 & 66 & Risk Ratio (M-H, Random, 95\% Cl) & $0.29[0.11,0.78]$ \\
\hline 1.2 Headache & 1 & 66 & Risk Ratio (M-H, Random, 95\% Cl) & $0.2[0.02,1.62]$ \\
\hline 1.3 Bloatedness & 2 & 131 & Risk Ratio (M-H, Random, 95\% Cl) & $0.33[0.04,2.60]$ \\
\hline 1.4 Dizziness & 1 & 66 & Risk Ratio (M-H, Random, 95\% Cl) & $0.4[0.08,1.92]$ \\
\hline 1.5 Tiredness & 1 & 66 & Risk Ratio (M-H, Random, 95\% Cl) & $1.33[0.32,5.50]$ \\
\hline 1.6 Vomiting & 1 & 66 & Risk Ratio (M-H, Random, 95\% Cl) & $0.0[0.0,0.0]$ \\
\hline 1.7 Pain & 2 & 129 & Risk Ratio (M-H, Random, 95\% Cl) & $0.14[0.02,1.15]$ \\
\hline $\begin{array}{l}1.8 \text { Total number of } \\
\text { side effects }\end{array}$ & 1 & 63 & Risk Ratio (M-H, Random, 95\% Cl) & $0.21[0.07,0.59]$ \\
\hline 1.9 Taste & 1 & 63 & Risk Ratio (M-H, Random, 95\% Cl) & $0.99[0.76,1.29]$ \\
\hline $\begin{array}{l}2 \text { Plasma glucose } \\
(\mathrm{mmol} / \mathrm{L})\end{array}$ & 3 & & Mean Difference (IV, Random, 95\% Cl) & Subtotals only \\
\hline
\end{tabular}




\begin{tabular}{lllll}
\hline $\begin{array}{l}\text { Outcome or subgroup } \\
\text { title }\end{array}$ & No. of studies & $\begin{array}{l}\text { No. of partici- } \\
\text { pants }\end{array}$ & Statistical method & Effect size \\
\hline 2.1 At 1, 2 and 3 hours & 3 & 239 & Mean Difference (IV, Random, 95\% Cl) & $-0.20[-0.71,0.32]$ \\
\hline 2.2 At 2 hours & 1 & 100 & Mean Difference (IV, Random, 95\% Cl) & $-0.40[-0.85,0.05]$ \\
\hline 2.3 At 3 hours & 1 & 100 & Mean Difference (IV, Random, 95\% Cl) & $0.0[-0.45,0.45]$ \\
\hline $\begin{array}{l}\text { 3 Gestational age at } \\
\text { birth (weeks) }\end{array}$ & 1 & 100 & Mean Difference (IV, Fixed, 95\% Cl) & $-0.80[-1.69,0.09]$ \\
\hline
\end{tabular}

\section{Analysis 2.1. Comparison $250 \mathrm{~g}$ glucose polymer drink versus $50 \mathrm{~g}$ glucose monomer drink, Outcome 1 Maternal side effects.}

\begin{tabular}{cccc} 
Study or subgroup & $\begin{array}{c}50 \text { g glucose } \\
\text { polymer }\end{array}$ & $\begin{array}{c}50 \text { glucose } \\
\text { monomer }\end{array}$ & Risk Ratio \\
& $\mathrm{n} / \mathrm{N}$ & $\mathrm{n} / \mathrm{N}$ & $\mathrm{M}-\mathrm{H}, \mathrm{Random}, 95 \% \mathrm{Cl}$ \\
\hline
\end{tabular}

Risk Ratio
M-H, Random, $95 \% \mathrm{CI}$

\subsubsection{Nausea}

USA 1992

Subtotal $(95 \% \mathrm{CI})$

$4 / 33$

33

$14 / 33$

33

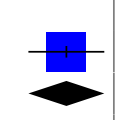

Heterogeneity: Not applicable

Test for overall effect: $Z=2.45(P=0.01)$

\subsubsection{Headache \\ USA 1992}

Subtotal $(95 \% \mathrm{CI})$

$1 / 33$

33

$5 / 33$

33

Total events: 1 (50g glucose polymer), 5 ( $50 \mathrm{~g}$ glucose monomer) Heterogeneity: Not applicable

Test for overall effect: $\mathrm{Z}=1.51(\mathrm{P}=0.13)$

\subsubsection{Bloatedness}

$\begin{array}{lr}\text { USA } 1992 & 4 / 33 \\ \text { USA } 1994 & 0 / 43 \\ \text { Subtotal }(\mathbf{9 5 \%} \mathbf{C l}) & \mathbf{7 6}\end{array}$

Total events: 4 (50g glucose polymer), 9 (50g glucose monomer) Heterogeneity: $\operatorname{Tau}^{2}=1.25 ; \mathrm{Chi}^{2}=1.97, \mathrm{df}=1(\mathrm{P}=0.16) ; \mathrm{I}^{2}=49.26 \%$ Test for overall effect: $Z=1.05(P=0.29)$

\subsubsection{Dizziness}

USA 1992

Subtotal $(95 \% \mathrm{Cl})$

$2 / 33$

33

Total events: 2 (50g glucose polymer), 5 (50g glucose monomer) Heterogeneity: Not applicable

Test for overall effect: $Z=1.15(P=0.25)$

\subsubsection{Tiredness}

USA 1992

Subtotal $(95 \% \mathrm{CI})$

$4 / 33$

33

Total events: 4 (50g glucose polymer), 3 (50g glucose monomer) Heterogeneity: Not applicable
$100 \%$

$100 \%$

$0.29[0.11,0.78]$

$0.29[0.11,0.78]$

\begin{tabular}{llllllll} 
& & & & & \\
\hline & Favours 50g polymer & 0.005 & 0.1 & 1 & 10 & 200 & Favours 50g monomer
\end{tabular}




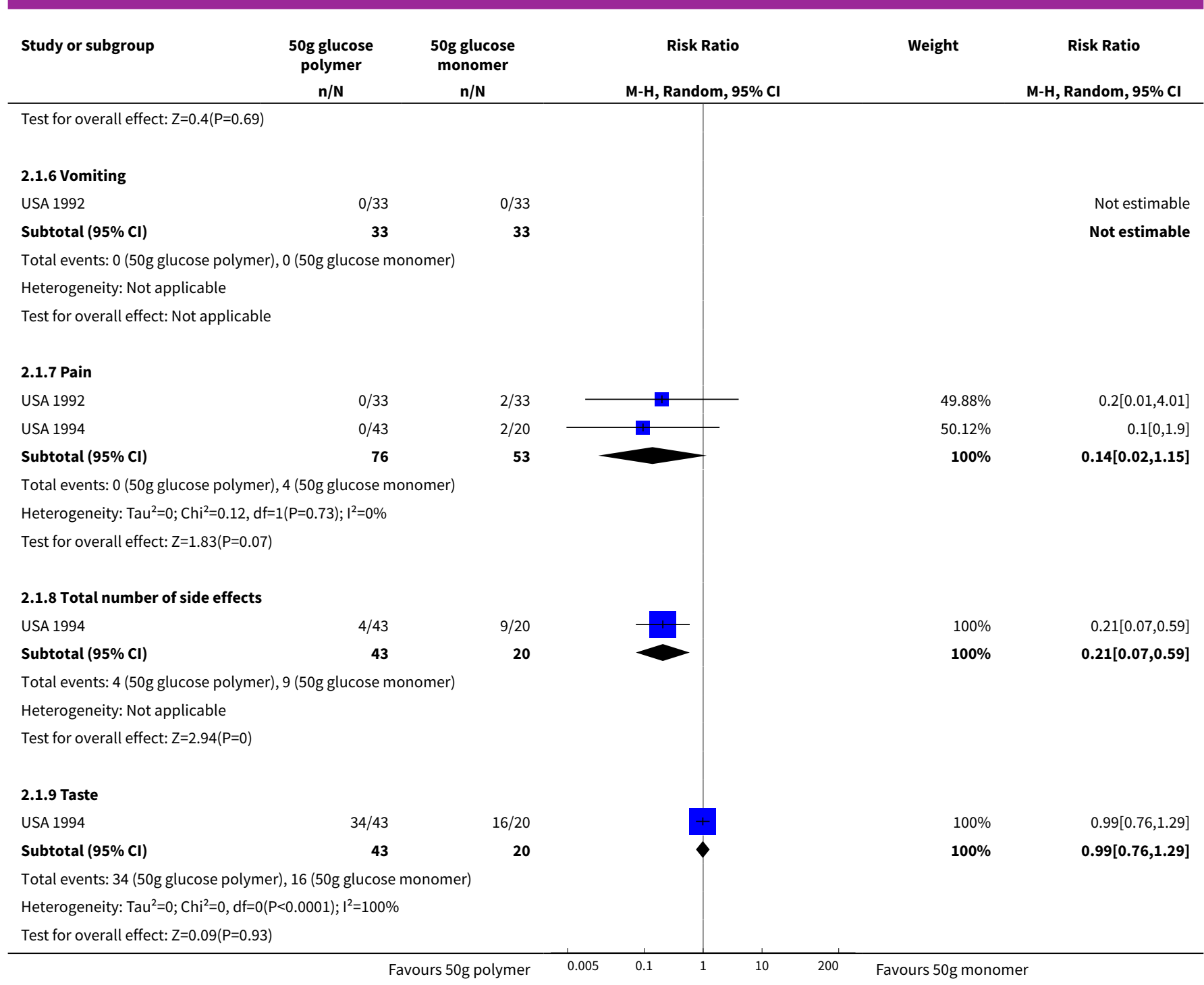

Analysis 2.2. Comparison $250 \mathrm{~g}$ glucose polymer drink versus $\mathbf{5 0}$ g glucose monomer drink, Outcome 2 Plasma glucose ( $\mathrm{mmol} / \mathrm{L})$.

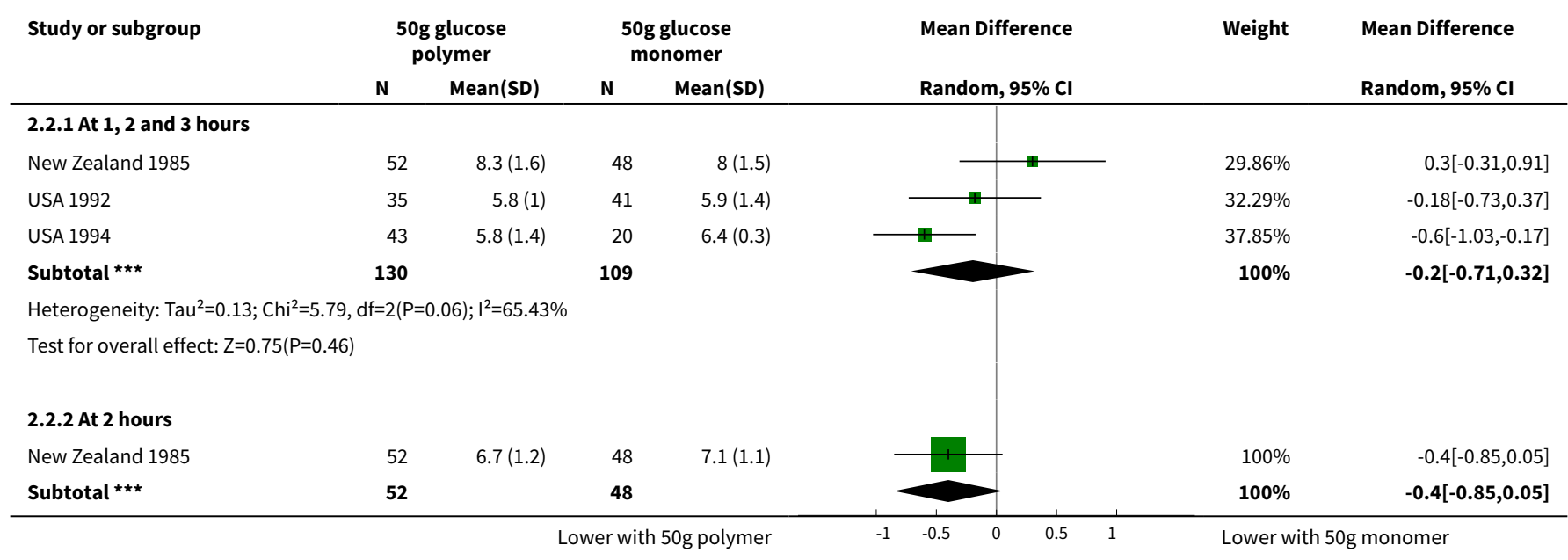




\begin{tabular}{|c|c|c|c|c|c|c|c|}
\hline \multirow[t]{2}{*}{ Study or subgroup } & \multicolumn{2}{|c|}{$\begin{array}{c}50 \mathrm{~g} \text { glucose } \\
\text { polymer }\end{array}$} & \multicolumn{2}{|c|}{$\begin{array}{l}50 \mathrm{~g} \text { glucose } \\
\text { monomer }\end{array}$} & \multirow{2}{*}{$\begin{array}{l}\text { Mean Difference } \\
\text { Random, 95\% Cl }\end{array}$} & \multirow[t]{2}{*}{ Weight } & \multirow{2}{*}{$\begin{array}{l}\text { Mean Difference } \\
\text { Random, } 95 \% \mathrm{Cl}\end{array}$} \\
\hline & $\mathbf{N}$ & $\operatorname{Mean}(S D)$ & $\mathbf{N}$ & $\operatorname{Mean}(S D)$ & & & \\
\hline \multicolumn{8}{|l|}{ Heterogeneity: Not applicable } \\
\hline \multicolumn{8}{|l|}{ Test for overall effect: $Z=1.74(P=0.08)$} \\
\hline New Zealand 1985 & 52 & $6(1.1)$ & 48 & $6(1.2)$ & . & $100 \%$ & $0[-0.45,0.45]$ \\
\hline Subtotal ${ }^{\star \star \star}$ & 52 & & 48 & & & $100 \%$ & $0[-0.45,0.45]$ \\
\hline \multicolumn{8}{|l|}{ Heterogeneity: Not applicable } \\
\hline \multicolumn{8}{|l|}{ Test for overall effect: Not applicable } \\
\hline & & & r wit & $50 \mathrm{~g}$ polymer & $\begin{array}{ll}-1 & -0.5\end{array}$ & Lower wi & gmonomer \\
\hline
\end{tabular}

Analysis 2.3. Comparison $250 \mathrm{~g}$ glucose polymer drink versus $50 \mathrm{~g}$ glucose monomer drink, Outcome 3 Gestational age at birth (weeks).

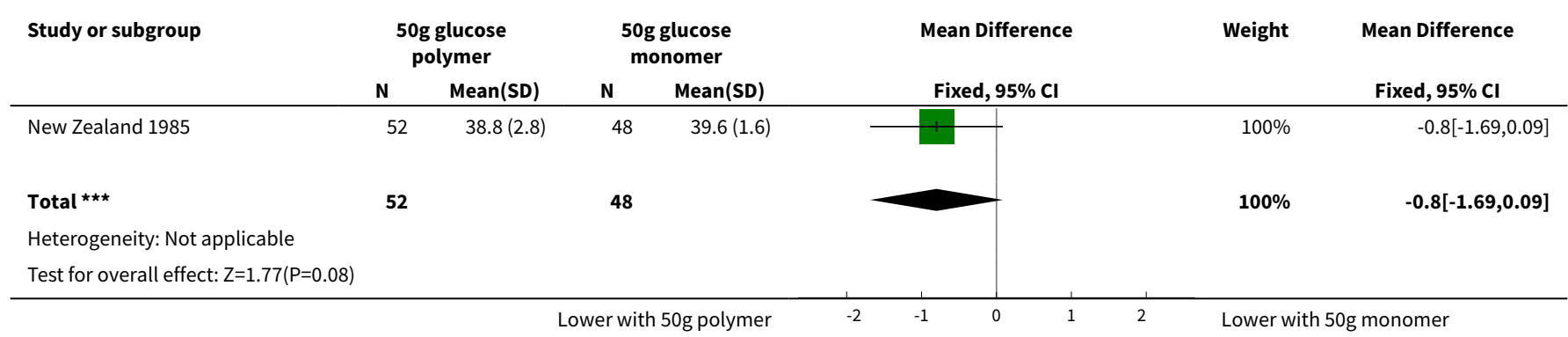

\section{Comparison 3. Candy bar versus $50 \mathrm{~g}$ glucose monomer drink}

\begin{tabular}{lllll}
\hline $\begin{array}{l}\text { Outcome or subgroup } \\
\text { title }\end{array}$ & No. of studies & $\begin{array}{l}\text { No. of partici- } \\
\text { pants }\end{array}$ & Statistical method & Effect size \\
\hline 1 Maternal side effects & 1 & & Risk Ratio (M-H, Fixed, 95\% Cl) & Subtotals only \\
\hline 1.1 Pain & 1 & 58 & Risk Ratio (M-H, Fixed, 95\% Cl) & $0.17[0.01,3.91]$ \\
\hline 1.2 Bloatedness & 1 & 60 & Risk Ratio (M-H, Fixed, 95\% Cl) & $1.08[0.21,5.40]$ \\
\hline $\begin{array}{l}1.3 \text { Total side effects } \\
1.4 \text { Taste }\end{array}$ & 1 & 58 & Risk Ratio (M-H, Fixed, 95\% Cl) & $1.03[0.58,1.82]$ \\
\hline $\begin{array}{l}\text { 2 1-hour serum glucose } \\
\text { level (mmol/L) }\end{array}$ & 1 & 59 & Risk Ratio (M-H, Fixed, 95\% Cl) & $0.60[0.42,0.86]$ \\
\hline
\end{tabular}


Analysis 3.1. Comparison 3 Candy bar versus $50 \mathrm{~g}$ glucose monomer drink, Outcome 1 Maternal side effects.

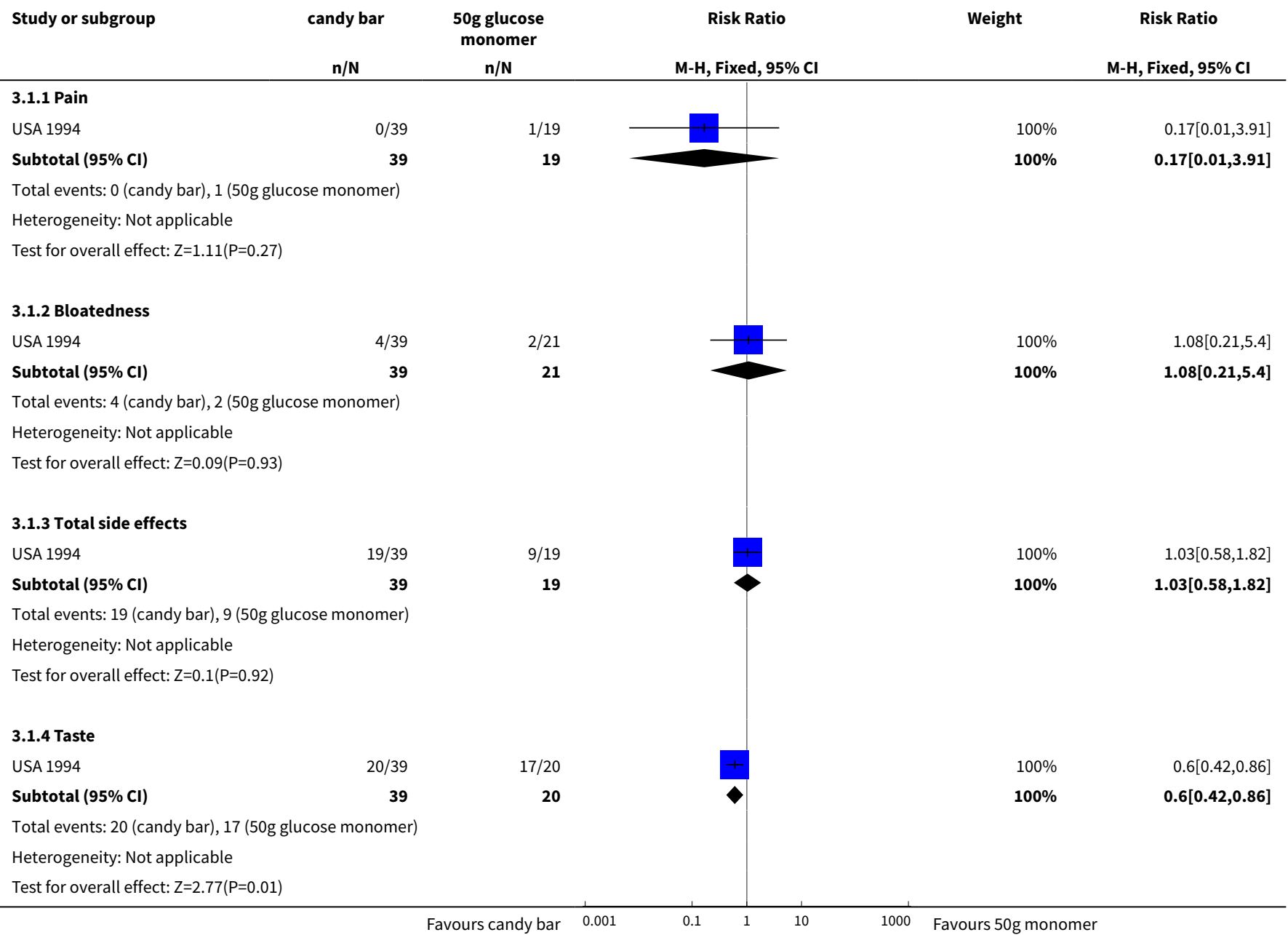

Analysis 3.2. Comparison 3 Candy bar versus $50 \mathrm{~g}$ glucose monomer drink, Outcome 2 1-hour serum glucose level (mmol/L).

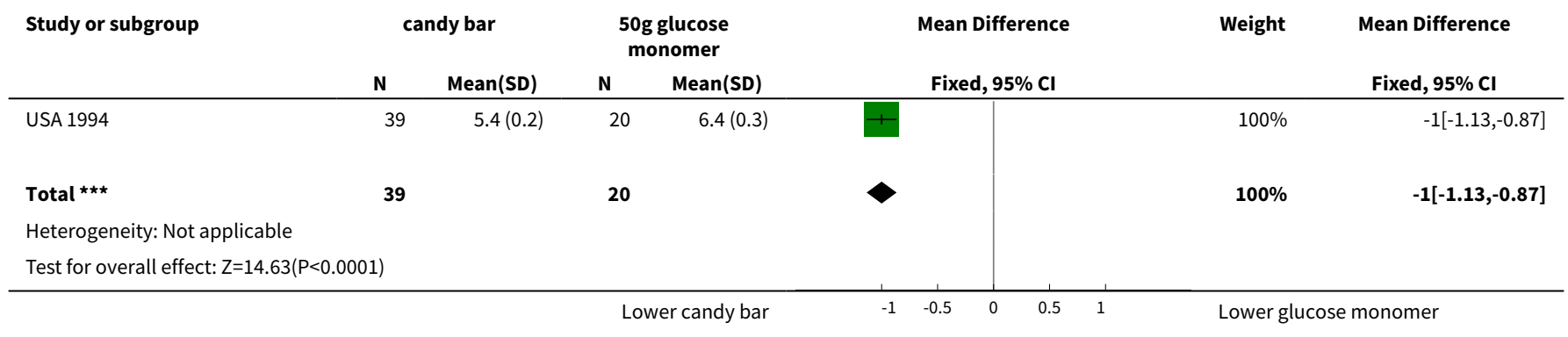


Comparison 4. $50 \mathrm{~g}$ glucose in food versus $50 \mathrm{~g}$ glucose drink

\begin{tabular}{|c|c|c|c|c|}
\hline Outcome or subgroup title & No. of studies & $\begin{array}{l}\text { No. of partici- } \\
\text { pants }\end{array}$ & Statistical method & Effect size \\
\hline 1 Maternal side effects & 1 & 30 & $\begin{array}{l}\text { Risk Ratio (M-H, Fixed, 95\% } \\
\mathrm{Cl} \text { ) }\end{array}$ & $0.08[0.01,0.56]$ \\
\hline $\begin{array}{l}2 \text { Need for repeat testing by same or } \\
\text { alternative method }\end{array}$ & 1 & 30 & $\begin{array}{l}\text { Risk Ratio (M-H, Fixed, 95\% } \\
\mathrm{Cl} \text { ) }\end{array}$ & $0.14[0.01,2.55]$ \\
\hline
\end{tabular}

Analysis 4.1. Comparison $450 \mathrm{~g}$ glucose in food versus $50 \mathrm{~g}$ glucose drink, Outcome 1 Maternal side effects.

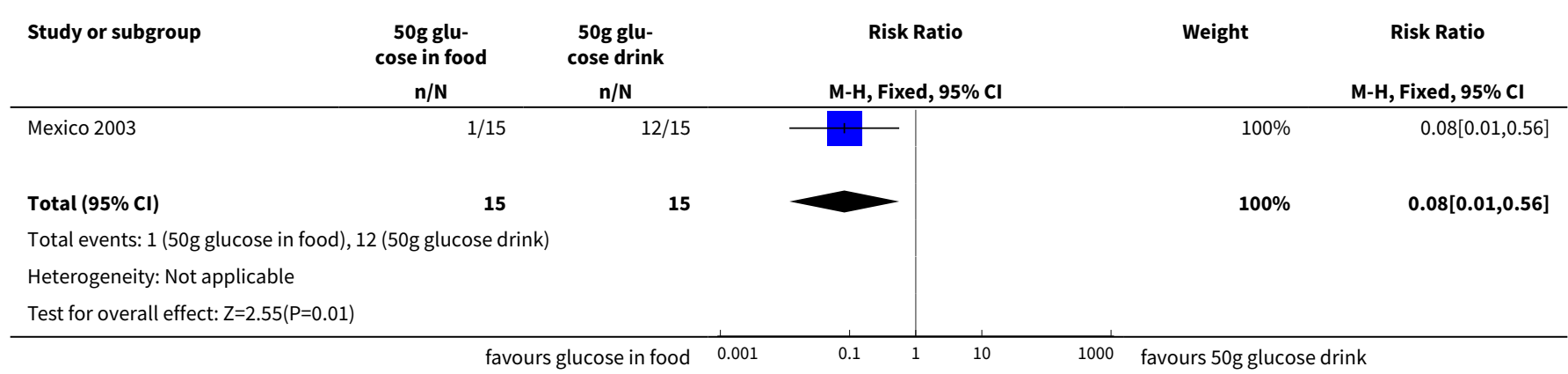

Analysis 4.2. Comparison $450 \mathrm{~g}$ glucose in food versus $50 \mathrm{~g}$ glucose drink, Outcome 2 Need for repeat testing by same or alternative method.

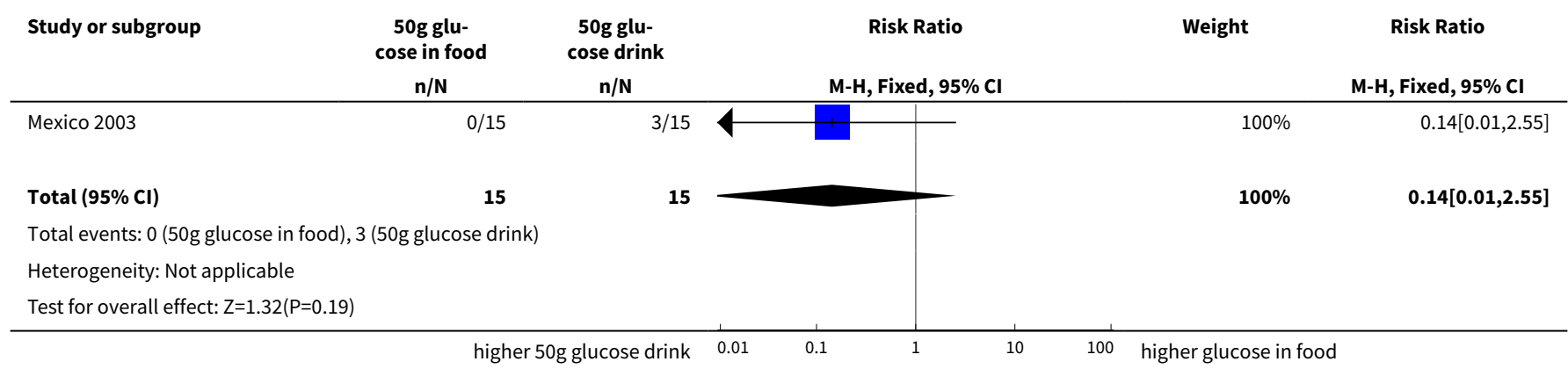

\section{Comparison 5. 75 g OGTT (WHO criteria) versus 75 g OGTT (ADA criteria)}

\begin{tabular}{lllll}
\hline $\begin{array}{l}\text { Outcome or subgroup ti- } \\
\text { tle }\end{array}$ & No. of studies & $\begin{array}{l}\text { No. of partici- } \\
\text { pants }\end{array}$ & Statistical method & Effect size \\
\hline 1 Caesarean section & 1 & 116 & Risk Ratio (M-H, Fixed, 95\% Cl) & $1.07[0.85,1.35]$ \\
\hline 2 Instrumental delivery & 1 & 116 & Risk Ratio (M-H, Fixed, 95\% Cl) & $0.21[0.01,3.94]$ \\
\hline $\begin{array}{l}3 \text { Diagnosis of gestational } \\
\text { diabetes }\end{array}$ & 1 & 116 & Risk Ratio (M-H, Fixed, 95\% Cl) & $1.47[0.66,3.25]$ \\
\hline
\end{tabular}




\begin{tabular}{lllll}
\hline $\begin{array}{l}\text { Outcome or subgroup ti- } \\
\text { tle }\end{array}$ & No. of studies & $\begin{array}{l}\text { No. of partici- } \\
\text { pants }\end{array}$ & Statistical method & Effect size \\
\hline 4 Macrosomia & 1 & 116 & Risk Ratio (M-H, Fixed, 95\% Cl) & $0.73[0.19,2.79]$ \\
\hline 5 Stillbirth & 1 & 116 & Risk Ratio (M-H, Fixed, 95\% Cl) & $0.49[0.02,11.68]$ \\
\hline
\end{tabular}

Analysis 5.1. Comparison $575 \mathrm{~g}$ OGTT (WHO criteria) versus $75 \mathrm{~g}$ OGTT (ADA criteria), Outcome 1 Caesarean section.

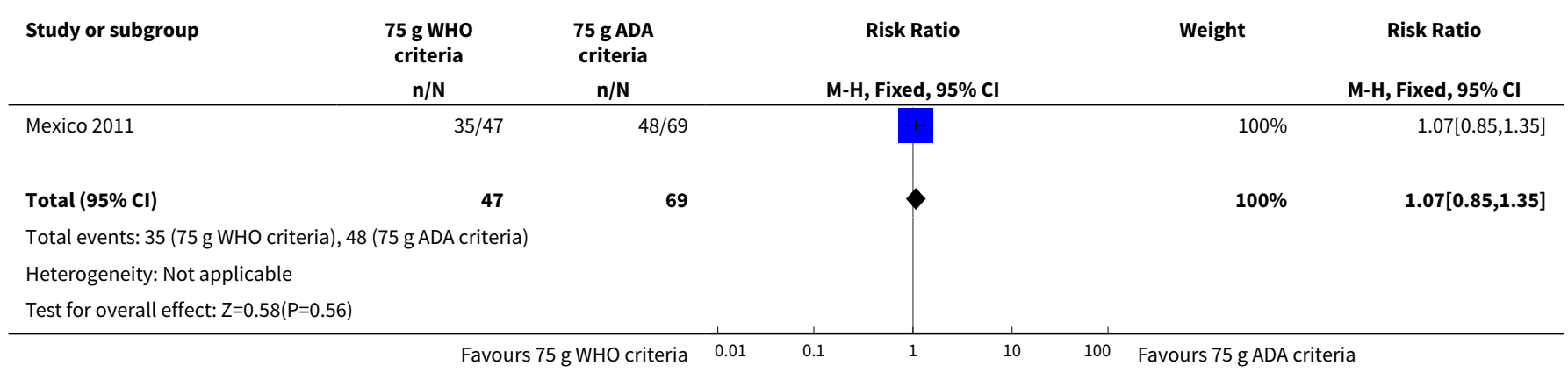

Analysis 5.2. Comparison $575 \mathrm{~g}$ OGTT (WHO criteria) versus 75 g OGTT (ADA criteria), Outcome 2 Instrumental delivery.

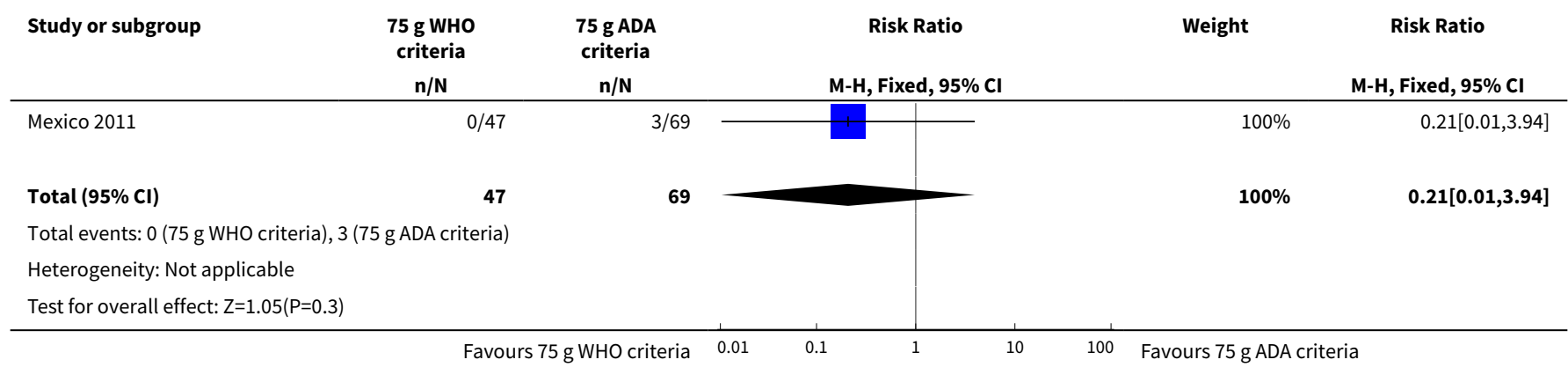

Analysis 5.3. Comparison $575 \mathrm{~g}$ OGTT (WHO criteria) versus $75 \mathrm{~g}$ OGTT (ADA criteria), Outcome 3 Diagnosis of gestational diabetes.

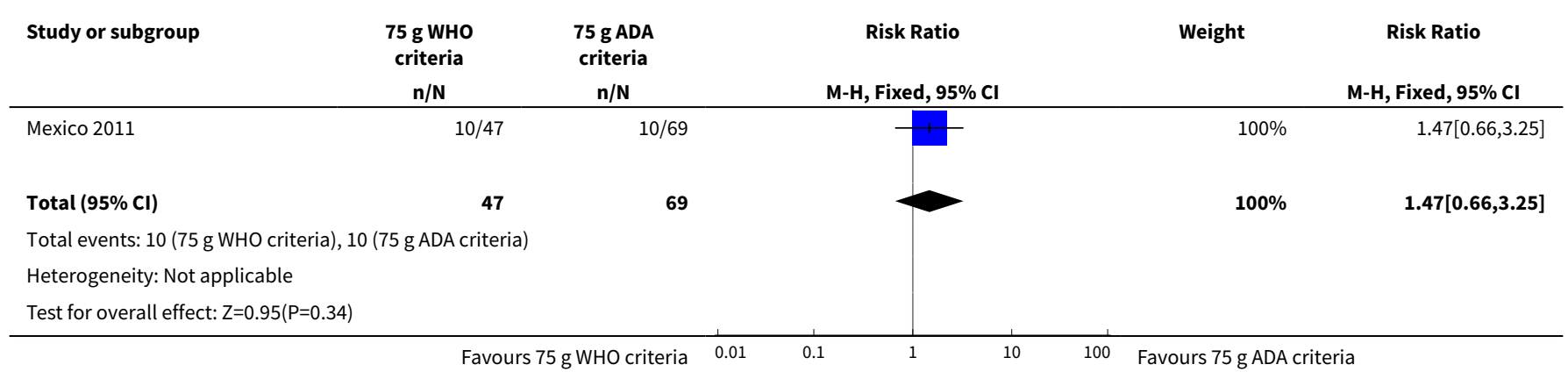


Analysis 5.4. Comparison $575 \mathrm{~g}$ OGTT (WHO criteria) versus $75 \mathrm{~g}$ OGTT (ADA criteria), Outcome 4 Macrosomia.

\begin{tabular}{|c|c|c|c|c|c|}
\hline Study or subgroup & $\begin{array}{l}75 \text { g WHO } \\
\text { criteria }\end{array}$ & $\begin{array}{l}75 \mathrm{~g} \mathrm{ADA} \\
\text { criteria }\end{array}$ & $\begin{array}{c}\text { Risk Ratio } \\
\text { M-H Fixed }\end{array}$ & Weight & Risk Ratio \\
\hline Mexico 2011 & $3 / 47$ & $6 / 69$ & $+\sqrt{1+2}$ & $100 \%$ & $0.73[0.19,2.79]$ \\
\hline Total $(95 \% \mathrm{Cl})$ & 47 & 69 & & $100 \%$ & $0.73[0.19,2.79]$ \\
\hline \multicolumn{6}{|c|}{ Total events: 3 (75 g WHO criteria), 6 (75 g ADA criteria) } \\
\hline \multicolumn{6}{|c|}{ Heterogeneity: Not applicable } \\
\hline Test for overall effec & & & & & \\
\hline
\end{tabular}

Analysis 5.5. Comparison $575 \mathrm{~g}$ OGTT (WHO criteria) versus $75 \mathrm{~g}$ OGTT (ADA criteria), Outcome 5 Stillbirth.

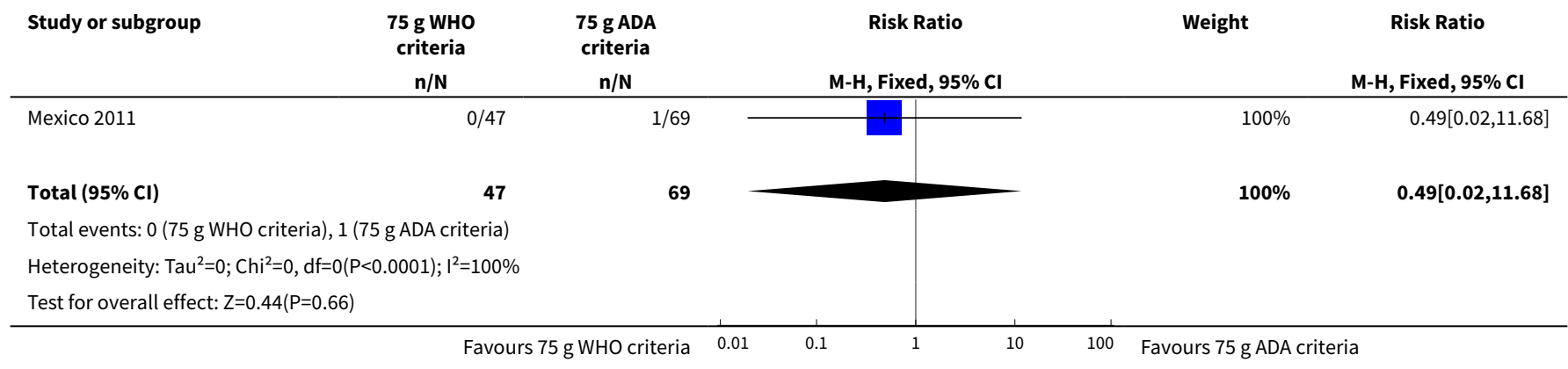

Comparison 6. Two-step (50 g OGCT and $100 \mathrm{~g}$ OGTT) versus one-step (75 g OGTT) approach

\begin{tabular}{lllll}
\hline Outcome or subgroup title & No. of studies & $\begin{array}{l}\text { No. of partici- } \\
\text { pants }\end{array}$ & Statistical method & Effect size \\
\hline 1 Diagnosis of gestational diabetes & 1 & 726 & $\begin{array}{l}\text { Risk Ratio (M-H, Random, 95\% } \\
\mathrm{Cl})\end{array}$ & $0.51[0.28,0.95]$ \\
\hline
\end{tabular}

Analysis 6.1. Comparison 6 Two-step (50 g OGCT and $100 \mathrm{~g}$ OGTT) versus onestep (75 $\mathrm{g}$ OGTT) approach, Outcome 1 Diagnosis of gestational diabetes.

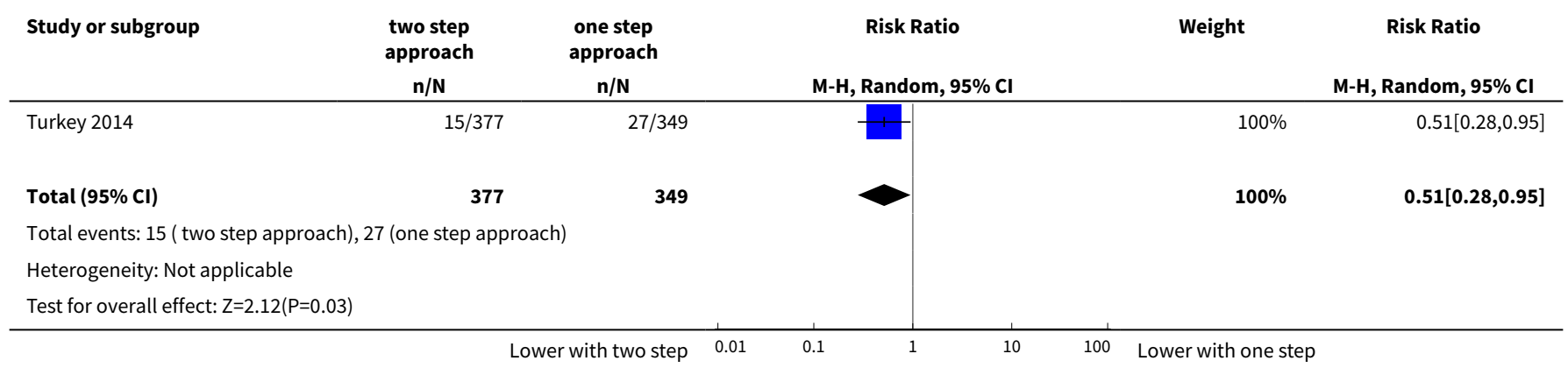


ADDITIONAL TABLES

Table 1. International Association of Diabetes and Pregnancy Study Groups (IADPSG)

\begin{tabular}{ll}
\hline Time & Plasma \\
\hline Fasting glucose $(\geq)$ & $5.1 \mathrm{mmol} / \mathrm{L}$ \\
\hline 1-hour glucose $(\geq)$ & $10.0 \mathrm{mmol} / \mathrm{L}$ \\
\hline 2-hour glucose $(\geq)$ & $8.5 \mathrm{mmol} / \mathrm{L}$ \\
\hline
\end{tabular}

IADPSG cutoff levels for diagnosis of gestational diabetes for plasma glucose; gestational diabetes is diagnosed if any one value equals or exceeds any other value (Metzger 2010). World Health Organization (WHO) published revised guidance in 2013 recommended IADPSG cutoff levels for the diagnosis of gestational diabetes (WHO 2013).

Table 2. World Health Organization criteria for $75 \mathrm{~g}$ OGTT

\begin{tabular}{lllll}
\hline Time & Whole blood venous & Whole blood capillary & Plasma venous & Plasma capillary \\
\hline Fasting glucose $(\geq)$ & $6.1 \mathrm{mmol} / \mathrm{L}$ & $6.1 \mathrm{mmol} / \mathrm{L}$ & $7.0 \mathrm{mmol} / \mathrm{L}$ & $7.0 \mathrm{mmol} / \mathrm{L}$ \\
\hline 2-hour glucose & $6.7 \mathrm{mmol} / \mathrm{L}$ & $7.8 \mathrm{mmol} / \mathrm{L}$ & $7.8 \mathrm{mmol} / \mathrm{L}$ & $8.9 \mathrm{mmol} / \mathrm{L}$ \\
\hline
\end{tabular}

Cutoff levels for diagnosis of gestational diabetes for whole blood and plasma glucose. Diabetes is diagnosed if fasting plasma glucose level is > $7.0 \mathrm{mmol} / \mathrm{L}$, or if 2-hour level is $>11.1 \mathrm{mmol} / \mathrm{L}$ (WHO 1999).

Table 3. Alternative criteria for the $100 \mathrm{~g}$ oral GTT

\begin{tabular}{llcc}
\hline Time & O'Sullivan 1964 $\boldsymbol{a}$ & NDDG 1997 $\boldsymbol{b}$ & Carpenter 1982 $\boldsymbol{c}$ \\
\hline Fasting glucose $(\geq)$ & $5.0 \mathrm{mmol} / \mathrm{L}$ & $5.8 \mathrm{mmol} / \mathrm{L}$ & $5.3 \mathrm{mmol} / \mathrm{L}$ \\
\hline 1-hour glucose $(\geq)$ & $9.1 \mathrm{mmol} / \mathrm{L}$ & $10.0 \mathrm{mmol} / \mathrm{L}$ & $10.0 \mathrm{mmol} / \mathrm{L}$ \\
\hline 2-hour glucose $(\geq)$ & $8.0 \mathrm{mmol} / \mathrm{L}$ & $9.1 \mathrm{mmol} / \mathrm{L}$ & $8.6 \mathrm{mmol} / \mathrm{L}$ \\
\hline 3-hour glucose $(\geq)$ & $6.9 \mathrm{mmol} / \mathrm{L}$ & $8.0 \mathrm{mmol} / \mathrm{L}$ & $7.8 \mathrm{mmol} / \mathrm{L}$ \\
\hline
\end{tabular}

Gestational diabetes is diagnosed when two or more measurements in a single column exceed stated cutoff levels.

a O'Sullivan 1964: cutoff levels for diagnosis of gestational diabetes for whole blood.

b NDDG 1997: cutoff for diagnosis of gestational diabetes for plasma glucose.

c Carpenter 1982: cutoff for diagnosis of gestational diabetes for plasma glucose.

\section{A P P E N D I C E S}

\section{Appendix 1. Search terms for ICTRP and ClinicalTrials.gov}

gestational AND diabetes AND diagnosis

gestational AND diabetes AND diagnose

GDM AND diagnose

Different strategies for diagnosing gestational diabetes to improve maternal and infant health (Review) 
GDM AND diagnosis

WHAT'S NEW

\begin{tabular}{lll}
\hline Date Event & Description \\
\hline 9 January 2017
\end{tabular}

9 January $2017 \quad$ New search has been performed

Search updated. One trial was included (Turkey 2014). One trial is awaiting classification (China 2013). One trial was excluded (USA 2015) and a further five trial reports were added to a previously excluded trial (Ireland 2014a). Two trials (four reports) are ongoing (Ireland 2014b; USA 2014).

The following secondary outcomes were added to types of outcome measures: Maternal: Perineal trauma, Placental abruption, Weight gain during pregnancy, Breastfeeding, Neonatal: Apgar Score (less than seven at five minutes), Birthweight and Z-score, Ponderal index, Measures of adiposity, Shoulder dystocia, Bone fracture, Nerve palsy, and Relevant biomarkers (e.g. cord C-peptide, cord insulin).

9 January $2017 \quad$ New citation required but conclusions have not changed
One new comparison (Two-step approach ( $50 \mathrm{~g}$ oral glucose challenge test (OGCT) followed by selective $100 \mathrm{~g}$ OGTT Carpenter and Coustan criteria) versus one-step approach (universal $75 \mathrm{~g}$ OGTT ADA criteria)) added in this update. Conclusions not changed.

\section{H I S T O R Y}

Protocol first published: Issue 2, 2008

Review first published: Issue 10, 2011

\begin{tabular}{lll}
\hline Date & Event & Description \\
\hline 31 October 2014 & New search has been performed & $\begin{array}{l}\text { Search updated with 3 new reports identified: } 1 \text { trial was includ- } \\
\text { ed (Mexico 2011); } 1 \text { was excluded (Ireland 2014a); and 1 (USA } \\
\text { 2013) is ongoing. Methods updated and 'Summary of findings' } \\
\text { table added. }\end{array}$ \\
\hline 31 October 2014 & New citation required but conclusions & $\begin{array}{l}\text { Evidence is insufficient to permit assessment of which strategy is } \\
\text { best for diagnosing GDM. }\end{array}$ \\
\hline 18 January 2012 & Amended & Contact details updated. \\
\hline
\end{tabular}

\section{CONTRIBUTIONS OFAUTHORS}

Three review authors were involved in planning and development of the review (Diane Farrar, Leila Duley and Debbie Lawlor). Diane Farrar and Lelia Duley analysed the studies and extracted data for the original review. All review authors analysed the studies included in the updates. Diane Farrar and Therese Dowswell extracted data. Therese Dowswell generated the 'Summary of findings' table with comments from all remaining review authors. Diane Farrar drafted the review, incorporating comments from Lelia Duley, Therese Dowswell and Debbie Lawlor.

\section{DECLARATIONS OF INTEREST}

Diane Farrar: none known. 
Lelia Duley: I hold an NIHR Programme Grant for Applied Research addressing care at preterm birth.

Therese Dowswell: I am paid via my institution by the UK NHS to work on a range of Cochrane Reviews. In the last 36 months I have received funding from the WHO to work on other Cochrane Reviews. The Funders have no influence on the content or conclusions of the reviews I work on.

Debbie Lawlor: none known.

\section{SOURCES OF SUPPORT}

\section{Internal sources}

- Medical Research Council Integrative Epidemiology Unit, The University of Bristol, UK.

\section{External sources}

- National Institute for Health Research Post-doctoral Fellowship Award, UK.

- National Institute for Health Research (NIHR), UKNIHR Cochrane Programme Grant Project: 13/89/05 - Pregnancy and childbirth systematic reviews to support clinical guidelines, UK.

\section{DIFFERENCES BETWEEN PROTOCOLANDREVIEW}

*A number of the primary and secondary maternal and infant outcome measures are based on the core outcomes for Cochrane gestational diabetes reviews reached by consensus between the review authors of reviews for treatment of GDM. A number of these were added as secondary outcomes for this update and are labelled as non-prespecified in the following list.

\section{Maternal}

1. Perineal trauma (non-prespecified outcome).

2. Placental abruption (non-prespecified outcome).

3. Weight gain during pregnancy (non-prespecified outcome). ${ }^{\star}$

4. Breastfeeding (e.g. at discharge, six weeks postpartum) (non-prespecified outcome).

\section{Neonatal}

1. Apgar score (less than seven at five minutes) (non-prespecified outcome).*

2. Birthweight and z-score (non-prespecified outcome).*

3. Ponderal index (non-prespecified outcome).*

4. Measures of adiposity (non-prespecified outcome). ${ }^{*}$

5. Shoulder dystocia (non-prespecified outcome). ${ }^{*}$

6. Bone fracture (non-prespecified outcome). ${ }^{*}$

7. Nerve palsy (non-prespecified outcome). ${ }^{*}$

8. Relavent biomarkers, e.g. cord C-peptide, cord insulin (non-prespecified outcome). ${ }^{*}$

The outcome plasma glucose was not originally specified in the protocol but was added in the first version of this review.

Methods have been updated to current Cochrane Pregnancy and Childbirth Group standard text, and a 'Summary of findings' table has been incorporated.

\section{NDEX TERMS}

\section{Medical Subject Headings (MeSH)}

*Infant Welfare; *Maternal Welfare; Beverages; Candy; Diabetes, Gestational [*diagnosis]; Glucose [administration \& dosage]; Glucose Tolerance Test [methods]; Prenatal Exposure Delayed Effects [prevention \& control]; Randomized Controlled Trials as Topic

\section{MeSH check words}

Female; Humans; Infant, Newborn; Pregnancy 